MIGUEL DOS SANTOS ALVES FILHO

APLICAÇÃO DE CONCEITOS DE MIDDLEWARE EM REDES DE CONTROLE LONWORKS/EIA 709.1 PARA AUTOMAÇÃO DE AMBIENTES PERVASIVOS 
MIGUEL DOS SANTOS ALVES FILHO

\section{APLICAÇÃO DE CONCEITOS DE MIDDLEWARE EM REDES DE CONTROLE LONWORKS/EIA 709.1 PARA AUTOMAÇÃO DE AMBIENTES PERVASIVOS}

Tese apresentada à Escola Politécnica da Universidade de São Paulo para obtenção do título de Doutor em Engenharia Elétrica

Área de Concentração:

Sistemas Digitais

Orientador: Prof. Livre-Docente

Carlos Eduardo Cugnasca 
Este exemplar foi revisado e alterado em relação à versão original, sob responsabilidade única do autor e com a anuência de seu orientador.

São Paulo, 10 de agosto de 2009.

Assinatura do autor

Assinatura do orientador

FICHA CATALOGRÁFICA

Alves Filho, Miguel dos Santos

Aplicação de conceitos de middleware em redes de controle LonWorks®/EIA 709.1 para automação de ambientes pervasivos / M.S. Alves Filho. ed.rev. - São Paulo, 2009.

$144 \mathrm{p}$.

Tese (Doutorado) - Escola Politécnica de Universidade de São Paulo. Departamento de Engenharia de Computação e Sistemas Digitais.

1. Automação predial 2. Sistemas distribuídos 3. Redes de comunicação de dados I. Universidade de São Paulo. Escola Politécnica. Departamento de Engenharia de Computação e Sistemas Digitais II. t. 


\section{DEDICATÓRIA}

Dedico este trabalho a minha guerreira de todas as horas, Sandra Regina Bernardes, que sempre esteve do meu lado, ajudando a enfrentar os obstáculos, em construir a minha carreira. 


\section{AGRADECIMENTOS}

À Fundação de Amparo à Pesquisa do Estado de São Paulo (FAPESP), que através do apoio ao projeto do SDCTP financiou equipamentos e mão de obra que viabilizaram este trabalho.

Ao meu orientador Prof. Dr. Livre-docente Carlos Eduardo Cugnasca, e aos Prof. Dr. Livre-docente Antonio Mauro Saraiva e prof. Dr. Livredocente André Riyuiti Hirakawa pelo incentivo e apoio, trazendo a confiança que precisei nos momentos mais difíceis.

Ao amigo e companheiro de muitos empreitadas aqui e no exterior, quase um indiano ascendido, Rafael de Aquino Cunha.

Ao Dr. Cesar Augusto de Aguiar, cônsul da ilha de Chipre no Brasil, e excelente amigo que me orientou e incentivou muito para que eu submetesse o projeto à FAPESP.

Ao Prof. Francisco Romeu Landi por me orientar a procurar ao departamento PCS, que me acolheu prontamente para o desenvolvimento deste trabalho de pesquisa de doutorado.

Ao Martin Carlos Siu que ajudou muito revisando textos e questionando tudo que podia. Ao Alexander Moura da Silva e Gabriel Bernardes Seraphim pelo apoio e dedicação revisando e montando as figuras e tabelas, mantendo um excelente padrão na documentação.

A todos da empresa Conceito Tecnologia que, direta ou indiretamente, colaboraram na execução deste trabalho. 
Quem escolhe intenções elevadas no desempenho de suas atividades jamais esbarra no fracasso infeliz.

Emanuel

Se um dia você tiver que escolher entre o amor e o mundo, lembre-se ... Se escolher o mundo ficará sem o amor, mas se escolher 0 amor, com ele você conquistará o mundo.

Albert Einstein 


\section{RESUMO}

Este trabalho de pesquisa aprofunda o conhecimento associado aos sistemas de automação modernos baseados em redes de controle LonWorks $®$, visando torná-los mais facilmente utilizáveis como meios de implementar ambientes pervasivos. Para tanto, foi proposto um modelo de relacionamento dinamicamente reconfigurável entre dispositivos de uma rede de controle, que permite conferir a um sistema de automação distribuído algumas características previstas na computação pervasiva. É proposta uma extensão do modelo de objetos na tecnologia LonWorks $®$, utilizando conceitos de middleware, de forma a conferir aos módulos da rede a capacidade de auto-gerenciamento dinâmico, de modo a modificar os seus comportamentos à medida que novas situações sejam identificadas. A extensão proposta foi aplicada experimentalmente, visando a sua validação e refinamento, como o sistema de comunicação interno de uma empresa, substituindo os PABXs convencionais, considerado em maiores detalhes. Constatou-se a impossibilidade de sua implementação com a tecnologia LonWorks ${ }^{\circledR}$ atual, que utiliza conexões estáticas, necessitando de um operador ou integrador para configurá-las, caso não seja adotada a extensão proposta. Como estudo de caso o projeto de um PABX baseado na tecnologia LonWorks ${ }^{\circledR}$ foi avaliado e discutido, contribuindo para a geração de uma nova metodologia de concepção de sistemas de automação que possam atender algumas propostas previstas na computação pervasiva. É proposto integrar a Tecnologia da Informação e Comunicação, com as ações e os comportamentos convencionais que as pessoas apresentam. Essa metodologia proposta supera os desafios de projetistas de sistemas de automação de ambientes, em especial os prediais, e obtém integração entre processos de forma que as pessoas não percebam que estão interagindo com um computador, cuja presença deverá cada vez mais se tornar onipresente. Além de facultar interfaces fáceis e naturais, tem-se também a incorporação dos conceitos da computação sensível a contexto nos sistemas de automação.

Palavras-chave: middleware, RM-ODP, OSI, redes de controle, computação pervasiva, computação ubíqua, LonWorks®, LonTalk®, EIA709, EIA852. 


\begin{abstract}
Pervasive or ubiquitous computing, proposes the integration between the information and communication technology with the actions and common behaviors presented by people. One of the challenges that it imposes to the environmental automation systems developers, specially building automation developers, is that this integration is processed in such a way that people do not realize they are interacting with a computer, thus its presence becomes omnipresent. Besides the need of an easy and natural interface, there is also the need to incorporate the sensitive computing context to the automation systems. The current control networks utilized in automation systems, building, home and industrial control do not show resources that support the requirements of pervasive computing. This research intend to improve the knowledge associated to modern automation systems, based on LonWorks $®$ control networks, viewing to make them more easily usable as ways to implement pervasive environments. For that, a dynamically settable relationship model was proposed between the intelligent devices of a control network, which allows providing some foreseen characteristics on pervasive computing in a distributed automation system. A LonWorks ${ }^{\circledR}$ technology object model extension is proposed, using middleware concepts, in a dynamic way, to modify behaviors when new situations are identified. The proposed extension was experimentally applied to a few use cases, aiming at its validation and refinement, such as the internal communication of a company, which replaces the usual PABX, which was considered in greater detail. The impossibility of its implementation was found with the current technology, without the use of the proposed extension. Those cases were evaluated and discussed, contributing to a new automation system concept technology that can support provided proposals on pervasive computing.
\end{abstract}

Keywords: middleware, RM-ODP, OSI, control networks, LonWorks $®$, LonTalk, pervasive computing, ubiquitous computing, EIA709, EIA852 


\section{LISTA DE ILUSTRAÇÕES}

Figura 1: A infra-esturura completa da informação adaptado de RAJI (2002)........................28

Figura 2: SAP os níveis de automação (ECHELON CORPORATION, 1999).......................29

Figura 3: Rede de Controle e Supervisão na Tecnologia LonWorks ${ }^{\circledR}$......................................30

Figura 4: Desenho ilustrativo de um inter-networking (SWAN, 1997) ..................................36

Figura 5: Roteador BACnet ${ }^{\circledR}$ conectando uma LAN Ethernet a uma LAN MS/TP (BUSHBY,

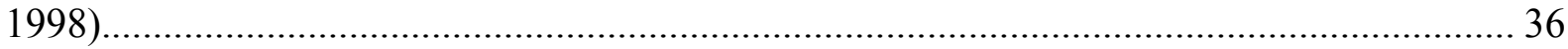

Figura 6: Modelo OSI de sete camadas (NEWMAN, 1999)...............................................38

Figura 7: Interface de um nó LonWorks ${ }^{\circledR}$ padrão LonMark ${ }^{\circledR}($ ECHELON CORPORATION,

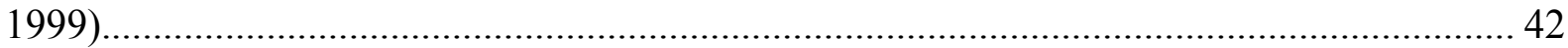

Figura 8: Desenho do Perfil Funcional de nó com parte de protocolo proprietário (ECHELON

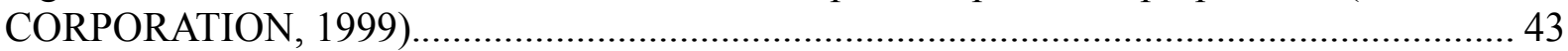

Figura 9: Nós com Interoperabilidade (ECHELON CORPORATION, 1999).......................46

Figura 10: Plug-and-Play da tecnologia LonWorks ${ }^{\circledR}($ ECHELON CORPORATION, 1999)..46

Figura 11: Diretrizes LonMark ${ }^{\circledR}($ ECHELON CORPORATION, 1999)...............................47

Figura 12: Proposta LonMark ${ }^{\circledR}$ para interoperabilidade (ECHELON CORPORATION, 1999).

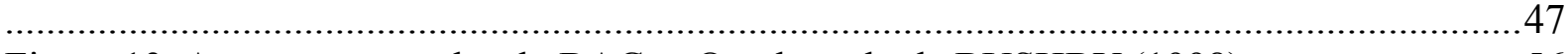

Figura 13: As quatro camadas do BACnet ${ }^{\circledR}$, adaptado de BUSHBY (1998)..........................56

Figura 14: Internetworking com BACnet ${ }^{\circledR}$, adaptado de BUSHBY (1998)...........................58

Figura 15: Conexão de estação de trabalho ao sistema de automação predial BACnet ${ }^{\circledR}$ via

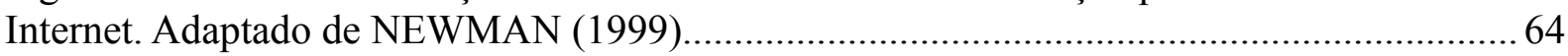

Figura 16: Organização de um nó ODP adaptado de HÜBNER, SICHMAN e BECERRA

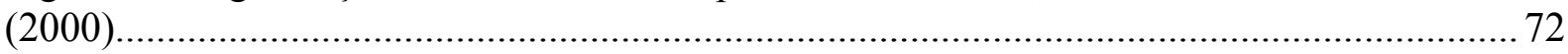

Figura 17: Visão de engenharia (FAROOQUI; LOGRIPPO; MEER, 1996)...........................73

Figura 18: Canais de comunicação HUBNER, SICHMAN e BECERRA (2000)....................74

Figura 19: Mecanismos utilizados para executar um canal de comunicação.............................75

Figura 20: Representação da posição relativa de um middleware extraída de Gartner Research

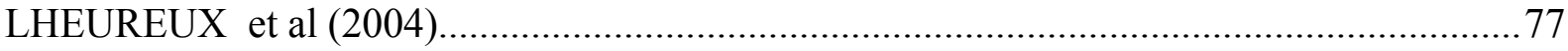

Figura 21: Representação da estrutura de um middleware (BAKKEN, 2003).........................80

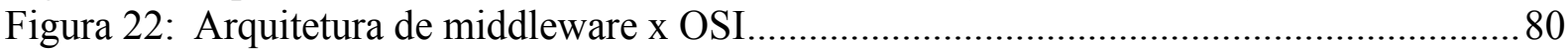

Figura 23: Contexto do middleware em ambiente de aplicação distribuída (BAKKEN, 2003).

Figura 24: Um barramento de rede de controle com diversos equipamentos de automação....88

Figura 25: Comparação entre o ambiente computacional de TI e um microcontrolador de TA

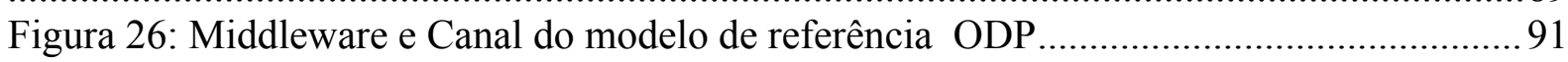

Figura 27: Discretizando as operações dentro do contexto middleware....................................92

Figura 28: Modelar a recomendação ODP as camadas OSI............................................. 95

Figura 29: Visão de Engenharia da implementação proposta.................................................. 96

Figura 30: Contexto de middleware incorporado com o modelo OSI e ODP apenas no canal

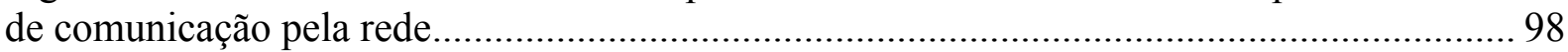

Figura 31: O contexto de middleware aplicando ODSIP......................................................99

Figura 32: Produtos de Automação com Objetos instanciados e interligados em tempo de

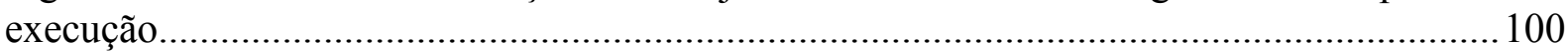

Figura 33: Mecanismo ODSIP esclarece a operação do objeto apenas pela representação

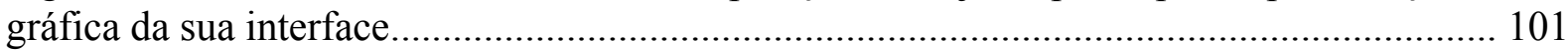

Figura 34: Objetos ou aplicações representadas pela sua interface.....................................102

Figura 35: Visão da computação de um sistema de automação............................................... 103 
Figura 36: Visão do seletor na área de automação ................................................................ 104

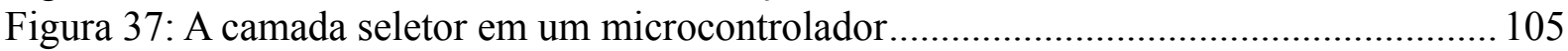

Figura 38: O contexto do middleware ODSIP em Automação.............................................. 106

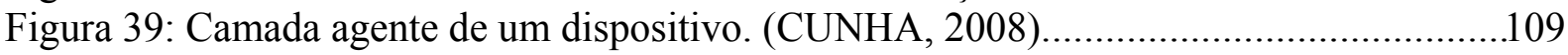

Figura 40: Diversos objetos instanciados nos hardwares. ................................................... 110

Figura 41: Funcionalidades que dependem de um hardware associado................................111

Figura 42: Dispositivos físicos atrelados diretamente ao hardware. .................................... 111

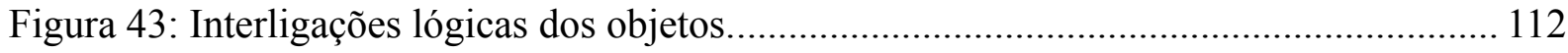

Figura 44: Ambiente de rede abstraído como um barramento de objetos.............................. 113

Figura 45: Ambiente de automação ODSIP acrescido dos conceitos de sistemas multi-agentes.

Figura 46: Frame de comunicação do protocolo LonTalk® ${ }^{\circledR}$ ou norma EIA 709.1 adaptado de

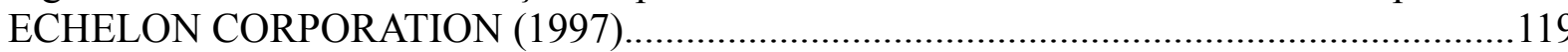

Figura 47: Alocação de memória e tratamento dos processadores de um NeuronChip ${ }^{\circledR}$

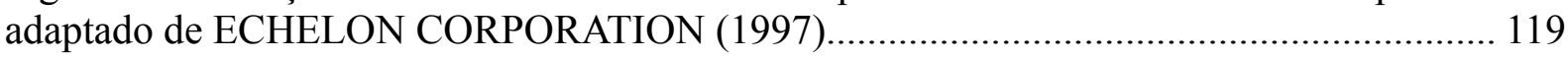

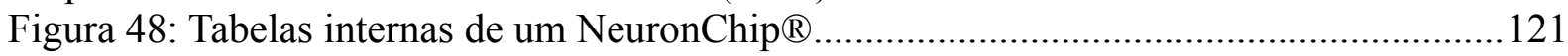

Figura 49: O Barramento de controle destacando o MTD em suas partes principais.............132

Figura 50: Visão da Computação de um enlace telefônico através de MTDs..........................133

Figura 51: O MTD com todos os objetos desenvolvidos em separado..................................135 


\section{LISTA DE TABELAS}

Tabela 1: Alguns exemplos da tabela geral de SNVTs baseado em LONMARK®

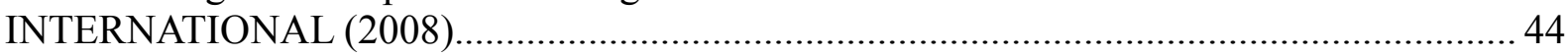

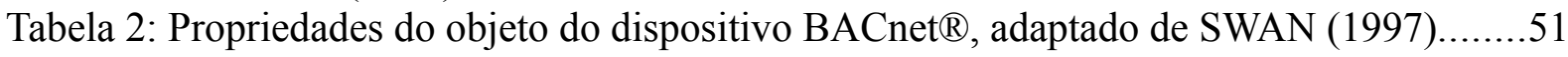

Tabela 3: Serviços de alarme e evento, adaptado de SWAN (1997)..........................................52

Tabela 4: Serviços de acesso a arquivos, adaptado de SWAN (1997)......................................52

Tabela 5: Serviços de acesso a objetos, adaptado de SWAN (1997).......................................53

Tabela 6: Serviços de gerenciamento remoto de dispositivo, adaptado de SWAN (1997).......54

Tabela 7: Serviços de terminal visual, adaptado de SWAN (1997)..........................................54

Tabela 8: Grupos de função, adaptado de SWAN (1997)........................................................ 55

Tabela 9: Custo x desempenho das tecnologias de LAN, adaptado de McENTEE (1997)......59 
API

ASHRAE

BDI

BMA

CAN

CCITT

CEN

CLP

CORBA

CPU

CSMA

DCIP

EEPROM

FAN

FAPESP

HTTP

IHM

10

ISO

JMS

LAN

LNS

LON

ME1

MGK

MIP

MLT

MOM
Application Programming Interface

American Society of Heating, Refrigerating and Air-Conditioning Engineers

Beliefs Desires Intention

BACnet Manufacturers Association

Controller-Area Network

Commite' Consultatif International de Telegraphique et

Telephonique

Comité Europeu de Normalização

Controlador Lógico Programável

Commom Object Request Broker Architecture

Central Processing Unit

Carrier Sense Multiple Access

Declaração de Conformidade de Implementação do Protocolo

Electrically-Erasable Programmable Read-Only Memory

Field Area Network

Fundação de Amparo à Pesquisa do Estado de São Paulo

Hypertext Transfer Protocol

Interface Homem-Máquina

Input/Output

International Organization for Standardization

Java Message Service

Local Area Networks

LonWorks ${ }^{\circledR}$ Network Services

Local Operating Networks

Módulo de Tronco E1

Módulo Gatekeeper

Microprocessor Interface Programm

Módulo de Linha Tronco

Message Oriented Middleware 


\begin{tabular}{|c|c|}
\hline MOMA & Message Oriented Middleware Association \\
\hline MRA & Módulo de Resposta Audível \\
\hline MS/TP & Master-Slave/Token Pass \\
\hline MSG & Message \\
\hline MTA & Módulo Terminal Telefônico Analógico \\
\hline MTD & Módulo Terminal Telefônico Digital \\
\hline NIC & Network Interface Card \\
\hline NV & Network Variable \\
\hline OBE & Objetos Básicos de Engenharia \\
\hline ODBC & Open Database Connectivity \\
\hline ODP & Open Distributed Processing \\
\hline ODSIP & Open Distributed System Interconnection Processing \\
\hline OMA & Object Management Architecture \\
\hline OMG & Object Management Group \\
\hline ORB & Object Request Brokers \\
\hline OSI & Open System Interconnection \\
\hline PABX & Private Automatic Branch Exchange \\
\hline PID & Controle Proporcional-Integral-Derivativo \\
\hline POO & Programação Orientada a Objetos \\
\hline PSTN & Public System Telephony Network \\
\hline PTP & Point to Point \\
\hline RAM & Random Access Memory \\
\hline RCSM & Reconfigurable Context-Sensitive Middleware \\
\hline RM-ODP & Reference Model of Open Distributed Processing \\
\hline RPC & Remote Procedure Call \\
\hline SAP & Sistema de Automação Predial \\
\hline SDCTP & Sistema Distribuído de Comunicação Telefônica Pervasiva \\
\hline SMS & Short Message Service \\
\hline SNVT & Standard Network Variable Type \\
\hline SO & Sistema Operacional \\
\hline SOAP & Simple Object Access Protocol \\
\hline SPI & Sistema de Programação Interface \\
\hline SQL & Structured Query Language \\
\hline TA & Tecnologia da Automação \\
\hline TCP/IP & Transmission Control Protocol /Internet Protocol \\
\hline
\end{tabular}


$\mathrm{TI}$

TMID

TPM

UIT

UIT-T
Tecnologia da Informação

Telefonia Modular Inteligente Distribuída

Transaction Processing Monitor

Union Internationale des Télécommunications

Secteur de la normalisation des telecommunications, UIT 


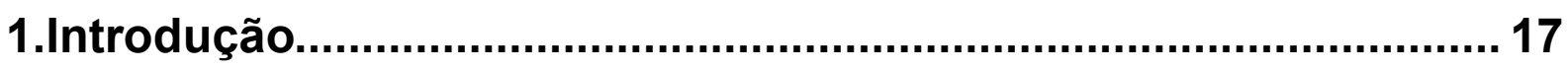

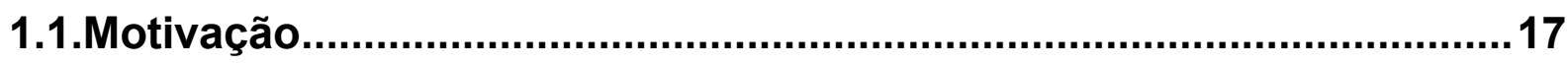

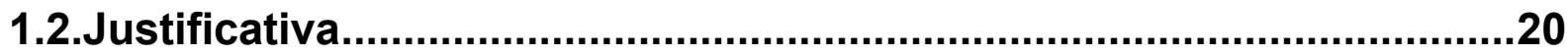

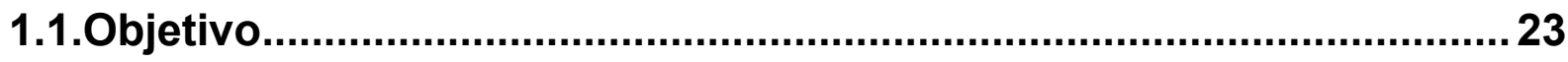

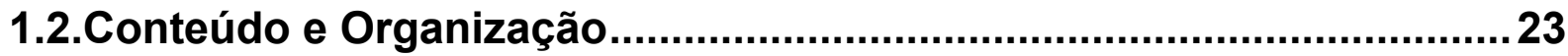

2.Considerações sobre os Sistemas de Automação Predial

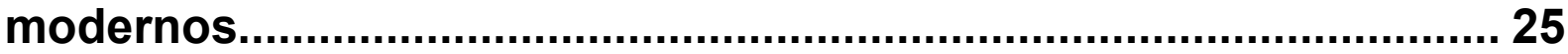

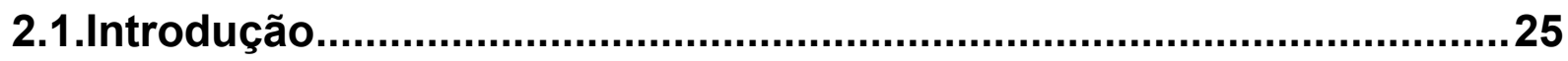

2.2.Níveis da Automação e suas Responsabilidades................................28

2.3.As quatro operações dentro de um Sistema de Automação Predial.. 31

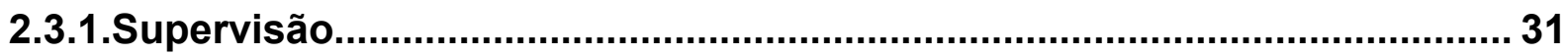

2.3.2.Operação de Campo.......................................................................... 32

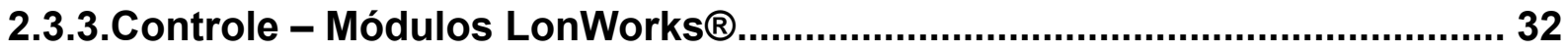

2.3.4.Atuadores e/ou Sensores de Campo............................................................. 33

2.4.Rede de Controle e Protocolo de Comunicação....................................33

2.5.Internetworking - Conexão entre Múltiplas Redes ................................35

2.6.Modelo Básico de Referência - Interconexão de Sistemas Abertos

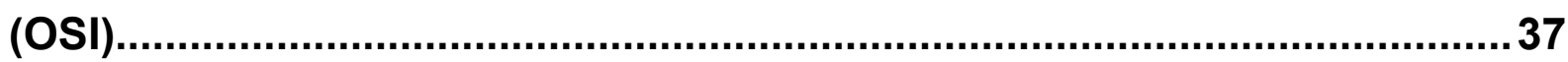

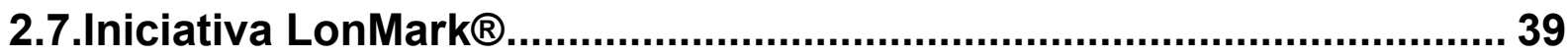

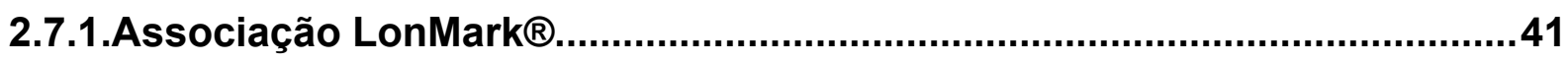

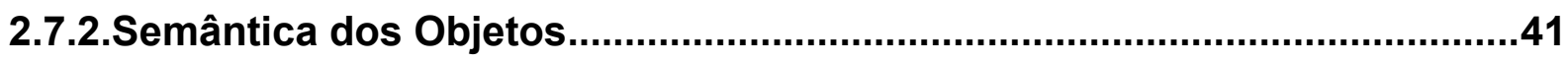

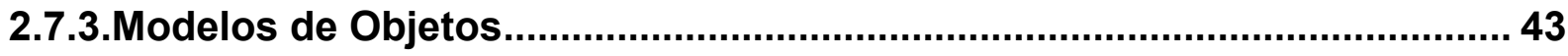

2.7.4.Compartilhamento dos meios físicos de comunicação.................................43

2.7.5.Compartilhamento das informações comuns...............................................44

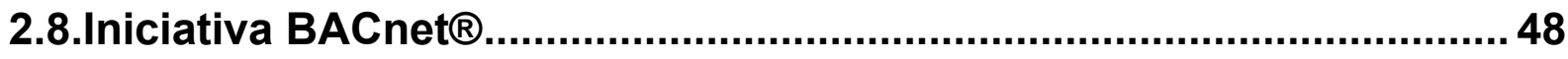

2.9.0 Padrão BACnet ${ }^{\circledR}$ para a camada 7 dos Protocolos de

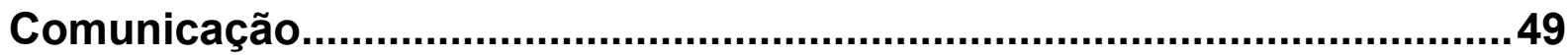

2.10.As Quatro Camadas do Padrão BACnet§.......................................56

2.10.1.Camada Aplicação.........................................................................................57 


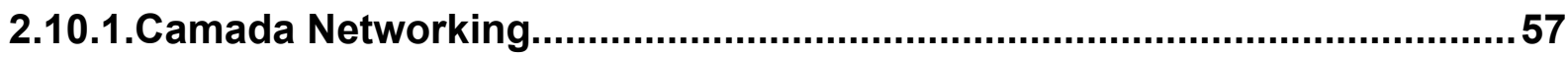

2.10.2.Camada "Data Link" e Física................................................................. 59

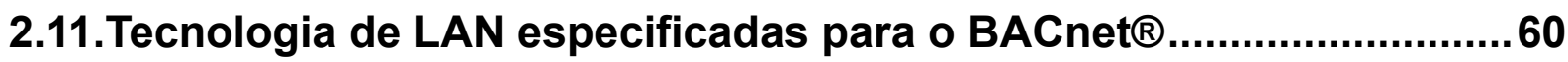

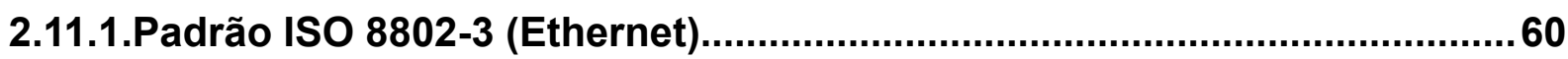

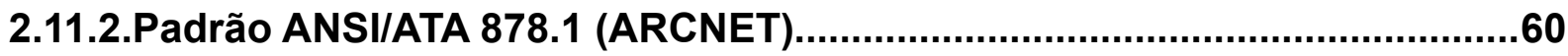

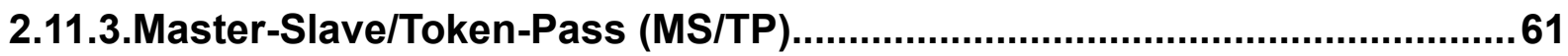

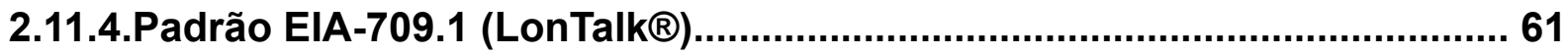

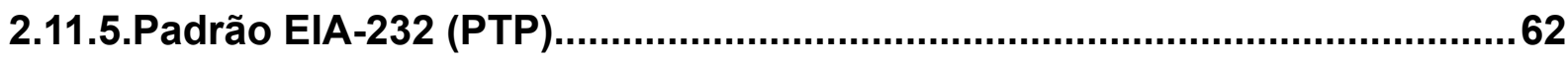

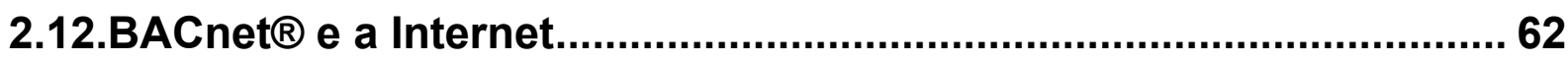

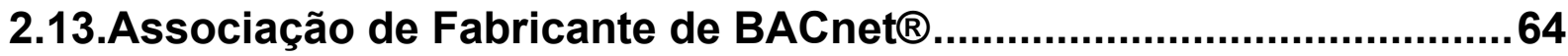

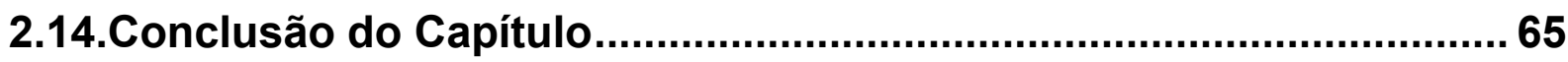

3. A recomendação ODP e a relação com middleware para arquitetura de objetos distribuídos................................................68

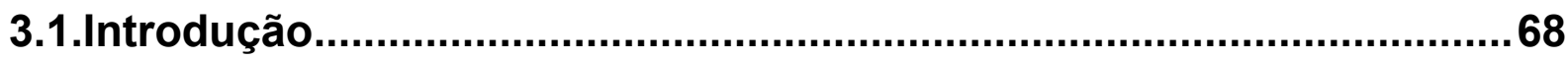

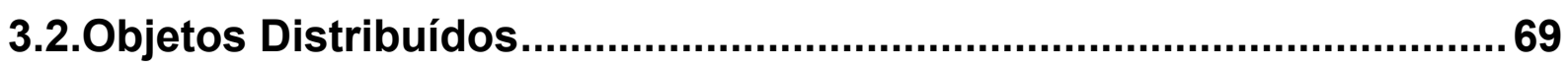

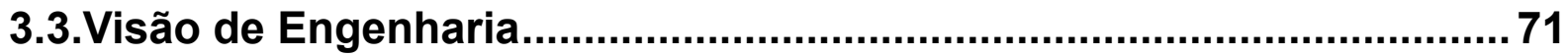

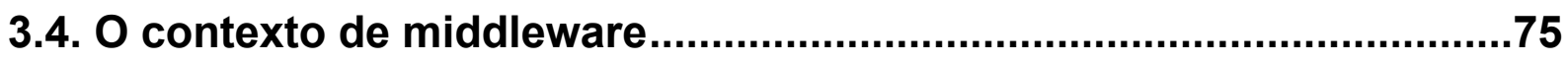

3.5.A associação OMG e o middleware CORBA.......................................81

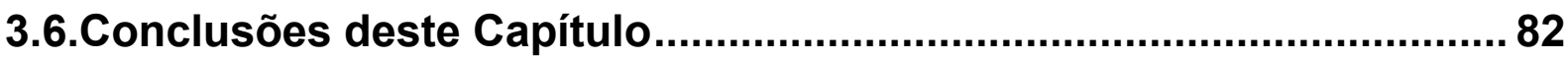

4. Desenvolvendo Tecnologia da Automação tendo como base RMODP e o contexto de middleware da Tecnologia da Informação.......84

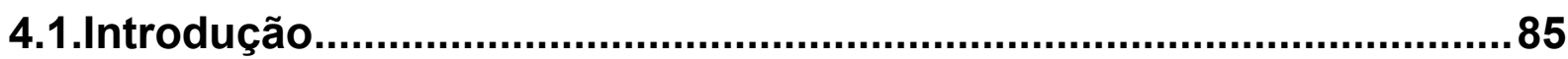

4.2. 0 contexto do middleware para automação.......................................87

4.3.A Visão de engenharia do RM-ODP no contexto de middleware ........90

4.4.Criando os mecanismos ODSIP.........................................................92

4.4.1.Visão da Engenharia ODP na criação do ODSIP........................................93

4.4.2.Visão da Tecnologia ODP na implementação do ODSIP...............................95

4.5. Visão da Computação ODP em projetos de automação...................101

4.6. Como representar o contexto do middleware ODSIP de automação. 
4.8.Visão nova de sistema de automação desenvolvido por orientação a objetos. 110

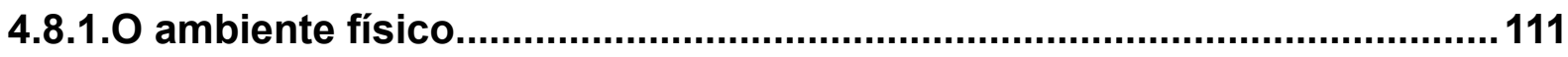

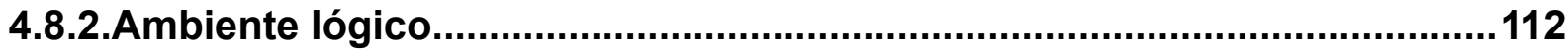

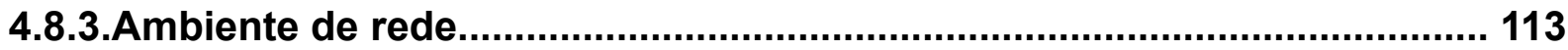

4.8.4.As possibilidades de middleware em automação com ORBs....................114

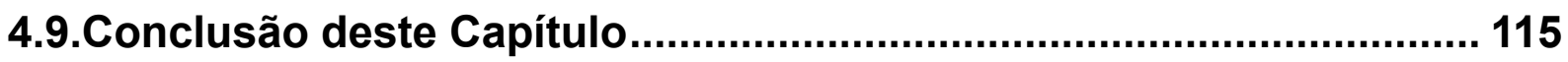

5. A Tecnologia LonWorks ${ }^{\circledR}$ e o middleware ODSIP de Automação

5.1. A Tecnologia LonWorks $₫$ e a norma EIA 709.1 .................................117

5.2. A operação do LonTalk $₫$ na rede de controle LonWorks $₫$................118

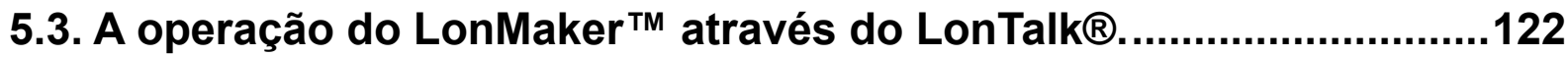

5.3.1. Mensagens de gerenciamento, diagnósticos e aplicação........................123

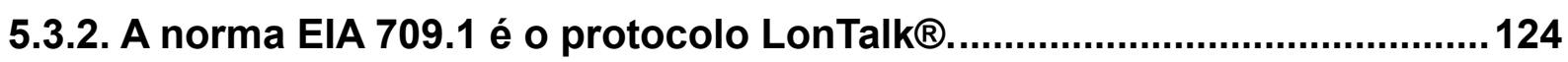

5.4. Comparando categorias do middleware de TI com ODSIP de

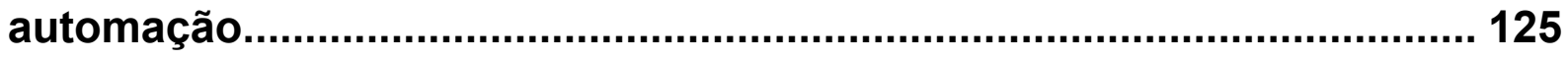

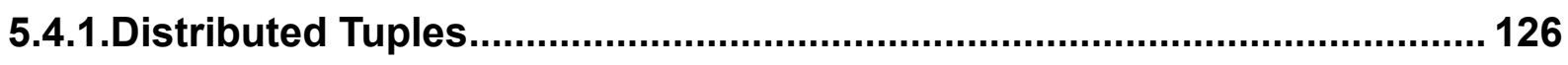

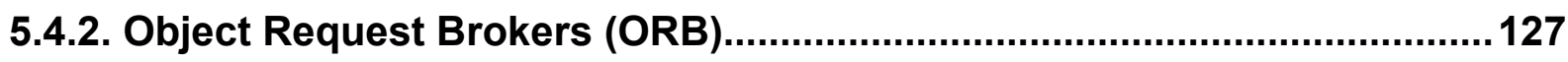

5.4.3. Message-Oriented middleware (MOM) ........................................... 128

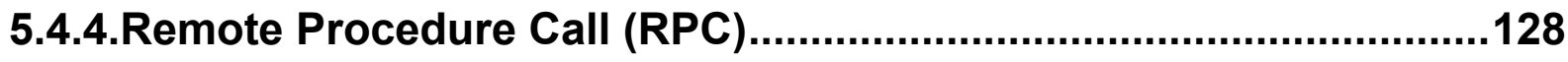

5.5.Conclusões deste Capítulo................................................................. 129

6.Estudos de casos.......................................................................... 130

6.1.Projeto do Sistema Distribuído de Comunicação Telefônica Privado

6.2.Conclusões deste Capítulo............................................................... 136

7. Considerações Finais.................................................................137

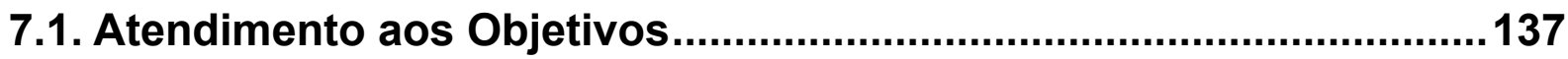

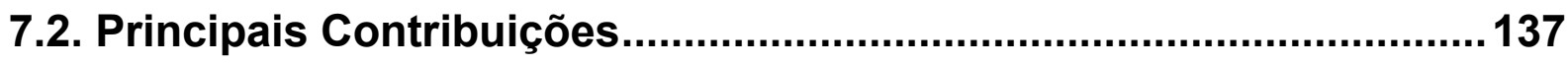

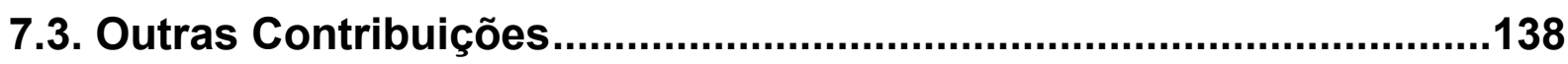

7.4. Perspectivas de Continuidade .........................................................139

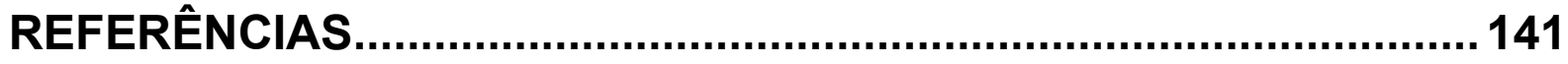




\section{Introdução}

\subsection{Motivação}

WEISER (1991), procurando responder às tendências de mudanças no comportamento das pessoas e às possibilidades dessas mudanças estarem vinculadas diretamente aos avanços da tecnologia dos computadores, criou um novo paradigma sobre os ambientes computacionais que estão em toda a parte e a todo momento.

Ele mostra, de uma forma clara, que em uma primeira fase, nos primórdios da computação havia várias pessoas ligadas a um único computador. $\mathrm{O}$ mainframe centralizava todo o processamento dos serviços e armazenamento de dados e cada usuário poderia acessar os dados e solicitar os serviços disponíveis por ele.

Já em uma fase seguinte, caracterizada pela evolução e barateamento do hardware, ele constata o convívio das pessoas com os computadores pessoais. Essa mudança gerou uma descentralização do processamento e ampliou o acesso, com a tendência de se utilizar um computador para cada usuário.

Em uma terceira fase dessa evolução, Weiser constata a tendência de um único usuário ter acesso a vários computadores ou equipamentos com capacidade de processamento computacional, como por exemplo, telefones celulares, laptop, pagers e PDAs. Assim, ele criou um novo segmento de estudo ou paradigma, que é da computação pervasiva.

Os cenários de computação pervasiva de hoje, que também considera a computação móvel, baseiam-se no aumento da mobilidade dos serviços computacionais, ou seja, o computador torna-se um dispositivo sempre presente, permitindo expandir a capacidade de trabalho do usuário e disponibilizando os serviços de um computador, independentemente de sua localização. Ampliando a capacidade de acesso, a computação móvel tem transformado a tecnologia da informação e da comunicação, com a tendência de torná-la presente em qualquer lugar, possibilitando que as aplicações e serviços possam se movimentar juntamente com os usuários e seus dispositivos portáteis (ARAUJO, 2003)(BERESFORD et al., 2003).

Muitos computadores embarcados em ambientes, de forma invisível para o usuário, têm a capacidade de obter informações desse ambiente no qual eles se 
inserem e utilizá-las para dinamicamente construir modelos computacionais sobre o mesmo, controlando, configurando e ajustando as aplicações para melhor atender às necessidades do usuário. O ambiente também pode e deve ser capaz de detectar e incorporar dinamicamente outros dispositivos, permanentes ou temporários, que venham fazer parte dele. Esta interação amplia a capacidade dos computadores agirem de forma "inteligente" nos ambientes típicos que as pessoas utilizam normalmente (ARAUJO, 2003) (BERESFORD et al., 2003). Isto implica que os equipamentos neste ambiente computacional pervasivo transcendam as fronteiras e diferenças entre interfaces, permitindo que um usuário seja encontrado e informado de tudo de seu interesse e necessidade onde quer que esteja.

Outras definições de redes surgiram dentro desse cenário, como a Personal Area Network (PAN), utilizada para designar as pequenas redes de dispositivos pessoais, como por exemplo os dispositivos baseados nas tecnologias Bluetooth ou ZigBee, incorporadas em pequenos objetos transportados nas roupas das pessoas, como etiquetas de vestimentas, relógios, fones de ouvido, telefones celulares, entre outros. Esses elementos, ao formar uma rede, são capazes de se comunicar e de realizar operações entre si. Dessa forma, cada um pode focalizar no desempenho de suas funcionalidades básicas e utilizar serviços de outros equipamentos. Isto implica em conectividade e mobilidade entre produtos diferentes, que podem compor, no conjunto, uma aplicação de maior amplitude.

Os estudos na área do conhecimento da tecnologia da informação estão se dirigindo a passos largos para prover soluções computacionais que possam atender ao novo paradigma apregoado pela computação pervasiva. Como exemplo, tem-se o projeto (AURA, 2009) e o projeto (GAIA, 2009), em laboratórios e universidades ou em empresas privadas. O ponto comum dessas iniciativas está em utilizar os computadores fixos e móveis com interfaces simples, acompanhando o usuário e moldando-se aos novos ambientes de outros computadores fixos e móveis, oferecendo ao usuário mais versatilidade e agilidade com todos os recursos computacionais pervasivos.

$\mathrm{Na}$ área de automação, principalmente predial e residencial, até o momento não se observa estudos específicos que venham a permitir projetos metódicos que possam atender aos requisitos da computação pervasiva. Observa-se que normalmente os sistemas desenvolvidos, em sua maioria, são orientados a resolver os aspectos de interoperabilidade entre diferentes produtos de fabricantes distintos, com a proposta de se tornarem sistemas abertos. As grandes empresas do mercado, entretanto, 
não apresentam soluções que consideram o contexto ou ao comportamento do usuário, ou ainda interfaces com o usuário para uso comum entre os diferentes sistemas presentes em uma automação predial (APPLEBAUM; BUSHBY, 1998) (COVIELLO NETO, 2002).

As tecnologias futuras deverão atender às necessidades dos usuários, sem a intervenção direta do mesmo, como por exemplo, indicar valores de setpoint ou dirigir uma câmera de Circuito Fechado de Televisão (CFTV) para o ponto correto de um evento importante (INTILLE, 2002)(CUNHA, 2008).

Ao se pensar em conceber ambientes pervasivos fora do contexto dos laboratórios de pesquisa, como um edifício inteligente ou controle automatizado de um chão de fábrica que atenda aos requisitos dos seus usuários e que opere em função do contexto do usuário ou operador, será necessário solucionar diversos problemas, como por exemplo, tratar automaticamente os problemas importantes de demanda da energia: 0 posicionamento dos elevadores de alta rotatividade (em função do público que está sendo credenciado na portaria e observando o andar de destino estabelecido), e os sistemas de ar condicionado, que tratarão não só da qualidade do ar interior, mas também procurarão atender os desejos dos usuários, respeitando os seus parâmetros pessoais de conforto.

Outros sistemas que podem ser citados são: os sistemas de iluminação que acompanham o usuário de forma inteligente e econômica (observando a posição do usuário e o sentido de seu deslocamento); e os sistemas de controle de acesso que, além de atuar em roletas e cancelas, tratarão de enviar os sinais de seus usuários e ocupantes de uma edificação, de forma a se poder determinar o local de cada pessoa, bem como com quem ela está a cada momento. Podem-se citar também os sistemas de controle de segurança patrimonial com inteligência, capazes de gravar apenas cenas importantes para serem analisadas, além de solicitar as providências para os usuários e, com isso, não sobrecarregar o armazenamento nas fitas, CDs, ou quaisquer que seja a mídia utilizada. Isso auxilia o usuário ao procurar alguma ocorrência mediante horário ou local específicos, com mais simplicidade.

Com tudo isso, tornar-se-á possível uma automação inteligente, que minimiza as interrupções ao usuário a todo momento, trazendo-lhe mais conforto. Atualmente, tem-se sistemas de automação nos quais é indispensável a supervisão humana a todo momento. Em um ambiente industrial típico, observam-se poucos operadores, comparativamente com o que ocorria há algumas décadas. Mesmo assim, esses ambientes industriais também poderiam se beneficiar da proposta da computação 
pervasiva futuramente, liberando os operadores para que realizem atividades mais nobres.

Assim, conforme o exposto poder-se-ia imaginar que os conceitos associados à computação pervasiva já poderiam estar sendo aplicados além dos laboratórios de pesquisa, nos novos sistemas concebidos, mesmo que de forma embrionária, trazendo benefícios reais. Este trabalho de pesquisa foca alguns aspectos associados à concepção de sistemas de automação, em particular os prediais, procurando contribuir para que tais sistemas venham a poder paulatinamente serem concebidos de forma a contemplar aspectos da computação pervasiva, com potencial para benefícios imediatos, agregando economia, evitando desperdício e principalmente, proporcionando maior conforto e facilidade para os seus usuários.

\subsection{Justificativa}

O novo paradigma, conhecido como computação pervasiva está evoluindo rapidamente, utilizando as mais avançadas tecnologias e equipamentos computacionais disponíveis, muitos dos quais de alto desempenho. Nesses ambientes especiais estão sendo criados novos métodos de programação e ferramentas, visando incorporar ao contexto as necessidades dos usuários (TANDLER; STREITZ; PRANTE, 2002).

Nesse sentido, percebe-se iniciativas na área de programação de diversas tecnologias, como Java e Corba-Mini (OH et al., 2003), além de outros, com sistemas operacionais otimizados para serem suportados por ambientes computacionais de menor porte, mas com bom desempenho.

A área de automação acompanha, de certa forma, as tendências da tecnologia da informação e da comunicação no contexto da computação convencional, com uma defasagem temporal, em especial quando se consideram os progressos da descentralização de processos computacionais (ECHELON CORPORATION, 2007) (RAJI, 2002). Em algumas soluções de automação predial, os sistemas centralizados constituídos por Controladores Lógicos Programáveis (CLPs) passaram a ser substituídos por sistemas distribuídos, com entradas e saídas distribuídas em equipamentos denominados estações remotas. Isso fez com que os protocolos de comunicação para 
tais aplicações fossem aprimorados, pois exige-se uma alta segurança e desempenho na entrega das informações trocadas pelos equipamentos utilizados em ambientes industriais, como a comunicação entre o módulo central de um CLP e suas estações remotas.

Outras iniciativas surgiram na tentativa de distribuir parte do processamento associado às aplicações entre os próprios sensores e atuadores que estão sendo utilizados em um processo, seja ele industrial, predial ou residencial, sendo conhecidas como Redes de Controle ou fieldbus. Entretanto, na área de automação industrial ainda tais redes não substituem os CLPs, pois estes garantem determinismo aos processos (FIELDBUS FOUNDATION, 2007).

Com a iniciativa de empresas como a Echelon, que concebeu uma rede de controle que possibilita distribuir totalmente a aplicação entre os módulos presentes em uma rede de controle, a área de automação predial e residencial ganhou novos produtos que não foram baseados na tecnologia já tradicional dos CLPs, permitindo, então, o começo do desenvolvimento de soluções de automação predial e residencial com aplicações distribuídas (CUNHA, 2008). Percebe-se com clareza a limitação das tecnologias existentes para automação predial e residencial, assim como a distância entre os aplicativos de um sistema CLP e um sistema de automação predial, com parte de seus aplicativos distribuídos e parte centralizados.

Observa-se também uma grande tendência de as soluções de automação predial e residencial serem concebidas de forma semelhante a pequenos CLPs interligados em redes de controle comum. Isso mostra que embora a tecnologia esteja caminhando para distribuir mais recursos computacionais em atuadores e sensores, os fabricantes ainda estão seguindo a mesma linha das soluções industriais, com soluções de pequenos CLPs com lógica distribuída sendo colocadas na indústria.

Analisando as pesquisas relacionadas com o conceito de middleware, observa-se diversos artigos que procuram modelar soluções com abstração dos sistemas operacionais e da comunicação entre objetos distribuídos (BAKKEN, 2003)(KUMAR et al., 2003). Também é observado que se utilizam um método de tratamento "request/response" nos protocolos de comunicação, como no caso do CAN e do LonWorks $®$, com uma solução baseada em três camadas. Verifica-se a tendência de se criar camadas complexas entre os sistemas operacionais e a aplicação (HUR; KIM; PARK, 2005).

Uma das principais funções de um middleware é prover abstração das dependências do SO e da comunicação entre estações interligadas em rede de 
informação. O middleware, tipicamente uma camada entre o sistema operacional e as aplicações, oferece certas operações e estruturas de dados que permitem aos processos e usuários inter-operarem em máquinas diferentes de forma consistente. Estas estruturas e operações são muitas vezes determinadas por APIs, frameworks, bibliotecas, etc, que são consideradas como componentes de middleware (KUMAR et al., 2003)(ROMÁN et al., 2002). Alguns componentes foram construídos como resultado de iniciativas de empresas, laboratórios de universidades e instituições de pesquisa. Bibliotecas, frameworks, toolkits e infra-estruturas de serviços têm sido construídas para suportar aplicações em ambientes pervasivos (RÜPING; HUNSTOCK; GUNREBEN, 1997). Nos laboratórios de pesquisa de universidades e empresas, algumas soluções têm sido pesquisadas com o objetivo de converterem um espaço físico e seus dispositivos de computação pervasiva em um sistema de computação programável. Um dos desafios dessa tarefa é como capturar e tratar os dados que são lidos de sensores e que, quando interpretados, definem um contexto que pode influenciar no fluxo da aplicação.

Com exceção do Context Toolkit que enfatiza o tratamento do contexto, projetos como o Aura, o Reconfigurable Context-Sensitive Middleware (RCSM) e vários outros encontrados na literatura têm objetivos comuns que, na verdade, são os desafios da computação pervasiva: tratamento da heterogeneidade de dispositivo, tratamento de contexto (localização do usuário, autenticação, atividade, presença de outras pessoas por perto, etc.); adaptação e descoberta de serviço, dentre outros (SALBER et al.,1999).

Outra iniciativa interessante observada nesta pesquisa foi simular, antes de construir a solução de uma automação, como o artigo RÜPING; HUNSTOCK e GUNREBEN (1997). Este artigo apresenta a simulação de uma rede LonWorks $®$, alegando a necessidade de ser desenvolvida alguma ferramenta desse tipo para auxiliar ao desenvolvimento de uma rede mais complexa, que poderá chegar aos 32.200 nós e necessitando verificar em simulação se o desempenho poderá ser atendida antes de se implementá-la. A forma de simulação que foi desenvolvida utiliza-se de uma biblioteca que permite simular o comportamento de nós LonWorks ${ }^{\circledR}$ em rede por meio de filas e temporizações, e é apresentado também alguns aspectos do comportamento de uma máquina de estado interno de uma operação macroscópica de processo.

Sistema de automação convencional e suas redes de controle de campo são considerados de forma isoladas e se comportam como vários computadores com múltiplos processadores e memórias independentes e concorrentes, dessa forma, o desenvolvimento das aplicações, seja distribuídas ou não, mantém o controle direto da 
informação em suas respectivas interface próxima ao usuário, dificultando o uso desta mesma interface por outros sistemas. Portanto dificulta a criação de um ambiente computacional pervasivo que utilize qualquer interface próxima ao usuário abstraindo o sistema que a compõem.

\subsection{Objetivo}

Este trabalho de pesquisa propõe um modelo de relacionamento dinamicamente reconfigurável entre dispositivos inteligentes de uma rede de controle LonWorks $®$, como extensão do seu modelo de objetos, viabilizando middleware em automação LON, que faculta modificar os seus comportamentos à medida que novas situações no ambiente sejam detectadas, que é uma característica prevista na computação pervasiva.

Portanto, os dispositivos inteligentes embarcados nestes ambientes, de forma transparente para o usuário, terão capacidade de obter informações do local no qual eles se inserem, alterando dinamicamente os modelos computacionais do ambiente, controlando, configurando e ajustando as aplicações para melhor atender às necessidades do usuário. Este ambiente também pode e deve ser capaz de detectar e incorporar dinamicamente outros dispositivos, permanentes ou temporários.

Sugerindo, dessa forma, o desenvolvimento de uma nova classe de aplicações que explora as mudanças de contexto dentro de um domínio dinâmico, tratando a informação de qualquer sistema em qualquer interface que esteja próxima do usuário, mantendo a abstração de tecnologias e protocolos entre sistemas.

\subsection{Conteúdo e Organização}

O Capitulo 1 apresentou a motivação, justificativas e objetivo do presente trabalho.

O Capítulo 2 apresenta uma visão das tecnologias utilizadas na 
automação predial e residencial e algumas das tendências associadas ao mercado de controle e automação.

O Capítulo 3 apresenta o modelo de referência ODP utilizado na área da tecnologia da informação e a sua co-relação com os contextos de middleware.

O Capítulo 4 apresenta a efetiva contribuição do autor em propor um modelo de relacionamento dinamicamente reconfigurável entre dispositivos de uma rede de controle, na área de automação, aplicando os modelos de referencia OSI e ODP e os contextos de middleware.

O Capítulo 5 discute a tecnologia LonWorks $\AA$, com a proposta de criar middleware de automação em função do modelo de relacionamento dinamicamente reconfigurável como extensão do modelo de objetos (Perfil Funcional) desta tecnologia.

O Capítulo 6 apresenta algumas aplicações experimentais da extensão proposta, visando a sua validação e refinamento. Os resultados de tais aplicações são avaliados e discutidos.

O Capítulo 7 encerra o trabalho apresentando as considerações finais, discussões, contribuições e perspectivas de continuidade. 


\section{Considerações sobre os Sistemas de Automação Predial modernos}

\subsection{Introdução}

Conforme já comentado no Capítulo 1 , muitos sistemas de automação industriais são baseados nos tradicionais CLPs, que foram desenvolvidos, em um primeiro momento, para substituírem painéis de relés que implementavam lógicas de intertravamentos, sendo que até hoje não houve mudanças significativas em sua arquitetura e forma de utilização (HULL, 1997)(HUR; KIM; PARK, 2005).

Os sistemas baseados em CLPs costumam apresentar arquitetura centralizada, podendo constituir um sistema hierárquico, semelhante a uma pirâmide, tendo em sua base dispositivos de campo - sensores e atuadores, seguidos pelos sistemas de controle de campo, pelo controle operacional e, no topo da pirâmide, os sistemas supervisórios.

Houve um avanço significativo na arquitetura de sistemas de automação quando se adotou uma arquitetura distribuída, baseada em rede (também conhecidas como redes de controle), envolvendo protocolos de comunicação robustos, na tentativa de se diminuir drasticamente o cabeamento envolvido (e custos associados). Passou-se então a distribuir as funções de um sistema de controle. Alguns equipamentos, como CLPs passaram a oferecer módulos de entradas e saídas remotas para serem instaladas próximas às mesmas, mas não necessariamente próximas do seu módulo central, responsável pela execução do programa associado. Funções de diagnóstico passaram a ser incorporadas às Estações Remotas, e em sistemas de maior porte a presença de mais de uma Estação Central passou a ser considerada, visando garantir que os tempos de resposta pudessem permanecer dentro dos padrões exigidos.

As redes de controle foram também aperfeiçoadas visando suportar taxas de transferência de dados mais altas podendo, assim, atender sistemas de maior porte.

No início da década de 1990 houve um grande impulso na adoção de sistemas de automação em prédios, sendo que as primeiras iniciativas basearam-se nos CLPs que já vinham sendo utilizados com sucesso na automação industrial. Contudo, o custo desses equipamentos era alto para o tipo de aplicação, de forma que outras iniciativas surgiram no sentido de reduzir tais custos. Surgem novos equipamentos 
específicos para a automação predial, que em geral traziam em suas especificações o conceito de sistemas distribuídos, solução natural para atender adequadamente uma classe de sistema caracterizado pela sua distribuição geográfica (KIM; CHO; PARK, 2000).

Muitos esforços foram feitos na área de protocolos de comunicação e modelo de referência Open Systems Interconnection (OSI). Alguns deles, mesmo sendo padrões abertos, ainda não puderam ser utilizados pelos CLPs, mas estimularam outras aplicações, viabilizando a manutenção do foco no produto e na camada de aplicação.

A disponibilidade de redes de controle e os protocolos associados de confiáveis e com bom desempenho, a evolução das potencialidades dos microprocessadores e microcontroladores a custos decrescentes estimularam a distribuição da aplicação de inúmeros módulos de pequeno porte, originando novos padrões, produtos e soluções.

Alguns padrões que merecem ser destacadas são o FieldBus e o ModBus, que puderam ser incorporados em dispositivos baseados em microcontroladores, surgindo no mercado pequenos produtos com capacidade de absorver a inteligência computacional requerida pelas aplicações (FIELDBUS FOUNDATION, 2007)(MODBUS-IDA, 2007).

Mesmo assim, não houve um impacto tão significativo na área industrial, sendo que as maiores alterações associadas ao nível hierárquico inferior, envolvendo sensores e atuadores, que passaram a ser interligados por meio de uma rede de controle com protocolo robusto e confiável, por meio do qual trafegavam informações em tempo real para um sub-sistema concentrador de pequenas redes que, por sua vez, as integrava a equipamento de nível hierárquico superior, como CLPs. Assim, a hierarquia típica utilizada em sistemas de automação permanecia, com alteração apenas na camada inferior, que agora passa a integrar os chamados sensores e atuadores inteligentes.

Os sistemas de automação prediais (e mais tarde os residenciais) foram, então, aos poucos se diferenciando dos sistemas de automação industrial, apresentando características próprias.

$\mathrm{Na}$ automação predial, por exemplo, diversos sub-sistemas precisavam ser integrados, convergindo as informações em um único módulo supervisório e a partir dessas características surgem novas iniciativas do mercado para atendê-las, como os sistemas baseados no padrão BACnet (COVIELLO NETO, 2001).

Outra iniciativa muito relevante para o campo de automação predial foi o 
surgimento da tecnologia LonWorks ${ }^{\circledR}$ que verdadeiramente revolucionou o mercado dessa área, devido a características como a interoperabilidade entre produtos constitutivos dos sistemas, possibilidade do aproveitamento de sistemas legados e possibilidade convergência das informações para um sistema supervisório (ECHELON CORPORATION, 1999)(KIM; CHO;PARK, 2000).

Tanto o BACnet como o LonWorks ${ }^{\circ}$ concorrem atualmente no mercado de automação predial.

$\mathrm{Na}$ automação residencial, área mais recente, outras necessidades passam a ser consideradas, além das tradicionalmente consideradas na automação predial, tais como o controle de iluminação, segurança, controle dos eletrodomésticos e dos equipamentos de entretenimento (som e vídeo). Aumentaram os esforços em controlar salas e ambientes com cenários específicos que o cliente estabelece em tempo de uso, ou seja, o usuário pode alterar qualquer cenário e programá-lo nos equipamentos de forma a garantir que determinadas luzes, imagens e sons sejam acionados em conjunto e, com isso, propõe-se determinados cenários personalizados de recreação ou trabalho .

Na última década foi possível observar a tendência em se conectar as redes locais das empresas, ou Local Area Networks (LANs), também conhecidas como Intranets, à Internet. Isso possibilitou mais aplicações e maior agilidade nos negócios sob o ponto de vista de integração de sistemas, automação de transações, eficiência nas comunicações, troca eletrônica de documentos, etc.

Assim como as LANs foram integradas à Internet, naturalmente surge a tendência de conectar as redes de controle às primeiras. RAJI (2002) chama as redes de controle locais de Infranets, podendo todas as redes se interligarem (Figura 1).

Uma outra designação de uma infranet é Field Area Network (FAN), utilizada em KUNES e SAUTER (2001).

É preciso considerar que as redes locais e a Internet são redes de dados com requisitos semelhantes. Além disso, o padrão atual de protocolo de comunicação baseado no TCP/IP utilizados por elas, torna a sua interligação mais fácil. Integrá-las com redes de controle, que apresenta requisitos diferentes, requer que cuidados adicionais sejam tomados (CANOVAS, 2006) (KUNES; SAUTER, 2001). 


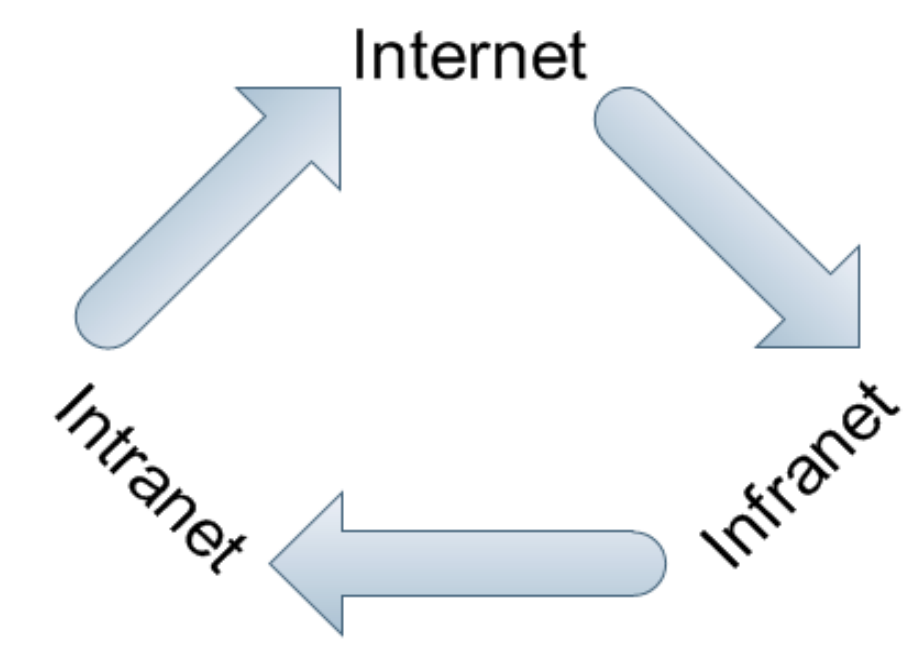

Figura 1: A infra-esturura completa da informação adaptado de RAJI (2002)

\subsection{Níveis da Automação e suas Responsabilidades}

Os sistema de automação predial com arquitetura convencional costumam apresentar alguns níveis de hierarquia, associados à rede de controle, como pode-se verificar na Figura 2, que ilustra uma arquitetura desse tipo, na qual cada computador em seu sub-sistema dedicado possui uma rede própria para atender às suas necessidades.

Um exemplo seria o sistema de deteç̧ão de fumaça e combate de incêndio, verificando-se a existência de duas redes no nível inferior: a rede dos controladores do sistema de sprinkler e a rede dos controladores dos detectores de incêndio, e ainda no nível mais baixo encontra-se a rede dos detectores. As duas redes de controladores estão interligadas ao computador de supervisão de incêndio.

A Figura 2 ainda mostra a interligação de diversas redes, que estão interligadas aos dois computadores que fazem a função de controle e supervisão de todos os níveis de rede, cada uma específica para cada função do prédio. O controle de todo o sistema é feito por apenas um dos computadores e a falha deste faz o outro entrar em operação do ponto em que o primeiro parou. 


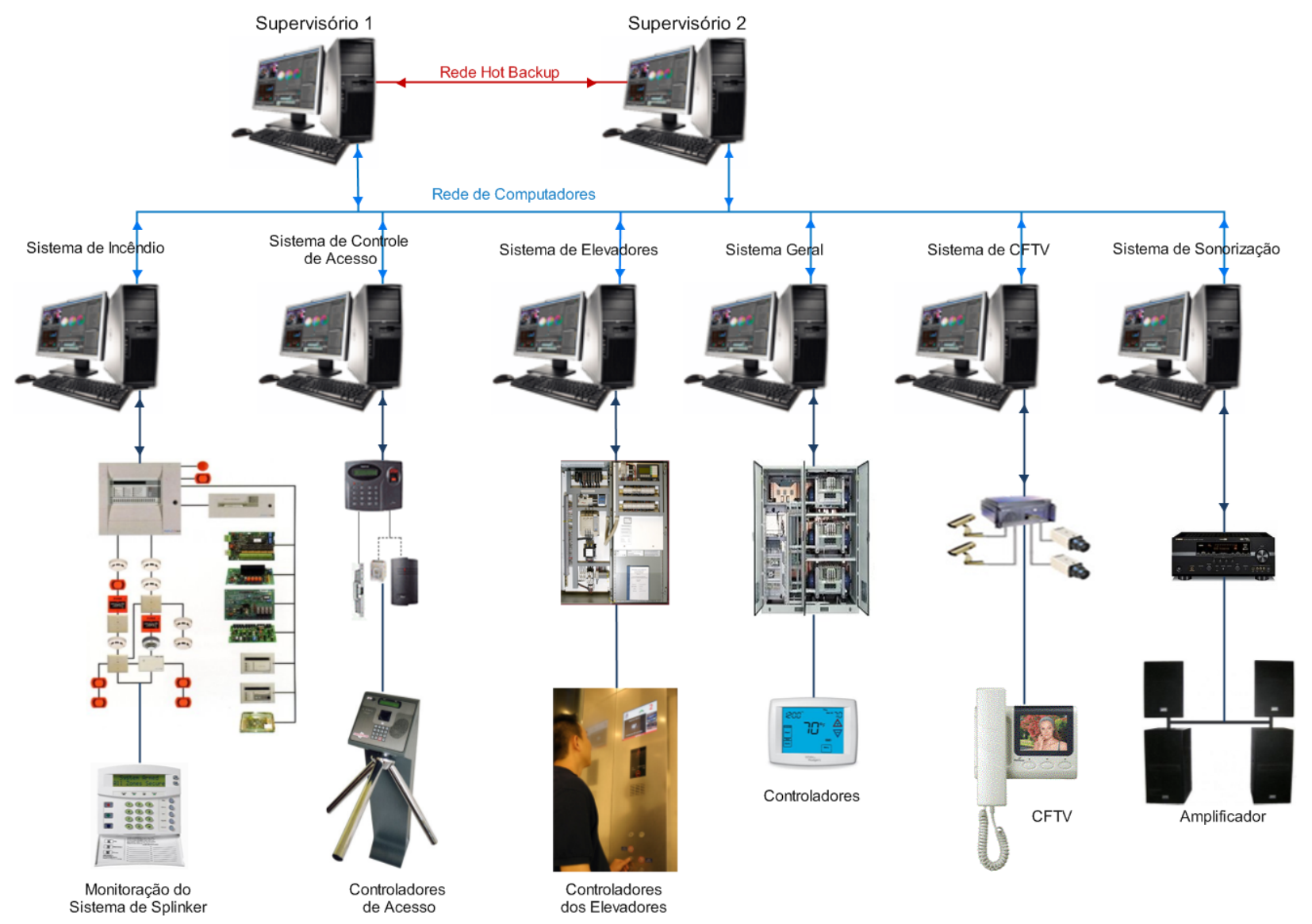

Figura 2: SAP os níveis de automação (ECHELON CORPORATION, 1999).

Entre as diversas redes de controle específicas não há troca de informação. Se houver a necessidade de uma informação, gerada em uma rede específica, exigir uma ação sobre outra rede (como por exemplo, a detecção de fumaça gerar um aviso sonoro), esta informação irá primeiro para o computador de controle e supervisão e somente depois, será processada e enviada ao seu destino.

Para criar mecanismos de usabilidade de interfaces de um sistema para o outro a solução deverá partir dos fabricantes dos sistemas de supervisão. A solução de apresentar mensagens em um display do controle de iluminação, geradas nos sistemas de Tecnologia da Informação ( $\mathrm{Tl}$ ), como por exemplo uma mensagem de telefones celulares (SMS), ficam difíceis de serem transportadas por sistemas aparentemente tão diferentes. Deverá, então, ser enviada aos sistemas de supervisão e ele se incumbirá de repassar a mensagem ao sistema mais próximo do usuário a ser informado. Isso mostra um grau ainda maior de dificuldade, pois necessita que os sistemas de controle de acesso monitorem a posição das pessoas e ainda as informem aos outros sistemas da automação, levando-se em conta que coisas mais simples e necessárias de interoperabilidade não são triviais, estas então serão pouco prováveis de serem 
conseguidas em sistemas convencionais.

Considerando-se agora um sistema baseado na tecnologia LonWorks $®$ (Figura 3), pode-se identificar apenas um único nível hierárquico, uma vez que todo o processamento é distribuído entre os diversos módulos. Computadores para a supervisão podem também ser conectados a essa rede. Utilizando o mesmo exemplo do sistema de detecção e combate a incêndio já citado, se houver uma informação gerada na sub-rede de incêndio que exige uma ação na sub-rede de sonorização, esta informação irá diretamente à sub-rede de sonorização e tomará a ação necessária, não tendo a necessidade de ser enviada primeiramente ao computador de controle e supervisão.

Da mesma forma, quando houver a necessidade de gravar uma informação em uma memória de massa, como num disco rígido, essa informação irá direto para o computador de supervisão para ser armazenada.

Neste tipo de rede é possível se fazer conexões diretas entre interfaces do usuários em diferentes sistemas. Contudo, neste caso a tecnologia é estática e tem interoperabilidade mas não se pode garantir o atendimento a requisitos de tempo real.

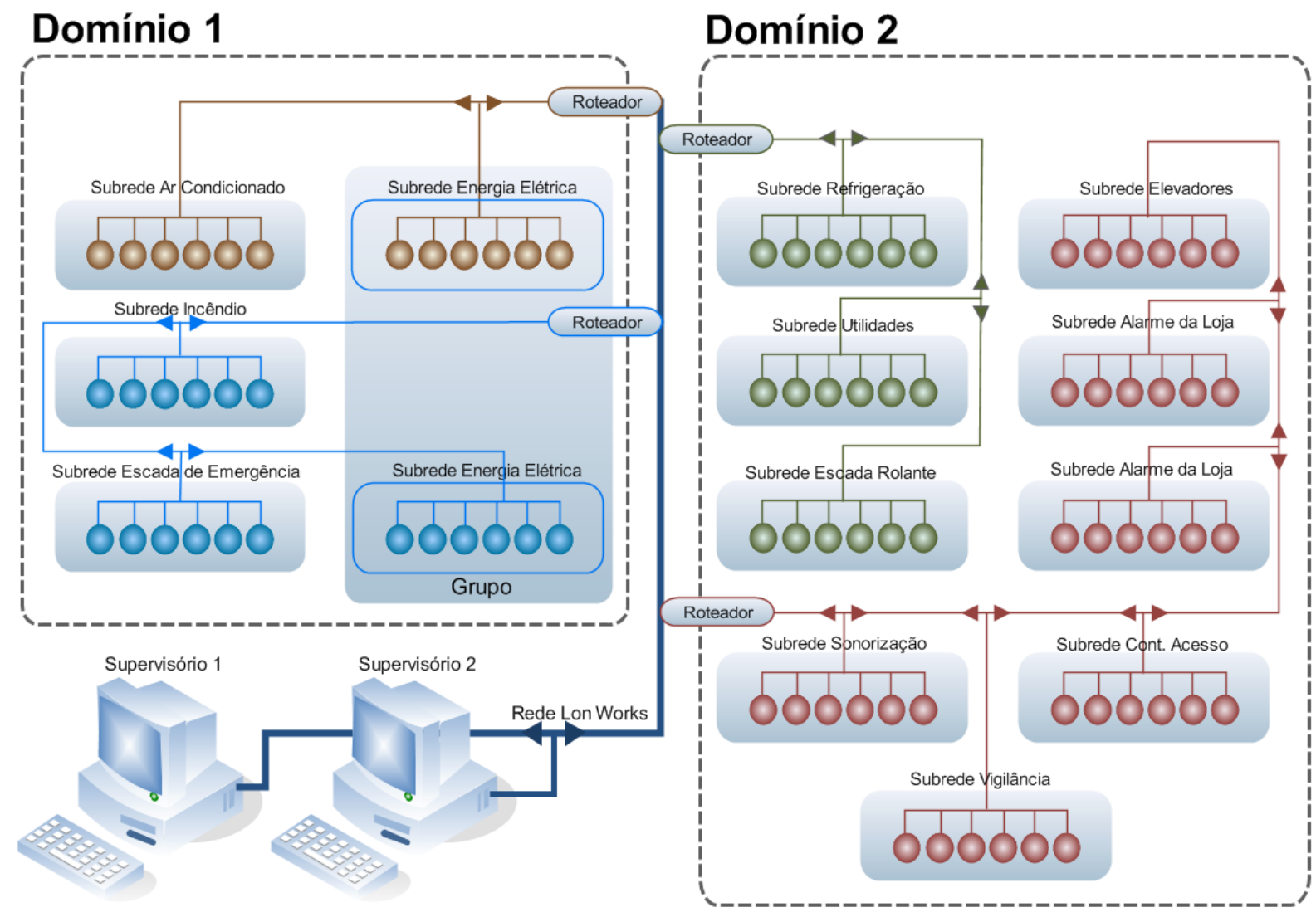

Figura 3: Rede de Controle e Supervisão na Tecnologia LonWorks ${ }^{\circledR}$

A implementação de solução de automação na rede LonWorks ${ }^{\circledR}$ é feita 
através do software de manutenção e comissionamento LonMaker ${ }^{\mathrm{TM}}$ ou NL220 pelo integrador (ECHELON CORPORATION, 2003a). Depois de configurada não se altera até que uma nova manutenção ou integração seja necessária.

As mesmas ferramentas permitem que integradores possa alterar, incrementar ou eliminar dispositivos e com isso configurar a solução ao cliente da forma mais simples e direta.

\subsection{As quatro operações dentro de um Sistema de Automação Predial}

Diversos autores identificam quatro níveis de operação nos Sistemas de Automação Prediais (SAP) atuais: "Supervisão", "Operação de Campo", "Sistema de Controle" e "Sistema de Atuação/Sensoreamento de Campo", descritos a seguir, considerando-se uma rede de controle LonWorks ${ }^{\circledR}$ (APPLEBAUM; BUSHBY, 1998) (BUTLER, 1997)(COVIELLO NETO, 2002).

\subsubsection{Supervisão}

O nível de operação de Supervisão fornece ferramentas de análise e possibilidade de intervenção na planta pelos operadores do sistema, ou seja, este nível permite a operação do sistema através de telas de um painel sinóptico ou de operação e janelas de comandos.

Basicamente existem dois tipos de operação: um é denominado "Operação Manual" e permite ao operador comandar individualmente cada um dos equipamentos através de seleção no sinóptico e comando por meio de janelas específicas; a outra opção é chamada "Operação Automática". Nesta, o operador poderá selecionar sequências automáticas por um menu específico disponível em todas as telas.

Quando selecionada uma sequência automática, os equipamentos de controle (LonWorks $®$ ) dentro da rede, ao receber a(s) variável(veis) de rede respectivas, determinam sua disponibilidade em função do "Perfil Funcional" que possuem. Caso todos os equipamentos estejam disponíveis para a conclusão da atividade, esses módulos de 
controle atuam nos equipamentos em acordo com o Perfil Funcional pré-estabelecido, executando a sequência pretendida.

Outro objetivo do Sistema de Supervisão é fornecer ao operador o maior número de informações possíveis, com o intuito de melhorar o seu poder de decisão sobre determinadas áreas do sistema. Para isso, alarmes e eventos que necessitam de aviso serão representados através de janelas específicas, que aparecerão automaticamente. Neste caso, serão registradas a data e a hora da ocorrência.

Operações específicas como um controle Controle Proporcional-IntegralDerivativo (PID) para controle da temperatura pelo sistema de ar-condicionado e outras serão tratadas através de janelas dedicadas que poderão ser chamadas com comandos disponíveis nas telas.

Para um acompanhamento histórico do sistema, serão fornecidos gráficos de tendência e relatórios que podem ser preenchidos periodicamente, acessando o equipamento de controle.

\subsubsection{Operação de Campo}

A operação de Campo disponibiliza dados e ferramentas de operação no campo através de equipamentos denominados de Interface Homem-Máquina (IHM). Essa IHM, por possuir construção robusta e protegida, permite ao operador acompanhar e comandar setores do processo próximos ao local em que elas ocorrem. Contudo, devido às suas limitações físicas, perdem ferramentas para relatórios, gráficos de tendência e outras disponíveis no nível de Supervisão. Ela é utilizada quando se caracteriza a necessidade de operação próxima do equipamento ou setor específico.

\subsubsection{Controle - Módulos LonWorks ${ }^{\circledR}$}

O nível de operação de Controle define toda a programação de seqüências, intertravamentos e comandos que responderão pela operação do Sistema do módulo e que estão distribuídos e definidos nos "Perfis Funcionais", estabelecidos em 
toda a planta internamente aos módulos com inteligência distribuída ou nós LonWorks®.

\subsubsection{Atuadores e/ou Sensores de Campo}

Este é o nível de operação das entradas e saídas de todos os equipamentos de monitoramento e atuação da planta, tais como instrumentos de medição, comandos e proteção de motores, válvulas, sensores de temperatura, detetores de fumaça, além de outros.

Esta forma de interligação é um grande diferencial da tecnologia LonWorks ${ }^{\circledR}$ em relação à tecnologia convencional. Na convencional existem cartões de entrada e saída, colocados em racks, que se comunicam com um Módulo Central. Esta configuração caracteriza-se pela concentração de um grande número de pontos e uma instalação cara e complexa.

No caso da tecnologia LonWorks $®$, esse mesmo processo é realizado ao colocar os módulos de inteligência distribuída o mais próximo possível dos sensores e atuadores, simplificando e determinando um número significativamente menor dos gastos na construção, na manutenção e start-up da planta. Por outro lado, uma aparente desvantagem que ela apresenta é que descentralizou-se o processamento, gerando alguma dúvida a respeito da segurança do intertravamento gerado nessas condições.

\subsection{Rede de Controle e Protocolo de Comunicação}

Uma rede de controle é a combinação de vários controladores conectados juntos de forma que eles possam compartilhar dados e recursos. O meio que interliga os computadores pode ser fios de cobre, fibra óptica ou por radiofrequência, sem conexão física (wireless). Controladores presentes na rede são programados de forma específica para esse tipo de ambiente, que envolve um protocolo específico para a comunicação entre os dispositivos (nós) da rede (MOTOROLA, 1997). Os recursos de computação e dados podem ser utilizados de forma compartilhada pelos controladores conectados na rede, permitindo a múltiplos usuários o compartilhamento de informação, documentos, 
programas e dispositivos. Esse compartilhamento permite não apenas reduções nos custos como também permite que o SAP possa realizar funções de controle mais complexas.

Uma rede de controle pode ser classificada segundo diversos critérios, como por exemplo:

- Tipo: operando como cliente/servidor, onde o controlador que compartilha seus recursos é um servidor, enquanto o controlador que usa esses recursos é um cliente; peer-to-peer, envolvendo controladores semelhante com a mesma hierarquia, compartilhando e utilizando os recursos com os demais dispositivos na rede; ou de forma centralizada, onde um controlador mestre controla o acesso à rede. Controladores podem acessar a rede quando forem escolhidos, conectados ou quando um intervalo de tempo determinado transcorre (FIELDBUS FOUNDATION, 2007);

- Tamanho/Escala: pode possuir a dimensão desde de uma rede de área local (LAN) até uma rede de área ampla (WAN), podendo abranger, por exemplo, um estado ou o próprio planeta (BUSHBY, 1998);

- Topologia: é a configuração física da rede, que determina como cada dispositivo em uma rede é conectada a um outro dispositivo. A conexão pode ser em barramento (bus), estrela, anel ou ainda uma combinação das anteriores. Certas topologias requerem regras de comunicações especiais que devem ser cumpridas (ECHELON CORPORATION, 1999) (ECHELON CORPORATION, 2001);

- Protocolo de Comunicações: especifica as regras para a troca de informação na rede; como empacotamento, formatos de dados e mensagens, além dos requisitos dos requisitos de velocidade (IDA; WEBER, 2003);

- Cabeamento: é a conexão física de comunicação entre os dispositivos de uma rede, podendo utilizar fibra óptica, cabo coaxial, par trançado, radiofrequência ou uma combinação destas opções (ECHELON CORPORATION, 1999).

Uma rede de controle é composta por diversos dispositivos, como estações de trabalho, controladores, dispositivos periféricos, e sensores e atuadores inteligentes. Dependendo das dimensões e complexidade da rede, podem ser necessários dispositivos típicos utilizados em redes, como Hubs, Roteadores, Switches, Repetidores, Bridges, Gateways, Servidores e Cartões de Interface de Rede. 


\subsection{Internetworking - Conexão entre Múltiplas Redes}

Em uma área com múltiplos edifícios ou em aplicações com conexões via rede pública de telefone, o sistema de automação predial deve necessariamente ser composto de múltiplas redes separadas, mas que viabilizam a interação eventual entre dispositivos das diversas redes (internetworking) (BUSHBY, 1998).

Nem todas as redes usarão a mesma tecnologia por razões de custo e desempenho. As principais questões associadas à interconexão de redes são:

- Como obter informações de dispositivos através de múltiplas redes?

- Como controlar e isolar o tráfico desnecessário de mensagens entre as redes?

- Como inter-facear sinais elétricos e tecnologias de redes de controle local diferentes?

Uma das vantagens principais de um protocolo de comunicações é a sofisticação e a flexibilidade de seu internetworking, o qual deve ser alcançado a um custo baixo para a maioria dos dispositivos conectados na rede.

Tipicamente, o internetworking é realizado independente do protocolo adotado usando dispositivos especiais chamados roteadores, os quais são capazes de acoplar duas ou mais redes diferentes. Embora os roteadores possam usar a mesma tecnologia de LAN em cada lado do roteador, o mais comum é o roteador ser usado para acoplar diferentes redes de controle, ou seja, um roteador de um determinado protocolo acopla duas ou mais redes de controle daquele protocolo (BUSHBY, 1998).

Já o gateway acopla uma rede de controle local de um determinado protocolo em uma rede de controle local de um protocolo distinto. Ele é mais complexo que um roteador, porque além de equalizar as diferenças entre tipos de redes de controle local, ele deve reconhecer diferentes protocolos de aplicação. 


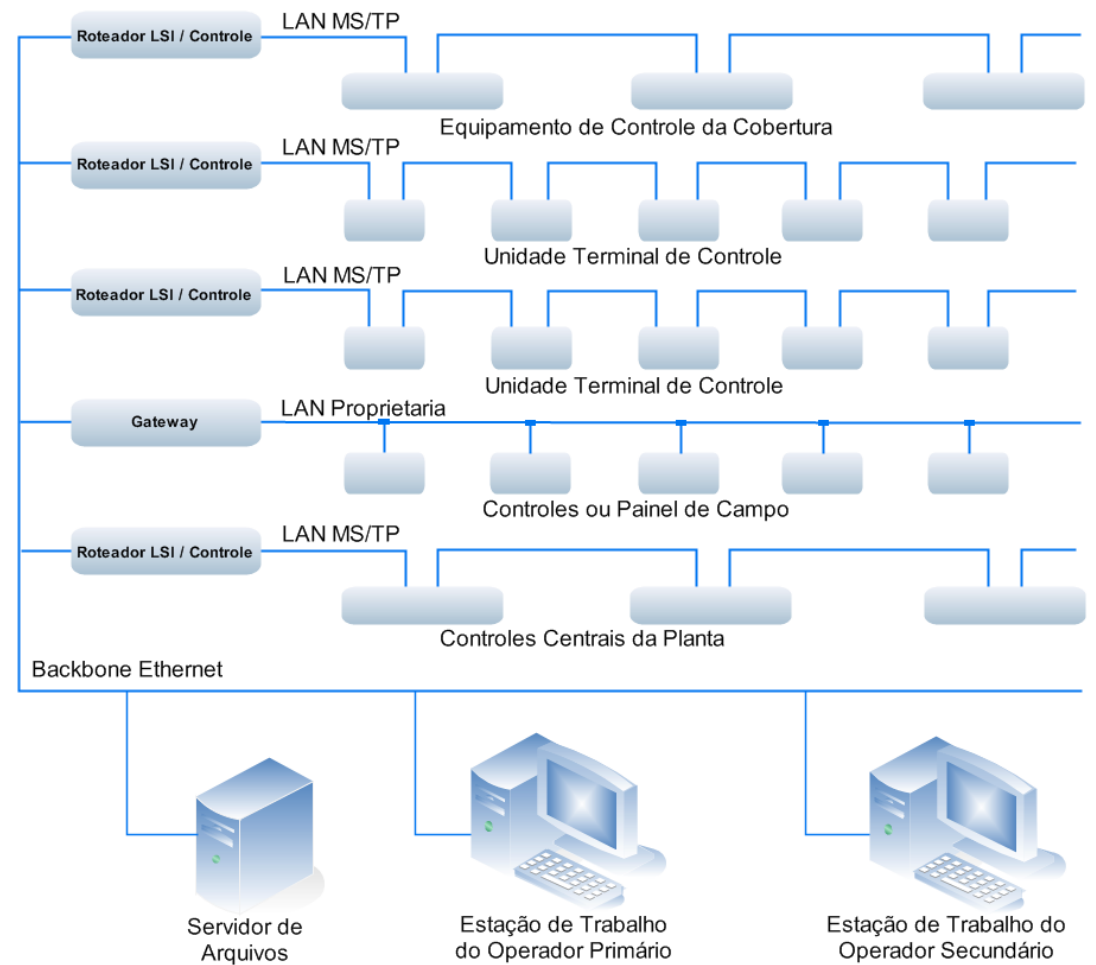

Figura 4: Desenho ilustrativo de um inter-networking (SWAN, 1997).

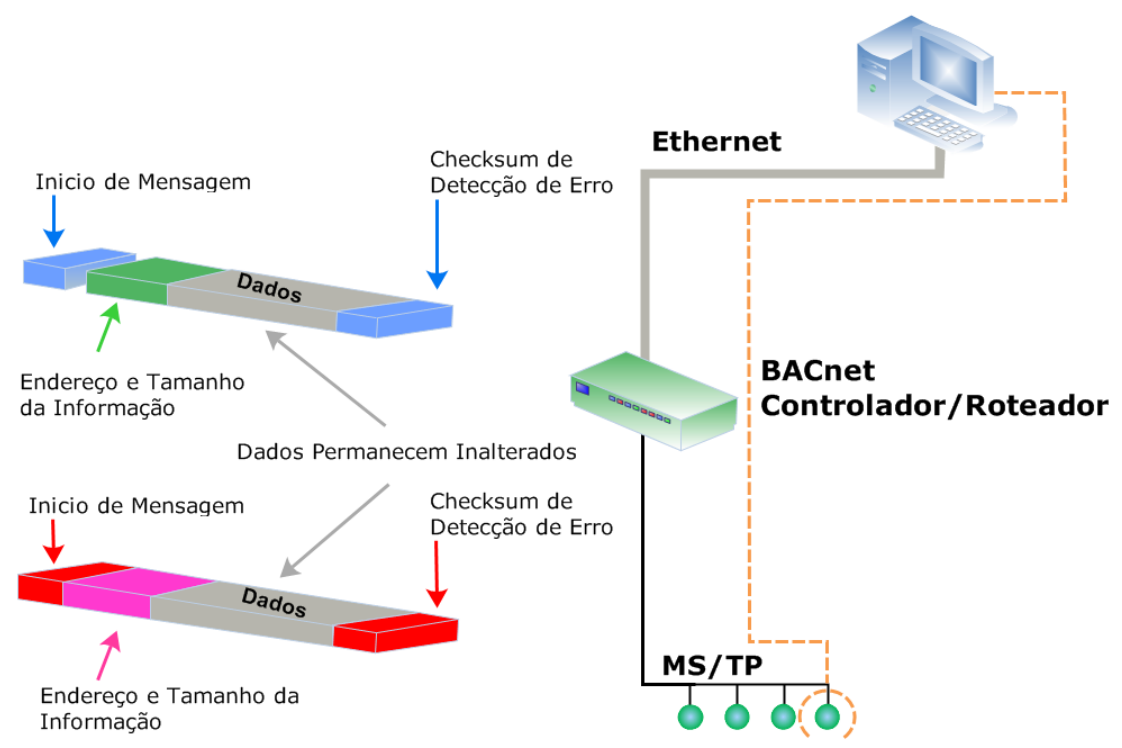

Figura 5: Roteador BACnet $\circledast$ conectando uma LAN Ethernet a uma LAN MS/TP (BUSHBY, 1998). 


\subsection{Modelo Básico de Referência - Interconexão de Sistemas Abertos (OSI)}

Quando os primeiros sistemas de automação predial foram apresentados no final dos anos de 1970, não havia nenhum padrão de referência ao desenvolvimento de protocolos de comunicação, dificultando futuras interconexões. Programas de gateways customizados tinham que ser desenvolvidos, cuidando das peculiaridades de cada protocolo (TANENBAUM, 1996).

O primeiro movimento no sentido da definição de padrões ocorreu em 1984, quando a Organização Internacional para Padronizações (ISO) publicou o modelo conceitual para Interconexão de Sistemas Abertos (OSI); conhecido como modelo OSI e publicado como Padrão ISO 7498. Este documento organiza todas as tarefas que um protocolo deve tratar em uma arquitetura de sete camadas ou passos envolvidos em comunicações de dados, incluindo (TANENBAUM, 1996):

- Conexão física (Physical Link): trata da conexão física entre um dispositivo de rede e a rede propriamente dita;

- Conexão de dados (Data Link): define como os dados são codificados e transmitidos para e de cada dispositivo da rede;

- Rede (Network): define o encaminhamento, chaveamento e os protocolos de acesso para sub-redes por toda a rede;

- Transporte (Transport): garante a transferência de dados entre os nós da rede e dispositivos;

- Seção (Session): Controla as comunicações durante o andamento das "conversações" entre os nós e os dispositivos;

- Apresentação (Presentation): traduz os dados de forma que eles possam ser entendidos por uma aplicação;

- Aplicação (Application): permite acesso à rede para serviços tais como transferência de arquivos, correio eletrônico e aplicações para controle.

O modelo OSI é apropriado para prover uma estrutura conceitual que os projetistas de protocolo podem usar para implementar tecnologias de comunicação. O conjunto resultante de protocolos é chamado uma "pilha de protocolo" porque os mesmos são hierarquicamente organizados, um em cima do outro. As camadas podem também ser úteis para ajudar a focalizar uma discussão de vários assuntos de comunicação 
(Figura 6) (TANENBAUM, 1996).

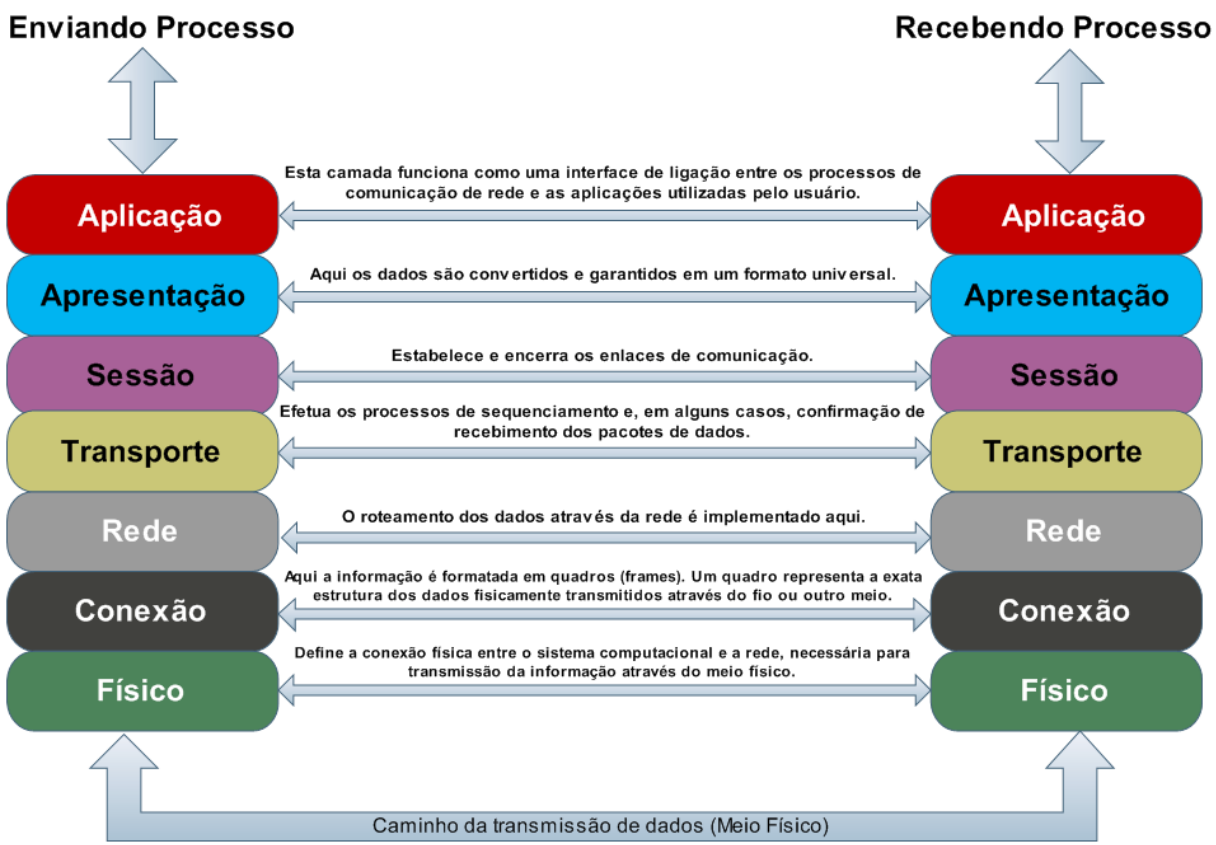

Figura 6: Modelo OSI de sete camadas (NEWMAN, 1999).

Os pontos mais importantes sobre o modelo OSI são (TANENBAUM, 1996):

- Cada camada fornece serviços de comunicações para a camada imediatamente superior. Preservando-se a interface entre as camadas, implementações específicas podem ser substituídas sem afetar a comunicação global;

- Cada camada comunica com a camada semelhante da máquina destino por um protocolo, adicionando informação de controle do protocolo;

- As funções de cada camada podem ser implementadas em separado, como protocolos distintos, embora não seja necessário. É possível implementar as funções de várias camadas em um único protocolo. Reciprocamente, vários protocolos podem implementar uma função definida para uma única camada, como por exemplo, segmentação de mensagem e a sua remontagem, mesmo sendo ineficiente;

- Nem todas as funções de todas as camadas são sempre necessárias. Muitos protocolos de sistemas de controle somente implementam os níveis Físico, Conexão de Dados e Aplicação. Alguns adicionam uma camada de protocolo de Rede se a comunicação entre áreas mais 
extensas ou comunicação entre tipos diferentes de LANs são requeridas.

\subsection{Iniciativa LonMark®}

A empresa Echelon $®$, que desenvolveu a tecnologia LonWorks $®$, investiu também na criação de uma associação sem fins lucrativos, para disseminar a sua tecnologia dando ênfase em uma de suas características, que é facultar interoperabilidade entre produtos que fossem criados com sua plataforma de desenvolvimento. Essa associação internacional foi denominada LonMark ${ }^{\circledR}$ (LONMARK® INTERNATIONAL, 2008), fundada em Maio de 1994 por 36 empresas e hoje conta com mais de 3.000 membros e grupos de estudos, entre eles a Motorola, Cipress e TAC, Hitachi e Distech.

A plataforma LonWorks ${ }^{\circledR}$ fornece mecanismos pelos quais objetos de instrumentação e automação emitem pedidos e recebem respostas em um ambiente distribuído de forma totalmente transparente. Essa características difundida pela LonMark® objetivou reduzir a complexidade, diminuir os custos e acelerar a introdução de novas aplicações distribuídas, sem que, para isso, fosse preciso realizar grandes mudanças nos sistemas já instalados. O modelo de referência LonMark® foi então especificado, caracterizando os componentes, as interfaces e protocolos, resultados da tecnologia LonWorks $®$.

Essa plataforma faculta o desenvolvimento de sistemas orientados a objetos inteligentes distribuídos ou "Perfil Funcional", que inicialmente teve grande aceitação em automação predial e residencial, e atualmente ganhando espaço em automação industrial, e em sistemas embarcadas em ferrovias e aeronaves, além de outras áreas de automação e controle. Todo esse sucesso é devido a característica de distribuir a inteligência da aplicação pela rede, onde cada um dos dispositivos conectados trocam informações diretamente de um nó para o outro nó (comunicação "ponto a ponto"), sem a necessidade de interação com algum computador central (MOTOROLA, 1997) (ECHELON CORPORATION, 2007).

A Echelon $®$ lançou entre 1987 e 1990 um microprocessador denominado NeuronChip $®$, dotado com software e hardware internos para executar, de forma concorrente, aplicações genéricas utilizando sensores e atuadores, somados à 
capacidade de comunicação em rede LonWorks ${ }^{\circledR}$ desses dispositivos (MOTOROLA, 1997).

Na mesma época foi criado coincidentemente o Grupo de Gerenciamento de Objetos (Object Management Group, OMG), iniciativa de fabricantes, usuários e integradores que se interessaram na possibilidade de definir a estrutura de mensagens e seu conteúdo, estabelecendo para essa plataforma a semântica e formas de mensagens para serem transportados em um protocolo comum (LONMARK INTERNATIONAL, 2008).

Em 1999 foi padronizado o protocolo LonTalk® que, além de eliminar o monopólio da Echelon $®$, também padronizaria as interfaces de hardware para diferentes mídias. Portanto, desde 1999, o protocolo LonTalk®, ficou definido na norma ANSI/EIA 709.1. As interfaces de hardware, dos transceptores, para diferentes mídias de rede foram definidas nas normas ANSI/EIA 709.2 e ANSI/EIA 709.3. (ECHELON CORPORATION, 2007).

O intuito da associação LonMark® foi padronizado, visando estimular a adoção da tecnologia com produtos classificados como objetos. Seus princípios incluem o estabelecimento de diretrizes industriais e especificações de gerenciamento de objetos, dentro de produtos, para prover uma base comum e adequada para o desenvolvimento das aplicações LonWorks $®$. A adequação à essas especificações torna possível desenvolver ambientes de aplicação heterogêneos através de diferentes plataformas de hardware e sistemas operacionais. A LonMark ${ }^{\circledR}$ incrementou a interoperabilidade da tecnologia LonWorks $₫$ que estabeleceu a norma ANSI/EIA 709.1 para rede LonWorks $®$ e fornece interoperabilidade entre aplicações em diferentes dispositivos atuadores e sensores em ambientes heterogêneos distribuídos. A norma apresenta como características (MOTOROLA, 1997):

- Mecanismos pelos quais os objetos fazem pedidos e recebem respostas de forma transparente;

- Interoperabilidade entre aplicações em diferentes dispositivos microcontroladores em ambientes distribuídos e heterogêneos. 


\subsubsection{Associação LonMark®}

A LonMark ${ }^{\circledR}$ define uma estrutura para que diferentes implementações com a tecnologia LonWorks ${ }^{\circledR}$ possam prover serviços e interfaces comuns para suportar clientes e implementações de objetos portáveis, como ilustrado na Figura 7 e na Figura 8. Dentre os aspectos relevantes para a caracterização da plataforma LonWorks ${ }^{\circledR}$, destacam-se:

- Semântica dos objetos;

- Modelo de objetos;

- Implementação de objetos;

- O compartilhamento dos Meios físicos, definindo:

- Especificações elétricas e mecânicas comuns;

- Mecanismos comuns de acesso aos meios.

- O compartilhamento de Informações, definindo:

- Um mecanismo comum de mensagem (protocolo);

- Um formato comum de dados (sintaxe);

- Um significado comum nos dados (semântica);

- Procedimentos comuns para instalação e gerenciamento.

\subsubsection{Semântica dos Objetos}

Todo objeto presente em um nó tem em seu perfil:

- O hardware de entrada, que liga o meio físico dos sinais de entrada desse objeto que vai ler e acondicionar;

- O hardware de saída, que liga o meio físico os sinais de saída desse objeto que vai controlar e atuar;

- Mensagens obrigatórias para controle do objeto ou objetos dentro de um nó;

- Mensagens opcionais que o objeto criado precisa para se relacionar com as aplicações dos objetos vizinhos da planta automatizada;

- Mensagens de configurações das propriedades de cada mensagem 
ou objeto presente no nó;

- Mensagens que podem ser definidas pelo usuário e que não necessariamente tenham obrigação de serem conhecidas para 0 perfeito funcionamento do objeto;

- Todo o sistema de automação com interoperabilidade LonMark® tem as premissas básicas de funcionamento, dentro de qualquer perfil funcional de controle conforme apresentados nas Figura 7 e Figura 8.

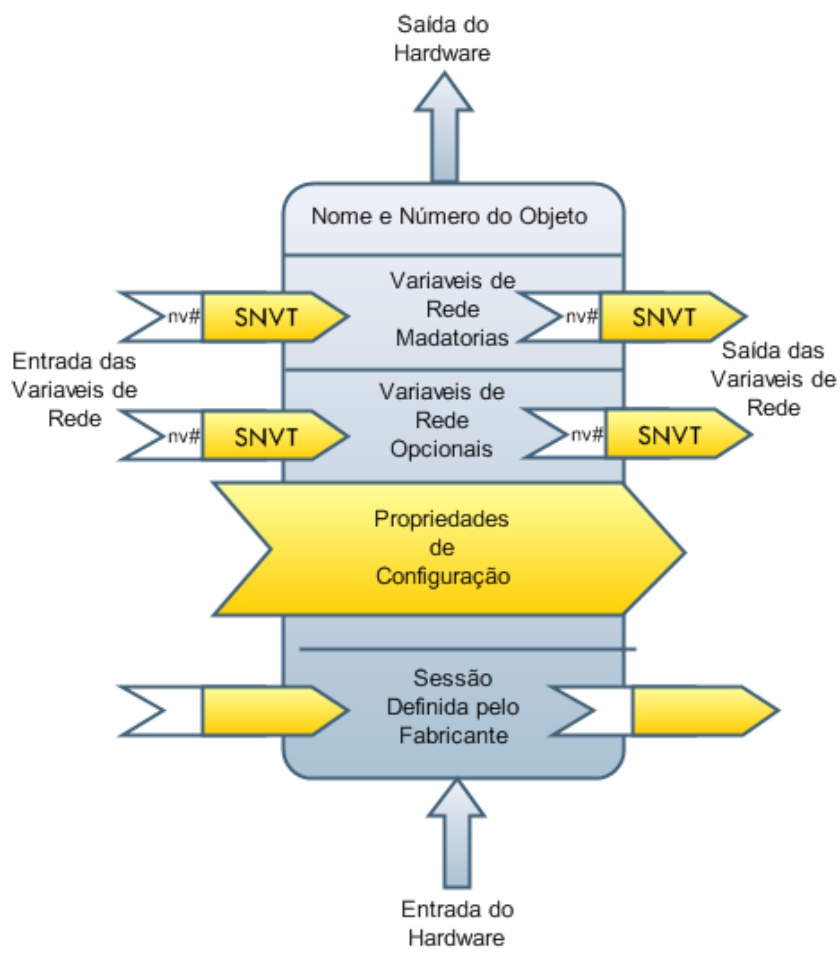

Figura 7: Interface de um nó LonWorks $®$ padrão LonMark® $($ ECHELON CORPORATION, 1999). 


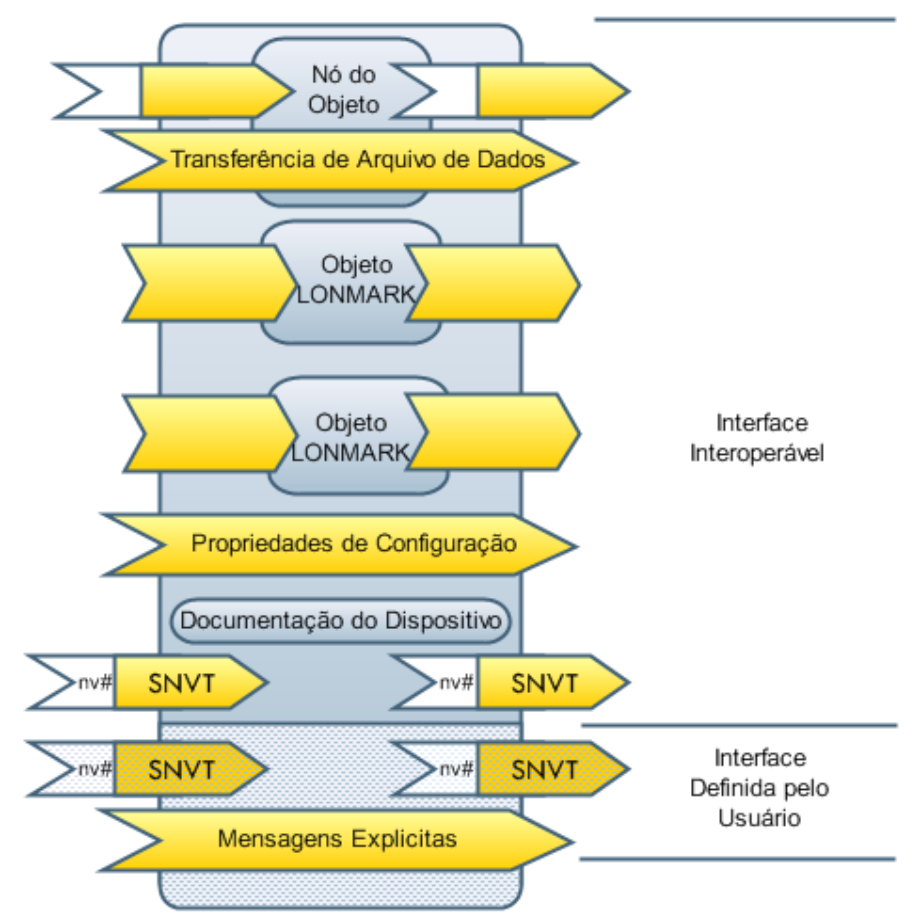

Figura 8: Desenho do Perfil Funcional de nó com parte de protocolo proprietário (ECHELON CORPORATION, 1999).

\subsubsection{Modelos de Objetos}

Pode-se considerar aqui as classes de objetos possíveis dentro dos cenários de automação previstos pela associação e que, de forma direta ou indireta, cobre toda as funcionalidades:

- Objetos sensores com loop aberto ou fechado de controle;

- Objetos atuadores com loop aberto ou fechado de controle;

- Objetos de controle.

\subsubsection{Compartilhamento dos meios físicos de comunicação}

Foram definidos na norma ANSI/EIA709.2 e ANSI/EIA709.3 o tipo de transceptor e as normas para seu uso, considerando como meio físico o par trançado 
FTT-10, que é o mais usual em automação predial. E também foi definido o transceptor para uso das linhas de alimentação do próprio dispositivo PLT-22 (Power Line Transceiver). Além desses, a associação definiu também outros meios físicos para os quais foram especificadas suas características principais, como infravermelho, fibra ótica e radiofrequência.

\subsubsection{Compartilhamento das informações comuns}

As Standard Network Variable Type (SNVTs) são relacionadas em uma tabela geral com todas as possíveis variáveis de rede que pode estar associado a um perfil funcional em qualquer nó de uma rede LonWorks ${ }^{\circledR}$ com certificado LonMark®, pois os fabricantes, usuários e integradores participam dessa associação e todas essas especificações foram feitas em conjunto com quem fabrica, usa e instala (Tabela 1). Além disso, é uma lista em que, desde o seu lançamento, são incrementadas novas SNVTs a cada ano, em função de novas áreas que estão adotando e incorporando a tecnologia em seus produtos (ECHELON CORPORATION, 1999).

Desta forma, qualquer fabricante mundial com seu produto certificado pela associação LonMark®, garante que ele é um dispositivo plug-and-play e associa-se a qualquer outro produto com certificação LonMark®.

Tabela 1: Alguns exemplos da tabela geral de SNVTs baseado em LONMARK® INTERNATIONAL (2008).

\begin{tabular}{|l|c|c|c|c|}
\hline Nome & Tipo & Unidades & Escala & Resolução \\
\hline SNVT_tempo & Temperatura & Graus Celsius & $-274 . .6271$ & $0.1 \mathrm{C}$ \\
\hline SNVT_angulo & Fases/Rotação & Radianos & $0-65$ & $0.001 \mathrm{rads}$ \\
\hline SNVT_velocidade & Velocidade & Metros/seg & $0-6553$ & $0.1 \mathrm{~m} / \mathrm{s}$ \\
\hline SNVT_tmp_uso & Tempo Uso & HH:MM:SS & $0-65535$ dias & $1 \mathrm{mse}$ \\
\hline SNVT_lev_cont & Nivel Continuidade & Porcentagem & $0-100 \%$ & $0.5 \%$ \\
\hline SNVT_ascii & ASCII String & Caracteres & 30 Caracteres & nda \\
\hline SNVT_contador & Eventos & Contador & 065535 & 1 Contagem \\
\hline
\end{tabular}

As informações que são enviadas, através de uma rede LonWorks $®$, com produtos certificados LonMark®, serão sempre do tipo SNVTs identificadas na tabela geral 
da associação. Desta forma, toda solução proprietária, que é o aplicativo do produto, será encapsulada como firmware, e apenas as informações de entradas e/ou saídas de rede dessas implementações é que serão acessíveis por meio da interface do seu perfil funcional à qualquer integrador de soluções no mercado.

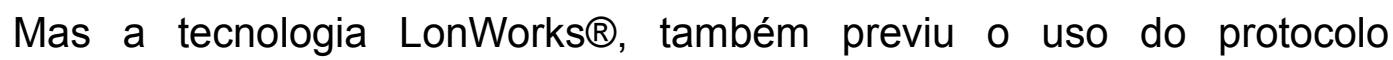
LonTalk® para comunicação em formato proprietário. No caso de mensagens explícitas, o fabricante terá que definir todas as estruturas da mensagens e todo o encaminhamento dessas mensagens deverá estar desenvolvido na aplicação do produto. No caso das mensagens implícitas, mesmo não sendo SNVTs, os mecanismos internos da tecnologia LonWorks $®$ farão todo o tratamento de encaminhamento das mensagens, de forma implícita depois de conectada. Assim, a tecnologia contempla qualquer tipo de tratamento de protocolo de comunicação e portanto, ambos os casos se enquadram fora do padrão LonMark®.

Todos os equipamentos certificados LonMark® têm um "Perfil Funcional" estabelecido de acordo com a tarefa que realiza em sua individualidade. Assim, todo produto de fabricação em série ou até mesmo módulos LonWorks ${ }^{\circledR}$ programáveis, determinados para as mesmas atividade dentro de um sistema na rede, poderão ser carregados com um mesmo perfil funcional, o que otimiza em muito o comissionamento e manutenção de qualquer que seja a planta ou tamanho do parque instalado (Figura 9 e Figura 10). Da mesma forma, facilita em muito a manutenção e substituição de módulos LonWorks $®$ para qualquer que seja a atividade necessária, bastando para isso, ter as mesma especificação física. Outra vantagem para a engenharia de sistemas é a facilidade de criar especificações mais abertas. Para o integrador também fica mais fácil solucionar e integrar grandes sistemas com os mesmos tipos de ferramentas que aprendeu em uma única vez, e que utiliza para todas as suas instalações, independente de fornecedor e fabricante. 


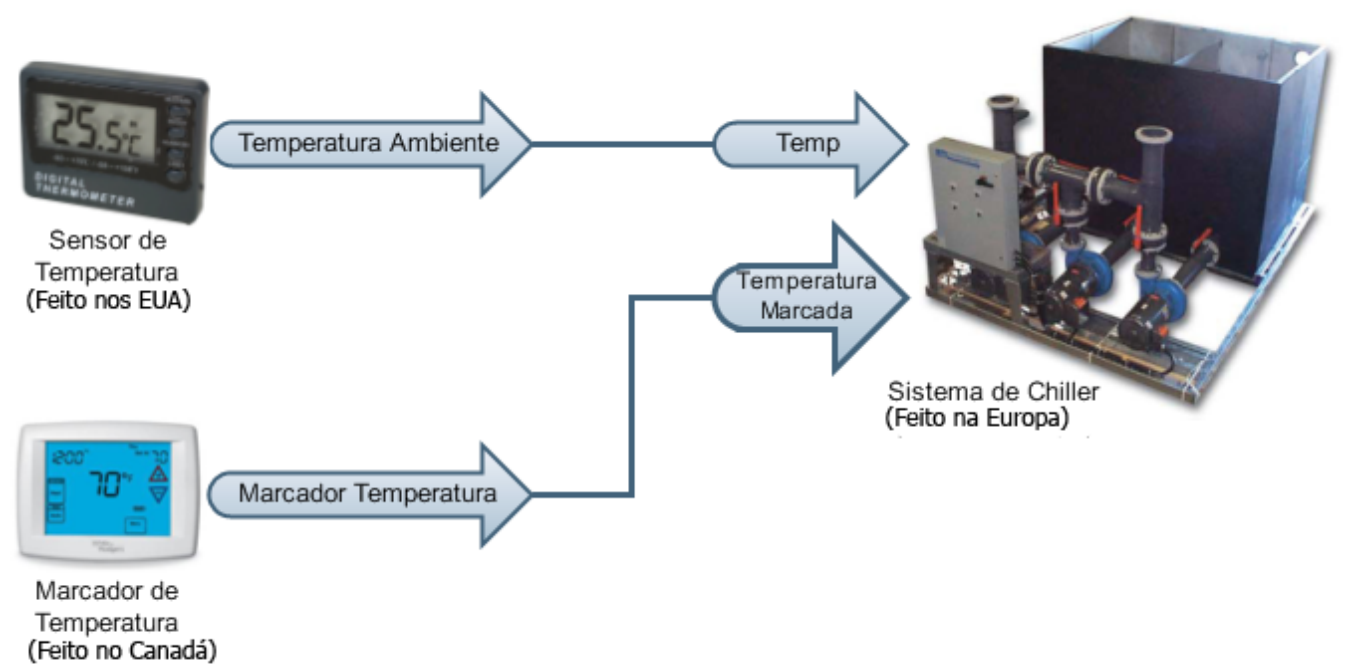

Figura 9: Nós com Interoperabilidade (ECHELON CORPORATION, 1999).

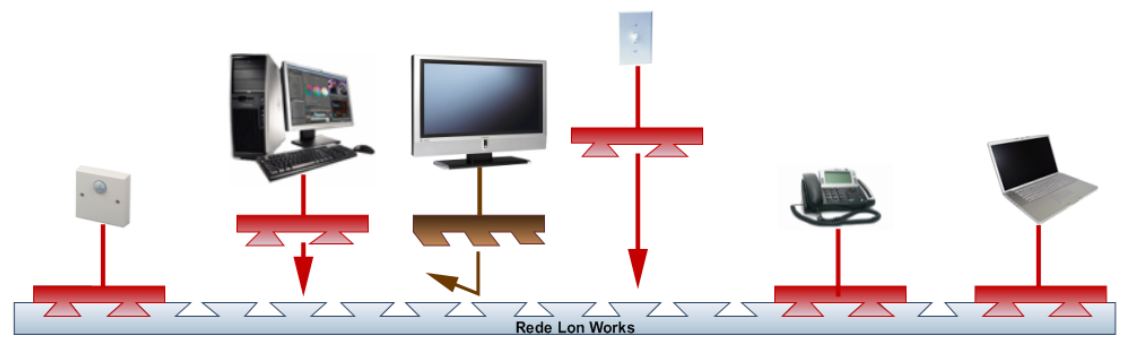

Figura 10: Plug-and-Play da tecnologia LonWorks $\AA(E C H E L O N$ CORPORATION, 1999).

Os componentes principais para garantir uma interoperabilidade entre qualquer componente de uma planta automatizada com LonWorks ${ }^{\circledR}$ são:

- Coexistência;

- Compatibilidade;

- Intercambiabilidade;

- Customização;

- Ligar e Funcionar.

A associação LonMark ${ }^{\circledR}$ contribui com seu papel de manter essa tecnologia diferenciada no mercado, pois não é um microcontrolador ou apenas um protocolo, mas sim um mecanismo de comunicação completo, fim-a-fim, que pode ser implementado em qualquer microcontrolador, como exemplo MC68360 ou L-Core $®$ da 
LoyTec (LOYTEC, 2009), que estará garantido a interoperabilidade pela associação, desde que implementado com a norma ANSI/EIA 709.1. Assim essa associação mantém as diretrizes apresentadas na Figura 11.

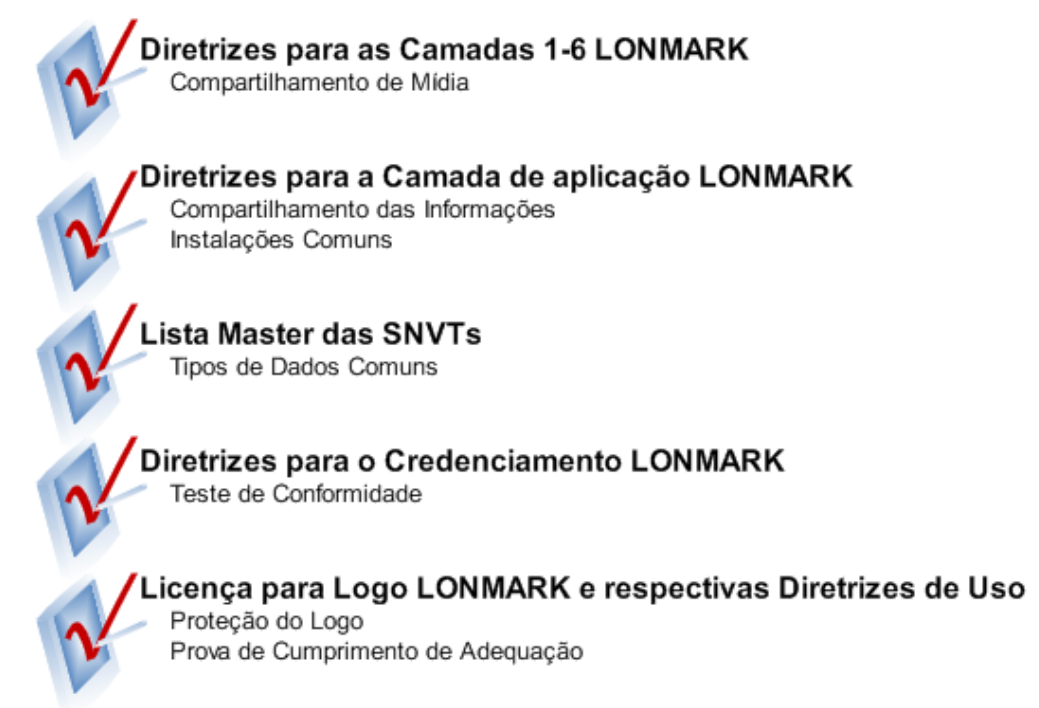

Figura 11: Diretrizes LonMark® (ECHELON CORPORATION, 1999).

Como o protocolo LonTalk $®$ e o NeuronChip $\AA$ sozinhos não definem interoperabilidade, foram necessários outros degraus que estão apresentados na Figura 12 para atingir a condição de interoperabilidade entre produtos utilizando essa mesma tecnologia.

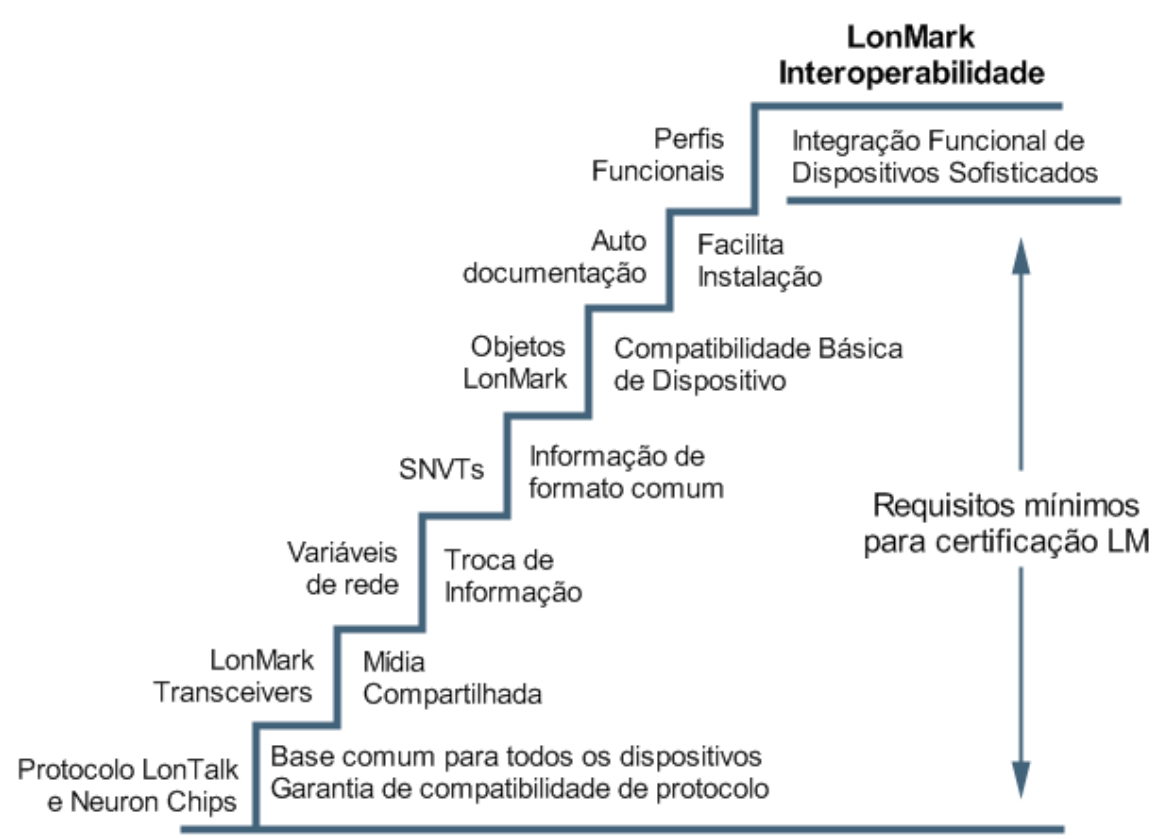

Figura 12: Proposta LonMark® para interoperabilidade (ECHELON CORPORATION, 1999). 
Depois da publicação da norma, tudo isso é possível de se realizar em instalações com nós com a tecnologia LonWorks $®$, que está aberta para novas implementações em outros componentes de hardware, por isso, o equipamento é definido como tecnologia aberta quando utiliza o protocolo LonTalk®.

\subsection{Iniciativa BACnet $\circledast$}

Os muitos problemas causados por protocolos de comunicação proprietário motivaram a Sociedade Americana de Engenheiros de Aquecimento, Refrigeração e $\operatorname{Ar}$ Condicionado (ASHRAE), em janeiro de 1987, a iniciar o desenvolvimento de um padrão industrial de protocolo de comunicação para sistemas de controle e automação predial. O Comitê para Projeto de Padrão 135P (SPC 135P) foi formado para realizar esta tarefa. (BUTLER, 1997) (COVIELLO NETO, 2001)

Os membros do SPC 135P foram selecionados para prover uma ampla e equilibrada representação da indústria de controles para edifícios. Os componentes do comitê vieram dos fabricantes, empresas de engenharia consultiva, universidades, e agências governamentais do Canadá e da ECHELON CORPORATION. A primeira reunião do SPC 135P aconteceu em junho de 1987. (BUTLER, 1997)

Em agosto de 1991 o primeiro documento para revisão pública do padrão BACnet $®$ proposto foi publicado para comentário. Aquela revisão gerou 507 comentários de 6 países diferentes. O número extraordinariamente alto de comentários e a resposta internacional foram um reflexo do alto nível de interesse no desenvolvimento deste padrão por toda a indústria de automação predial (BUTLER, 1997).

Após passar por três revisões, a versão final do documento foi aprovada para publicação como um padrão ASHRAE em junho de 1995, oito anos e meio após o processo formal de padronização ter iniciado. BACnet $\circledast$ foi aprovado pelo Instituto Nacional de Padrões Americanos (ANSI) como um padrão nacional em dezembro de 1995.

Enquanto o BACnet ${ }^{\circledR}$ estava sendo desenvolvido, a ASHRAE estabeleceu uma ligação com europeus trabalhando em uma tarefa semelhante, sob o patrocínio do Comitê Europeu de Normatização (CEN) Comitê Técnico 247. Este comitê completou seu trabalho e atualmente o BACnet® é um padrão CEN 247 (BUTLER, 1997). Em 2003 o 
BACnet $₫$ foi homologado como padrão ISO.

\subsubsection{Padrão BACnet® para a camada 7 dos Protocolos de Comunicação.}

O BACnet $\AA$ provê um método pelo qual os equipamentos de controle baseados em computadores de fabricantes diferentes possam trabalhar juntos, ou "interoperar", permitindo expandir, misturar e combinar equipamentos para melhor atender às necessidades de qualquer tipo de edifício no presente e no futuro.

Ele é concebido para trabalhar com alguns tipos de controles prediais, tais como: ar condicionado, iluminação, segurança, alarme e deteç̧ão de incêndio, controle de acesso, manutenção e gerenciamento de insumos entre outros (BUTLER, 1997) (HAAKENSTAD, 1997) (NEWMAN, 1999).

Além disso, ele provê um modelo sofisticado para descrever sistemas de automatização predial de todos os tipos. Este modelo está baseado na idéia de que para que os sistemas sejam verdadeiramente interoperáveis, deve haver um acordo sobre vários aspectos da operação global e individual dos sistemas. Para os equipamentos trabalharem juntos, eles devem ser capazes de trocar e entender as mensagens do BACnetß. O conteúdo das mensagens, a linguagem BACnet $₫$, é o foco da porção principal do padrão BACnet $\circledast$.

O BACnet ${ }^{\circledR}$ parte da convenção tradicional da indústria com sua nomenclatura orientada ao objeto, sendo que a última tem, por muito tempo, usado o termo "pontos" com propósito geral, o qual estaria se referindo às entradas de sensores, saídas de controle, com diferentes características dependendo do fabricante.

Também é definido um conjunto padrão de "objetos", totalizando 18 tipos diferentes, cada qual contendo um conjunto de "propriedades", que descreve o objeto e o seu estado atual para outros dispositivos na rede. Através destas propriedades, o objeto pode ser controlado por outros dispositivos BACnet ${ }^{\circledR}$.

O objetivo final dos projetistas do BACnet $₫$ é que a lista esteja completa, onde cada elemento de um sistema de controle predial seja representado por um ou mais objetos. Os objetos presentes em um dispositivo BACnet $₫$ são consequência de suas capacidades e de suas funções.

O padrão BACnet $\AA$ não obriga que os dispositivos possuam todos os 
objetos, como por exemplo, um dispositivo que controla uma caixa de VAV (Variation Air Volume) comumente terá vários objetos entradas e saídas analógicas, enquanto uma estação de trabalho Windows ${ }^{\circledR}$ não terá nem entradas de sensor e nem saídas de controle.

No caso em que se haja a necessidade de utilizar objetos não padrões, é permitido o uso de objetos proprietários nos dispositivos, desde que não interfiram com os objetos padrões. Essa liberalidade tem como objetivo não limitar a capacidade criativa de cada fabricante e permitir que vantagens competitivas possam ser oferecidas.

Existe um total de 123 propriedades diferentes que servem para caracterizar os objetos. Caso haja a necessidade de detalhar ainda mais esses objetos, essas propriedades podem ser divididas em subconjuntos. Existem propriedades que são obrigatórias e outras que são opcionais, além disso, algumas delas são passíveis de escrita enquanto outras apenas de leitura (BUTLER, 1997) (SWAN, 1997).

O chamado "objeto do dispositivo" é obrigatório em todo dispositivo BACnet $\circledast$. Esse objeto, além de identificar completamente o dispositivo na rede, disponibiliza suas informações e capacidades para outros dispositivos.

Como forma de identificar um dispositivo na rede, o "objeto do dispositivo" possui um número único na mesma, diferentemente do que ocorre com os outros objetos do mesmo dispositivo. A Tabela 2, abaixo, apresenta as propriedades do objeto do dispositivo.

Como forma de trocar informações entre dispositivos BACnet $\AA$, são oferecidos serviços de troca de mensagens. Esses serviços são dividido em dois tipos principais, sendo o primeiro deles os serviços do tipo "confirmados" e o segundo do tipo "não confirmados". No primeiro caso, o dispositivo que envia a mensagem espera chegar uma confirmação de recebimento dos dispositivos de destino, já no segundo caso, a mensagem é enviada e não é esperada nenhuma confirmação de recebimento.

Foram previstos um total de 32 serviços diferentes, divididos em 5 categorias: alarme e evento, acesso a arquivo, acesso a objeto, gerenciamento de dispositivo remoto, e terminal virtual. 
Tabela 2: Propriedades do objeto do dispositivo BACnet $\circledast$, adaptado de SWAN (1997).

\begin{tabular}{|c|c|}
\hline PROPRIEDADES & EXEMPLOS \\
\hline Object_Identifier & Dispositivo \#1076 (requerido) \\
\hline Object_Name & Escritório 36 (requerido) \\
\hline Object_Type & Dispositivo (requerido) \\
\hline System_Status & Operacional (requerido) \\
\hline Vendor_Name & Fabricante A (requerido) \\
\hline Vendor_Identifier & A (requerido) \\
\hline Model_Name & Controlador VAV (requerido) \\
\hline Firmware_Revision & 1.0 (requerido) \\
\hline Application_Software_Version & Duto Duplo (requerido) \\
\hline Location & Escritório 36 , andar 3 \\
\hline Description & Na rede numero 5 \\
\hline Protocol_Version & 1 (versão do Protocolo BACnet) (requerido) \\
\hline Protocol_Conformance_Class & 2(requerido) \\
\hline Protocol_Services_Supported & ReadProperty, writeProperty, ......(requerido) \\
\hline Protocol_Object_Types_Supported & AnalogInput, AnalogOutput, ...(requerido) \\
\hline Object_List & AnalogInput\#1,AnalogOutput\#3,.(requerido) \\
\hline Max_APDU_Length_Supported & 50 (bytes ou caracteres) (requerido) \\
\hline Segmentation_Supported & não(requerido) \\
\hline VT_Class_Supported & $\mathrm{n} / \mathrm{a}$ \\
\hline Active_VT_Sessions & $\mathrm{n} / \mathrm{a}$ \\
\hline Local_Time & $12: 30: 15.22$ \\
\hline Local_Date & Terça-feira, Março, 1996 \\
\hline UTC_Offset & +480 (minutos do GMT/UTM) \\
\hline Daylight_Saving_Status & Falso \\
\hline APDU_Segment_Timeout & $\mathrm{n} / \mathrm{a}$ \\
\hline APDU_Timeout & 3000 milisegundos (requerido) \\
\hline Number_Of_APDU_Retries & 0 (requerido) \\
\hline List_Of_Sessions_Keys & $\mathrm{n} / \mathrm{a}$ \\
\hline Time_Sincronization_Recipients & $\mathrm{n} / \mathrm{a}$ \\
\hline Max_Master & $\mathrm{n} / \mathrm{a}$ \\
\hline Max_Info_Frames & $\mathrm{n} / \mathrm{a}$ \\
\hline Device_Address_Binding & Nenhum (requerido) \\
\hline
\end{tabular}

Os serviços "alarme e evento" servem para detectar mudanças ocorridas nos objetos de um dispositivo BACnet ${ }$, como por exemplo, uma leitura fora da faixa considerada normal de um sensor de temperatura. A Tabela 3, abaixo, mostra um resumo dessa categoria de serviço. 
Tabela 3: Serviços de alarme e evento, adaptado de SWAN (1997).

\begin{tabular}{|l|l|}
\hline SERVIÇO & DESCRIÇÃO \\
\hline AcknowledgeAlarm & Usado para confirmar que o alarme foi visto \\
\hline ConfirmedCOVNotification & $\begin{array}{l}\text { Informa aos dispositivos que ocorreu COV em } \\
\text { uma propriedade }\end{array}$ \\
\hline ConfirmedEventCOVNotification & $\begin{array}{l}\text { Usado para informar sobre uma possivel } \\
\text { condição de erro }\end{array}$ \\
\hline GetAlarmSummary & $\begin{array}{l}\text { Pedido de uma lista de "alarmes ativos" feito } \\
\text { por dispositivo }\end{array}$ \\
\hline GenEnrollmentSummary & $\begin{array}{l}\text { Pedido de uma lista de objetos gerando } \\
\text { "eventos" }\end{array}$ \\
\hline SubscribeCOV & $\begin{array}{l}\text { Enviado por um dispositivo para pedir que seja } \\
\text { informado sobre COVs em um objeto }\end{array}$ \\
\hline UnonfirmedEventCOVNotification & $\begin{array}{l}\text { Informa aos dispositivos que uma mudança } \\
\text { ocorreu para uma ou mais propriedades de um } \\
\text { objeto }\end{array}$ \\
\hline
\end{tabular}

Os serviços de acesso a arquivos são usados para ler e manipular arquivos nos dispositivos. Os arquivos, neste caso, representam grupos de dados de bytes de significado e comprimento arbitrários e o termo "atômico" no nome do serviço significa que somente uma operação de leitura ou escrita pode ser realizada por vez. A Tabela 4, abaixo, apresenta a relação dos serviços de acesso a arquivo.

Tabela 4: Serviços de acesso a arquivos, adaptado de SWAN (1997).

\begin{tabular}{|l|l|}
\hline SERVIÇO & DESCRIÇÃO \\
\hline AtomicReadFile & $\begin{array}{l}\text { Pede partes ou o todo de um arquivo do } \\
\text { "Objeto Arquivo" }\end{array}$ \\
\hline AtomicWriteFile & $\begin{array}{l}\text { Escreve partes ou o todo de um arquivo do } \\
\text { "Objeto Arquivo" }\end{array}$ \\
\hline
\end{tabular}

Os serviços de acesso a objeto são utilizados para configuração do objeto. Especificando as ações de: ler; modificar e escrever propriedades; adicionar e excluir objetos. A Tabela 5 apresenta os serviços desta categoria com uma breve descrição. 
Tabela 5: Serviços de acesso a objetos, adaptado de SWAN (1997).

\begin{tabular}{|l|l|}
\hline SERVIÇO & DESCRIÇÃO \\
\hline AddListElement & $\begin{array}{l}\text { Adiciona um ou mais itens para uma } \\
\text { propriedade que é uma lista }\end{array}$ \\
\hline RemoveListElement & $\begin{array}{l}\text { Remove um ou mais itens para uma } \\
\text { propriedade que é uma lista }\end{array}$ \\
\hline CreateObject & $\begin{array}{l}\text { Usado para criar um novo exemplo de um } \\
\text { objeto em um dispositivo de serviço }\end{array}$ \\
\hline DeleteObject & $\begin{array}{l}\text { Usado para apagar um particular objeto em um } \\
\text { dispositivo de serviço }\end{array}$ \\
\hline ReadProperty & $\begin{array}{l}\text { Devolve um valor de uma propriedade de um } \\
\text { objeto }\end{array}$ \\
\hline ReadPropertyConditional & $\begin{array}{l}\text { Devolve os valores de múltiplas propriedades } \\
\text { em múltiplos objetos }\end{array}$ \\
\hline ReadPropertyMultiple & $\begin{array}{l}\text { Devolve os valores de múltiplas propriedades } \\
\text { de múltiplos objetos }\end{array}$ \\
\hline WriteProperty & $\begin{array}{l}\text { Escreve um valor para uma propriedade de um } \\
\text { objeto }\end{array}$ \\
\hline Escreve valores para múltiplas propriedades de \\
múltiplos objetos
\end{tabular}

Os serviços de gerenciamento de dispositivo remoto, proveem várias funções: .

- A função controle de operador é usada para realizar diagnósticos nos dispositivos BACnet $\AA$;

- A função transferência de mensagem especializada (proprietária), permite a troca de mensagens fora do padrão, como por exemplo mensagens de texto para impressoras e comandos de sincronismo de tempo;

- As funções de endereçamento são usadas para obter endereços de dispositivos em uma rede. Elas também permitem que outros dispositivos, que necessitem saber a mesma informação sobre o dispositivo que respondeu, adquiram a informação de endereço sem criar mais tráfico de rede;

- As funções de autoconfiguração são usadas para facilitar a configuração dos dispositivos ao utilizar a troca de objetos pela rede. A Tabela 6 apresenta os serviços elencados acima e uma breve descrição dos mesmos. 
Tabela 6: Serviços de gerenciamento remoto de dispositivo, adaptado de SWAN (1997).

\begin{tabular}{|c|c|}
\hline SERVIÇO & DESCRIÇÃO \\
\hline DeviceCommunicationControl & $\begin{array}{l}\text { Pede a um dispositivo para parar (e iniciar) de } \\
\text { aceitar mensagens da rede }\end{array}$ \\
\hline ConfirmedPrivateTransfer & $\begin{array}{l}\text { Envia uma mensagem proprietária de um } \\
\text { fabricante para um dispositivo }\end{array}$ \\
\hline UnconfirmedPrivateTransfer & $\begin{array}{l}\text { Envia uma mensagem proprietária de um } \\
\text { fabricante para um ou mais dispositivos }\end{array}$ \\
\hline ReinitializeDevice & Ordena a um dispositivo para reiniciar \\
\hline ConfirmedTextMessage & $\begin{array}{l}\text { Encaminha uma mensagem de texto para } \\
\text { outro dispositivo }\end{array}$ \\
\hline UnconfirmedTextMessage & $\begin{array}{l}\text { Envia uma mensagem de texto para um ou } \\
\text { mais dispositivos }\end{array}$ \\
\hline TimeSincronization & $\begin{array}{l}\text { Envia o horário atual para um ou mais } \\
\text { dispositivos }\end{array}$ \\
\hline Who-Has & $\begin{array}{l}\text { Pergunta qual dispositivo BACnet possui um } \\
\text { particular Objeto }\end{array}$ \\
\hline I-Have & Resposta afirmativa para Who-Has \\
\hline Who-ls & $\begin{array}{l}\text { Pergunta com relação à presença de } \\
\text { especificados dispositivos BACnet }\end{array}$ \\
\hline I-Am & Resposta afirmativa para Who-ls \\
\hline
\end{tabular}

Os serviços "terminal virtual" (VT) permitem o acesso externo a um dispositivo. Uma conexão bidirecional é estabelecida, baseada em texto, com um programa de aplicação que está sendo executado em um dispositivo remoto. Ver a Tabela 7 para maiores detalhes.

Tabela 7: Serviços de terminal visual, adaptado de SWAN (1997).

\begin{tabular}{|l|l|}
\hline SERVIÇO & DESCRIÇÃO \\
\hline VT-Open & $\begin{array}{l}\text { Estabelece uma sessão terminal com um } \\
\text { dispositivo BACnet remoto }\end{array}$ \\
\hline VT-Close & $\begin{array}{l}\text { Fecha uma sessão estabelecida terminal } \\
\text { virtual }\end{array}$ \\
\hline VT-Data & $\begin{array}{l}\text { Envia texto de um dispositivo para o outro } \\
\text { participante na sessão }\end{array}$ \\
\hline
\end{tabular}

Como os dispositivos BACnet巴 desempenham funções com níveis de complexidades diferentes em um sistema, muitas vezes, a escolha dos objetos e suas propriedades para um dispositivo não é um assunto trivial. Atentos a esse problema, os projetistas do padrão BACnet ${ }^{\circledR}$ criaram as chamadas "classes de conformidade", com a finalidade de melhor caracterizar as funções de um determinado dispositivo. 
São seis os níveis de conformidade, sendo que o nível mais baixo, a classe de conformidade 1 , apenas requer que o dispositivo BACnet $\circledast$ possua um objeto de dispositivo. Os níveis acima, sucessivamente, somam pedidos de serviço que devem ser executáveis pelo dispositivo, como também os pedidos de serviço que ele deve poder iniciar, portanto, as classes de conformidade estabelecem uma medida da habilidade do dispositivo para se comunicar com outros dispositivos.

As funções de automatização de um edifício são diferentes e complexas. Para solucionar este problema foram criados os "grupos de funções". que especificam uma combinação de objetos e serviços.

Os detalhes de cada dispositivo são acessíveis através da declaração de conformidade de implementação do protocolo (DCIP) criado pelo fabricante. A declaração identifica o fabricante, brevemente descreve o dispositivo e detalha sua implementação. Os grupos de função especificados pelo BACnet® são listados na Tabela 8.

Tabela 8: Grupos de função, adaptado de SWAN (1997).

\begin{tabular}{|l|l|}
\hline GRUPO FUNCIONAL & DESCRIÇÃO \\
\hline Clock & Capacidades associadas com um relógio \\
\hline Hand-held Workstation & Capacidades de estação de trabalho portátil \\
\hline Person Computer Workstation & Capacidades de estação de trabalho principal \\
\hline Event Iniciation & Deteta e gera alarmes e eventos \\
\hline Event Response & Habilidade para responder a alarmes e eventos \\
\hline COV Event Iniciation & Habilidade para notificações COV \\
\hline COV Event Response & Inscrição para e recebe notificações CoV \\
\hline Files & $\begin{array}{l}\text { Capacidade para ler, escrever, des/carregar } \\
\text { dados }\end{array}$ \\
\hline Reinitialize & $\begin{array}{l}\text { Habilidade para ser reinicializado de um } \\
\text { dispositivo remoto }\end{array}$ \\
\hline Virtual Operator & $\begin{array}{l}\text { Capaz de prover ambiente de operador da } \\
\text { sessão de terminal virtual }\end{array}$ \\
\hline Virtual Terminal & $\begin{array}{l}\text { Capaz de prover ambiente de servidor da } \\
\text { sessão de terminal virtual }\end{array}$ \\
\hline Device Communications & $\begin{array}{l}\text { Execução do pedido } \\
\text { DeviceCommunicationControlService suportada }\end{array}$ \\
\hline Time Master & $\begin{array}{l}\text { Hábil para iniciar o pedido de serviço } \\
\text { TimeSynchronization }\end{array}$ \\
\hline
\end{tabular}




\subsection{As Quatro Camadas do Padrão BACnet ${ }^{\circledR}$}

O Padrão BACnet ${ }^{\circledR}$ provê um modo para conduzir dados incluindo, mas não limitados para: valores de hardware nas entrada e saída binária, valores de hardware nas entrada e saída analógica, valores de software binário e analógico, informação de programação horária, informação de alarme e evento, arquivo e lógica de controle.

O BACnet $\circledast$ não define a configuração interna, estruturas de dados, ou lógica de controle dos controladores. A informação que precisa ser visível na rede de comunicação é resumida dos detalhes de implementação pelo uso de objetos padrão. $O$ mapeamento entre os objetos padrão, os dados subjacentes e os processos são destinados aos fabricantes.

BACnet ${ }^{\circledR}$ tem uma arquitetura de protocolo em camadas baseada em uma versão reduzida do Modelo Básico de Referência - Interconexão de Sistemas Abertos (OSI). As camadas 1,2,3 e 7 do modelo OSI são usadas conforme a Figura 13.

Os protocolos da camada de aplicação e da camada de rede (network) são usados com quaisquer das quatro opções de tecnologias para LAN ou um protocolo ponto a ponto (PTP) apropriado para comunicação telefônica tipo discada. A camada de rede (network) foi utilizada para auxiliar na conexão entre LANs diferentes, esse conceito é chamado internetwork. Cada camada do protocolo será descrita nas seções seguintes.

Camadas BACnet

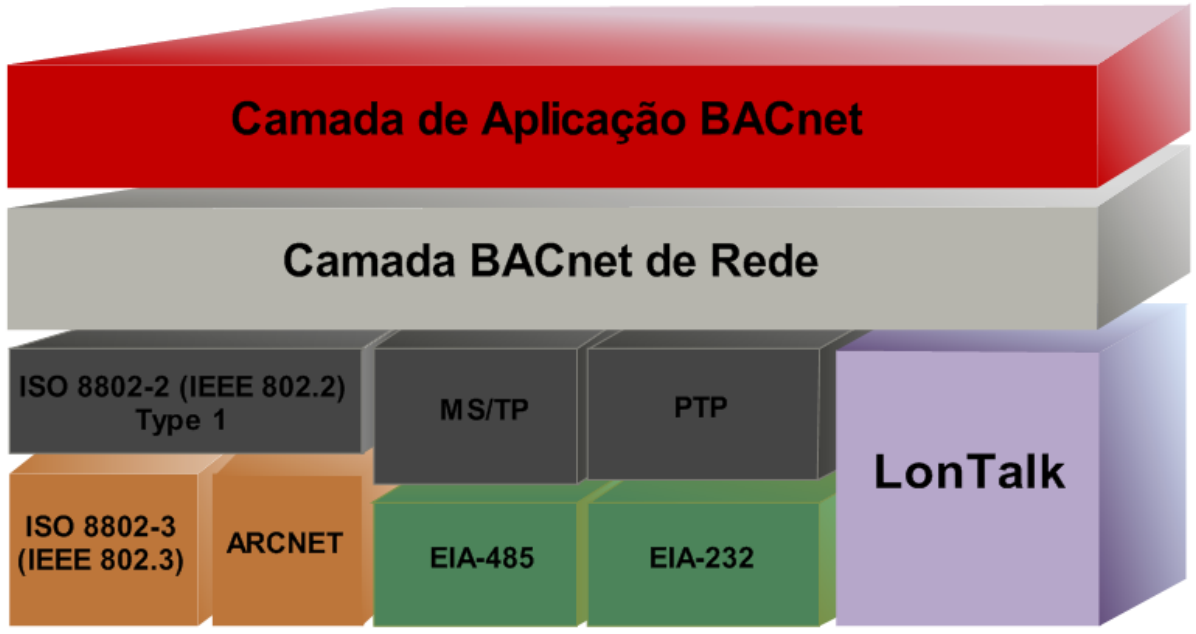

Camadas OSI Equivalentes

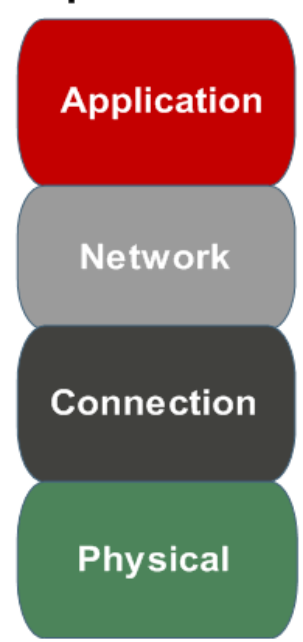

(1998). 


\subsubsection{Camada Aplicação}

O caminho mais fácil para entender a camada aplicação do BACnet® é entendê-la como duas partes separadas, porém relacionadas: um modelo de informação contida dentro um dispositivo de automação predial e um grupo de funções ou serviços usados para trocar informação.

O projeto interno e a configuração de um dispositivo BACnet® são proprietários em natureza e diferentes para cada fabricante. O padrão BACnet@ resolve este problema ao definir uma coleção de estruturas de dados abstratos chamados objetos, as propriedades que representam os vários aspectos do hardware, software, e a operação do dispositivo (BUTLER, 1997).

O fabricante não é obrigado a abrir o projeto interno de seu dispositivo, mantendo o sigilo sobre o método que utiliza em sua aplicação. Devido à estrutura desenvolvida no BACnet®, definindo uma coleção de estruturas de dados abstratos, os objetos, e propriedades que representam os vários aspectos do hardware, software e a operação.

Os objetos proveem meios de identificar e acessar informações dos dispositivos através de uma interface. Atualmente, existem 18 tipos de objetos padrão, sendo eles: analog input, analog output, analog value, binary input, binary output, binary value, calendar, command, device, event enrollment, file, group, loop, multi-state input, multi-state output, notification class, schedule, program.

\subsubsection{Camada Networking}

A finalidade da camada networking é possibilitar que as mensagens possam ser roteadas de uma rede BACnet® para outra, indiferente da tecnologia. Isso dá flexibilidade aos projeto de automação, uma vez que permite o desenvolvimento de redes com diversos protocolos de comunicação diferentes.

Em discordância do previsto no modelo de referência OSI, essa camada não suporta a segmentação de pacotes, sendo esta função repassada para a camada de aplicação. Além disso, a limitação no comprimento das mensagens é limitada pelos 
demais protocolos que estão sendo integrados.

$\mathrm{Na}$ Figura 14 exemplifica uma topologia com diversas redes diferentes sendo interligada por BACnet巴.

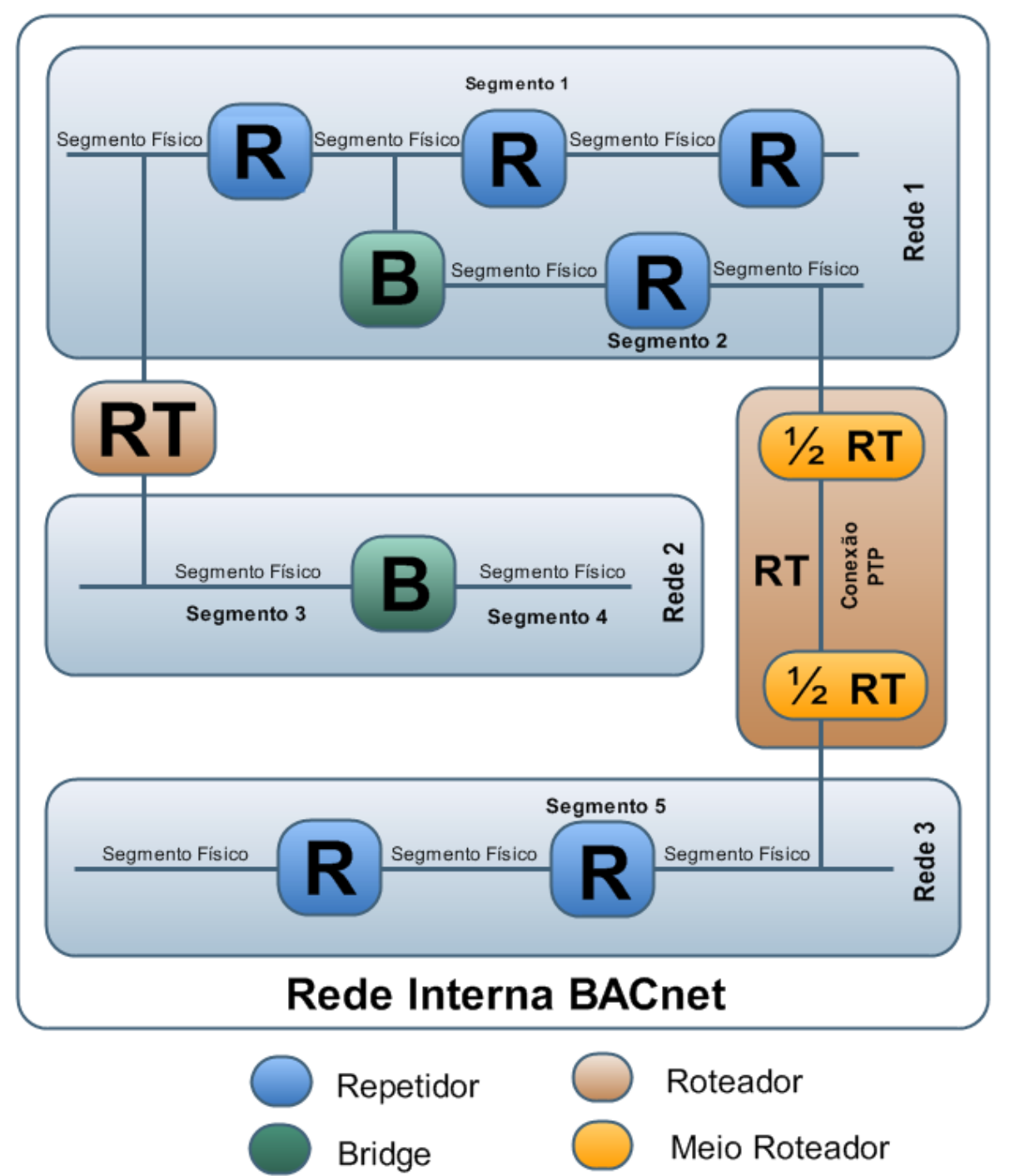

Figura 14: Internetworking com BACnet ${ }^{\circledR}$, adaptado de BUSHBY (1998).

Por fim, vale citar que o BACnet $®$ define diversos serviços de protocolo na camada de rede: configuração de tabelas de roteamento, a realização de buscas de caminho para redes de destino pelos roteadores, gerenciamento de conexões para redes, indicação de que o destino não pode ser alcançado para os clientes. 
Para aumentar a flexibilidade dos dispositivos BACnet ${ }^{\circledR}$, é especificado diversos meios físicos de comunicação diferentes, cada qual com sua característica específica, como por exemplo, alta velocidade, baixo custo, facilidade de instalação, etc.

A Tabela 9 resume os meios de comunicação especificados, com algumas vantagens e desvantagens.

Tabela 9: Custo $x$ desempenho das tecnologias de LAN, adaptado de McENTEE (1997).

\begin{tabular}{|c|c|c|c|c|}
\hline LAN & CUSTO & LIMITAÇÕES & BENEFÍCIOS & VELOCIDADE \\
\hline Ethernet & Alto & 10-100Mbps & $\begin{array}{l}\text { Padrão internacional } \\
\text { Largamente presente } \\
\text { Variedade de media } \\
\text { Muito rápida } \\
\text { Interface fácil com PC } \\
\text { Sem ferramentas } \\
\text { especiais para } \\
\text { desenvolvimento }\end{array}$ & $\begin{array}{l}\text { Custo alto } \\
\text { Limitação de distancia } \\
\text { Não deterministica }\end{array}$ \\
\hline Arcnet & Médio & $150 \mathrm{~K}-7,5 \mathrm{Mbps}$ & $\begin{array}{l}\text { Padrão ANSI } \\
\text { Resposta } \\
\text { deterministica } \\
\text {.Velocidade escalável } \\
\text {.Variedade de media } \\
\text { Alta performance com } \\
\text { baixo custo }\end{array}$ & $\begin{array}{l}\text { C.I. de fonte única } \\
\text { Somente para } \\
\text { controladores de campo } \\
\text {.Limitaçōes de distancia }\end{array}$ \\
\hline MS/TP & Baixo & $9,6 \mathrm{~K}-76 \mathrm{Kbps}$ & $\begin{array}{l}\text { Padrão ANSI } \\
\text {.Baixo custo } \\
\text { Implementado em } \\
\text { único C.I. } \\
\text {.Resposta } \\
\text { deterministica }\end{array}$ & $\begin{array}{l}\text { Media única (EIA-485) } \\
\text { Velocidade limitada }\end{array}$ \\
\hline PTP & Baixo & $9,6 \mathrm{~K}-56 \mathrm{Kbps}$ & $\begin{array}{l}\text {.Única opção dialup } \\
\text {.Somente aplicaçōes } \\
\text { ponto a ponto } \\
\text {.Recebe padrōes } \\
\text { modernos de modem }\end{array}$ & $\begin{array}{l}\text { Somente ponto a ponto } \\
\text { Limitada velocidade }\end{array}$ \\
\hline LonTalk & Baixo & $32 \mathrm{~K}-1,25 \mathrm{Mbps}$ & $\begin{array}{l}\text { Variedade de media } \\
\text { Velocidade escalável }\end{array}$ & $\begin{array}{l}\text { Não deterministica } \\
\text {.Limitada distancia } \\
\text { Único fornecedor de C.I. } \\
\text {.Ferramentas especiais } \\
\text {.Tamanho limitado de } \\
\text { aplicação }\end{array}$ \\
\hline
\end{tabular}

Na tabela acima, a coluna com o nome de "custo", representa o custo do sistema por nó ao usar a tecnologia indicada na linha em um sistema real. São considerados assuntos como: custos com a fiação, a instalação e a necessidade por dispositivos repetidores de sinais. 


\subsection{Tecnologia de LAN especificadas para o BACnet®}

\subsubsection{Padrão ISO 8802-3 (Ethernet)}

É geralmente conhecido pelo nome Ethernet. Esta é provavelmente a tecnologia de LAN mais usada no mundo hoje, principalmente por causa de sua presença frequente em escritórios e redes empresariais. É a tecnologia de LAN mais rápida usada com o BACnet $\circledast$. A maioria das companhias de automação predial oferece o Ethernet como uma opção para conectar os controladores de mais alto desempenho como estações de trabalho (BUSHBY, 2001).

Atualmente, a tecnologia Ethernet é bastante utilizada em escritórios e redes empresariais, sendo utilizada como o meio físico para as redes locais de computadores (LANs).

Do ponto de vista do $B A C n e t \circledR$, é a tecnologia de LAN mais rápida e a maioria das empresas de automação a oferece como uma opção para conectar os controladores de maiores desempenho e que exijam a troca de grandes quantidades de dados, como por exemplo as estações de trabalho contendo o sistema supervisório.

Podem ser utilizados três tipos diferentes de interconexão dos dispositivos, o cabo coaxial, o par trançado e a fibra ótica. O cabo coaxial, apesar de ser de custo baixo, é restrito à topologia barramento. $O$ cabo de par trançado (UTP) pode ser utilizado em configuração estrela, no entanto, requer o uso de equipamentos de rede, como o hub ou switch. Por fim, a fibra ótica oferece altas taxas de comunicação, maiores distâncias de cabeamento e imunidade à interferências, porém o custo é maior que os dois casos anteriores.

\subsubsection{Padrão ANSI/ATA 878.1 (ARCNET)}

A ARCNET é uma tecnologia de LAN que é mais lenta que o Ethernet, mas por outro lado é determinística, significando que é possível determinar o tempo máximo em que um dispositivo será capaz de transmitir uma mensagem. Ela foi popular 
em algumas linhas de produtos de SAP, como uma rede de relativa alta velocidade, por conectar os controladores de mais alto desempenho junto com as estações de trabalho (McENTEE, 1997).

A geração mais nova de camadas de ARCNET tem uma velocidade escalável e pode ser usada com sinais EIA-485. Esta opção está se tornando uma opção popular para uso com controladores unitários.

\subsubsection{Master-Slave/Token-Pass (MS/TP)}

O protocolo Master-Slave/Token Pass (MS/TP) foi criado pela ASHRAE para satisfazer as necessidades de controladores de automação predial de baixo custo e foi reaproveitada pelo BACnet ${ }^{\circ}$. O protocolo do MS/TP é implementado usando sinais EIA-485 e pode ser utilizado no modo mestre-escravo, peer-to-peer, token pass ou uma combinação dos dois (SWAN, 1997).

Apesar da velocidade ser limitada a aproximadamente $76 \mathrm{kbps}$, velocidades mais altas são teoricamente possíveis, mas requerem uma camada de protocolo dedicada para uma operação segura. No entanto, a complexidade dessa camada, somada ao custo, faz com que o LonTalk® ou ARCNET sejam melhores opções para velocidades mais altas.

\subsubsection{Padrão EIA-709.1 (LonTalk®)}

Como o protocolo LonTalk $®$ e a tecnologia LonWorks $®$ foram detalhados e comentados neste Capítulo, no item 2.7., no momento, apenas pode-se dizer que o BACnet $\AA$ também os utiliza como forma de meio de transporte para o protocolo BACnet $\circledast$, permitindo que seus dispositivos se comuniquem em uma rede LonWorks $®$. 


\subsubsection{Padrão EIA-232 (PTP)}

O padrão BACnet® explicitamente exclui qualquer definição do meio físico em cima do qual o protocolo PTP é usado, mas apoia o EIA-232 ou as conexões de modem discado (BUSHBY, 2001).

O protocolo PTP também foi projetado para as taxas de comunicação mais lentas (9,6 a 56 kbps), típico do EIA-232 ou conexões via modem. Esse protocolo é explicitamente apropriado para ser usado na transmissão de pacotes entre duas redes, sendo que os dois dispositivos interligados se comportam da mesma maneira que um roteador, recebendo o nome de meio-roteador. Normalmente, a conexão PTP é utilizada através de uma conexão tarifada, como a rede telefônica, por exemplo. Sendo assim, este tipo de conexão é cara e a mesma não fica continuamente ativa.

O padrão BACnet ${ }^{\circ}$ define mensagens pelas quais o meio pode informar 0 estado de sua conexão PTP aos roteadores em suas redes locais. Também define mensagens pelas quais o meio-roteador pode ser instruído para estabelecer ou terminar a conexão.

Uma conexão PTP é estabelecida quando um dispositivo BACnet ${ }^{\circledR}$ precisa se comunicar com um dispositivo na rede do outro lado da conexão. O dispositivo que inicia a comunicação envia um pedido para informação sobre como alcançar a rede. O meio-roteador do outro lado responde com uma mensagem declarando que a rede está do outro lado de uma conexão PTP. O dispositivo que inicia a comunicação instrui o meioroteador para fazer a conexão e, após a conexão ser feita, ocorre a troca de mensagens entre os meio-roteadores.

A conexão termina na ocorrência de uma das condições a seguir: a conexão é explicitamente terminada, o tempo de conexão limite é atingido, ou no caso de haver múltiplas conexões para a rede remota.

\subsection{BACnet® e a Internet}

Grandes corporações possuem varias localidades diferentes com sistemas de automação predial, muitas vezes tornando desejável o acesso à informações 
desses sistema de forma remota, ou seja, acessar essas redes de automação predial remotamente. Para suprir essa necessidade, o BACnet ${ }^{\circledR}$ permite que um sistema possa ser acessado diretamente através da Internet, ou como uma simples conexão remota para o sistema supervisório, ou como uma conexão direta entre duas redes de controle (NEWMAN, 1999).

No primeiro caso, a conexão de internet atua como uma conexão remota, onde o sistema supervisório tem acesso a todas as informações disponibilizadas pela rede de controle remota. Esta característica faz com que possam ser realizados diversos processos otimizados, como uma operação remota totalmente monitorada; a montagem de relatórios com dados baseados em objetos da rede, como por exemplo, um relatório do consumo de energia da planta; e a monitoramento constante permitindo a manutenção preditiva e o agendamento de manutenções preventivas com maior eficiência.

Já no caso em que as redes estejam interligadas através da internet, os dispositivos se comportarão como se estivessem em uma mesma rede local, ou seja, será possível que um dispositivo de uma rede acione automaticamente os dispositivos de uma rede remota. Isso permite que duas instalações separadas fisicamente sejam totalmente integradas e trabalhem em conjunto (NEWMAN, 1999).

Para realizar essa conexão através da internet, o BACnet@ utiliza o protocolo TCP/IP como meio de transporte para o seu protocolo específico, permitindo uma total compatibilidade com toda a base de switches e roteadores já instalados atualmente. A Figura 15 exemplifica uma conexão BACnet ${ }^{\circ}$ por meio da Internet. 


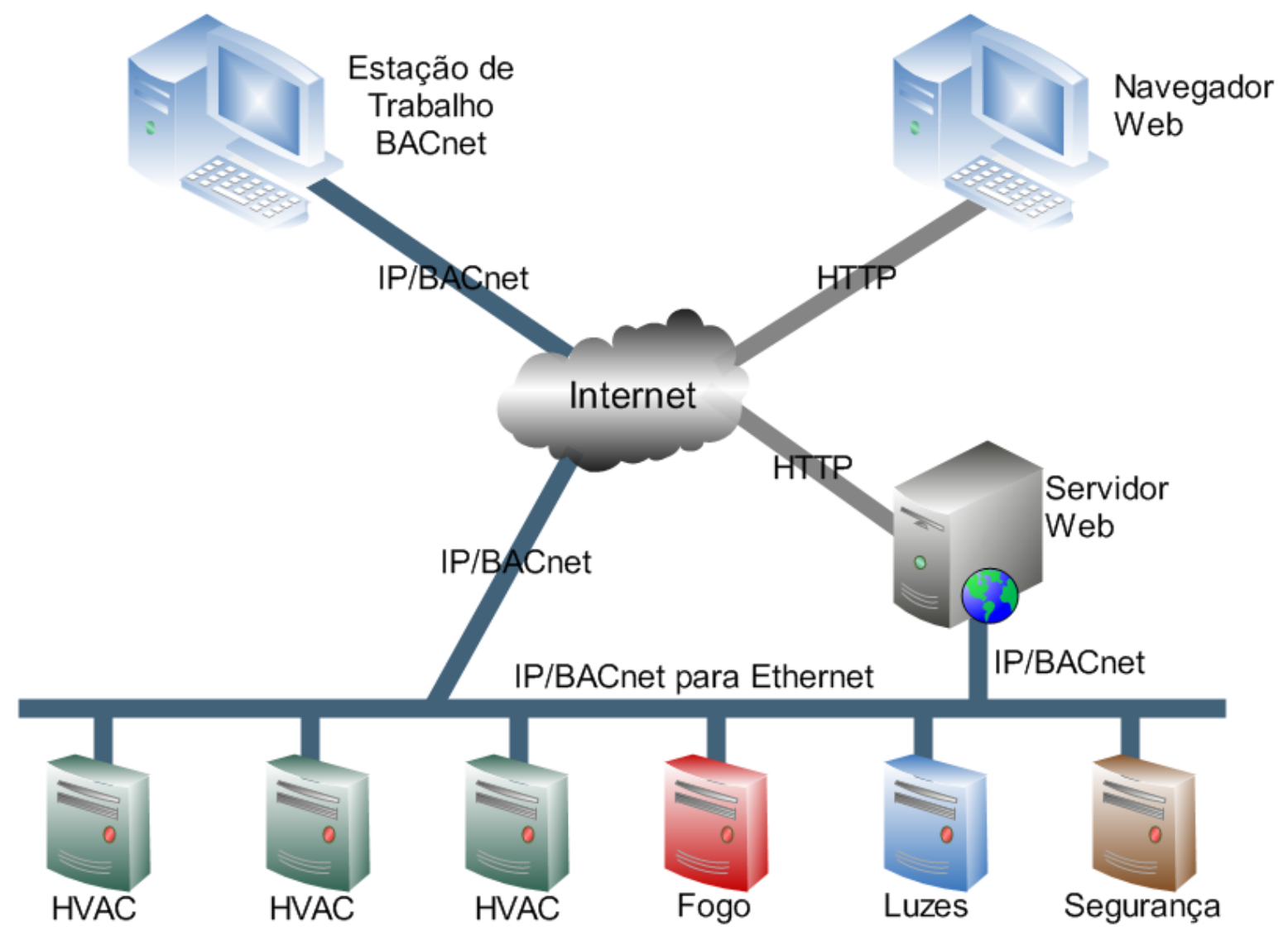

Figura 15: Conexão de estação de trabalho ao sistema de automação predial BACnet $₫$ via Internet. Adaptado de NEWMAN (1999).

\subsection{Associação de Fabricante de BACnet ${ }^{\circledR}$}

A associação de fabricantes $B A C n e t(~(B M A)$ é uma organização que encoraja o uso do $B A C n e t(~ e m$ sistemas de controle e automação predial, através de programas educacionais que testam a interoperabilidade, e atividades promocionais.

A BMA complementa o trabalho de outros grupos relacionados ao BACnet $\AA$, cujas licenças limitam suas atividades comerciais. Os membros da BMA incluem companhias envolvidas no projeto, instalação industrial, comissionamento e manutenção de equipamento de controle $B A C n e t \circledR$ para comunicação, como também outras pessoas interessadas.

Os objetivos da Associação de Fabricantes BACnet $₫$ (BMA) são:

- Desenvolver uma listagem de programas e certificação de conformidade BACnet $\AA$, que irá premiar uma marca de 
interoperabilidade para produtos compatíveis BMA e fortemente estimular as marcas registradas. Os procedimentos de testes serão baseados nos padrões da ASHRAE;

- Estabelecer um laboratório para apoiar testes de compatibilidade e de interoperabilidade;

- Promover interoperabilidade e compatibilidade com o Padrão BACnet $₫$ desenvolvendo software para teste de conformidade e organizar atividades de teste de interoperabilidade entre fabricantes distintos;

- Fornecer a mais recente informação sobre tecnologia BACnet@ e produtos através de eventos educacionais e a divulgação da lista dos produtos em conformidade;

- Disponibilizar no mercado e promover o uso do BACnet ${ }^{\circledR}$ para engenheiros consultores, usuários finais de equipamentos de automação predial e a comunidade de automação predial como um todo. Isto incluirá educação e publicação das implementações que agregam valor ao padrão;

- Trabalhar com organizações existentes para promover e melhorar o BACnet $₫$ tais como: ASHRAE BACnet $\AA$ Committee (SSPC 135), CEN TC247, EIEJ, BACnet $®$ Interoperability Testing, BIG-NA, BIGEurope, BIG-AA, NEMA, NFPA, ISO TC205.

\subsection{Conclusão do Capítulo}

Como pôde ser observado, procurou-se estabelecer, no decorrer dos anos das implantações de automação predial, uma produção de especificação e de produtos com tecnologia de tal forma a estabelecer uma segurança em se definir interoperabilidade entre os diversos sistemas pertinentes de um sistema de automação predial.

Constatou-se iniciativas semelhantes para atender à demanda dessa necessidade e, a partir deste ponto, registram-se duas importantes contribuições que foram as associações BACnet ${ }^{\circledR}$ e LonMark®. Na mesma época, portanto, em paralelo à 
automação predial, apareceu a associação OMG com a mesma finalidade, mas destinada à área da tecnologia da informação.

Neste Capítulo, procurou-se colocar essas iniciativas e contribuições de tal maneira a evidenciar a preocupação principal das associações e os mecanismos que cada uma delas utilizou para reagir ao mercado e suas necessidades.

A contribuição dada pelo modelo de referência OSI é importante, pois abreviou o amplo processo de comunicação em plataformas heterogêneas e manteve um grau de transparência adequado: por meio dele avaliou-se todo o movimento de interoperabilidade de diferentes produtos e fabricantes; Além de verificar que o foco das associações está na convergência para a camada 7, referente a aplicação, pois os demais níveis trouxeram a transparência ao transporte das informações nos diversos protocolos de comunicação que foram utilizados.

Com o que foi mostrado, nota-se que uma grande distância separa o ambiente de automação predial ou residencial no sentido de atender aos requisitos de ambiente computacional pervasivo. A preocupação que se constata é a de proporcionar interoperabilidade entre diferentes sistemas, que embora seja um ponto positivo, ainda não é suficiente para garantir que as interfaces de acesso aos usuários sejam utilizadas por outros sistemas, e com isso todas interfaces IHM sejam de uso comum e aproveitadas, além de sua atribuição principal, para outras atribuições secundárias, como a de informar o usuário com mensagens e informações de outros sistemas diferentes, mesmo que as mesmas não tenham sido originalmente concebidas para outros dispositivos.

Uma necessidade de ambiente computacional pervasivo seria, por exemplo, de uma interface em um elevador poder informar a um ou vários de seus passageiros, que exitem mensagens importantes em sua caixa postal de correio. Ou um display na catraca do sistema de controle de acesso, que informe ao usuário, no momento em que ele fosse entrar ou sair do edifício, uma mensagem informando a necessidade dele comparecer com urgência a um determinado departamento da empresa, naquele momento de seu acesso.

Para se ter este tipo de ambiente computacional pervasivo há a necessidade também de um processo criativo, que elimine as barreiras da tecnologia ou protocolos proprietários, entre diferentes sistemas. Além disso os produtos que terão contato com os usuários terão que ser desenvolvidas com o requisito básico de reconhecer mensagens de outros sistemas e mostrar em suas interfaces, seja de som ou 
imagem, a informação em momento oportuno e que não venham a atrapalhar o propósito inicial de suas atribuições.

Nos estudos realizados não foram encontrados sistemas comerciais que identifiquem qualquer usuário, indicando o local em que ele esteja, a qualquer tempo e qualquer hora, para poder saber identificar e indicar a interface mais próxima desse usuário para reportá-lo alguma informação relevante. Somente no âmbito acadêmico, tanto no Projeto (GAIA, 2009) e (AURA, 2009) mostra esse potencialidade nos equipamentos de $\mathrm{TI}$, pois tem identificação personalizadas nos equipamentos de uso pessoal. Dessa forma, a localização permanente dos usuários em um sistema de automação predial ou residencial é importante para os sistemas que pretendam ter esse tipo de funcionalidade.

Concluindo-se, novas e sofisticadas tecnologias estão à disposição para a concepção de novos sistemas de automação, com características até então não consideradas. Conceitos de computação pervasiva, por exemplo, tendem a estar cada vez mais presentes. A busca por soluções abertas, a exemplo de outras áreas, vem ganhando destaque, pois favorecem a interoperabilidade, característica desejável em sistemas de automação. 


\section{A recomendação ODP e a relação com middleware para arquitetura de objetos distribuídos}

\subsection{Introdução}

O uso cada vez maior de aplicações utilizando sistemas distribuídos tem motivado o aparecimento de ferramentas e técnicas necessárias para implementá-los. A exemplo das redes de computadores, a padronização com vistas a uma melhor interoperabilidade também favorece as aplicações com tais sistemas. Para tanto, são propostos modelos de referência que também ajudam na construção da infraestrutura e no desenvolvimento de aplicações distribuídas.

Modelos de referência são a base para a padronização de sistemas pela ISO. Eles têm se tornado uma técnica útil não só na definição de padrões como também um recurso importante para o entendimento dos mesmos.

O esforço de normalização, dentro de ISO e da Union Internationale des Télécommunications (UIT), Secteur de la normalisation des telecommunications, (UIT-T), (anteriormente CCITT) em relação ao Modelo de Referência Open Distributed Processing (RM-ODP), procurou responder às diversas iniciativas de desenvolvimento e evolução de sistemas distribuídos de computação.

O modelo de referência OSI estruturou em sete camadas os sistemas de protocolos de comunicação, sendo utilizado para a interconexão de sistemas heterogêneos, como comentado no item 37. Com este modelo estabelecido, verificou-se que as camadas de 1 a 6 forneceram suporte para os processos da comunicação, mas a camada 7, referente à aplicação, precisava de um modelo de referência mais geral, pois se fez necessário abordar todos os aspectos relacionados com a distribuição de aplicativos (FAROOQUI; LOGRIPPO; MEER, 1996).

Essa necessidade gerou como resposta o RM-ODP, que fornece um framework de coordenação para a padronização do processamento distribuído aberto, procurando atender à necessidade de modelos para o desenvolvimento de sistemas distribuídos complexos. Em contraste com o OSI, o ODP não se restringe a comunicação entre sistemas heterogêneos, tratando também da portabilidade da sua aplicação, com total transparência em diferentes sistemas distribuídos. Assim, pode-se considerar que o 
ODP estende e complementa o OSI.

No início de 1996, o RM-ODP passou a ser adotado como norma internacional (RAYMOND, 1995).

\subsection{Objetos Distribuídos}

Segundo as recomendações para o desenvolvimento de sistemas ODP, um sistema distribuído é aquele que apresenta as seguintes características (AAGEDAL; BERE, 1997)(RAYMOND, 1995):

- Distribuição geográfica: os elementos do sistema estão dispersos geograficamente, podendo ter interações locais ou remotas;

- Autonomia: cada componente do sistema é independente dos demais;

- Comunicação assíncrona: não há um sistema global de sincronização;

- Inexistência de estado global: o estado global do sistema não pode ser determinado;

- Concorrência: cada componente do sistema pode executar paralelamente aos demais;

- Heterogeneidade: não há garantias de que os componentes utilizam a mesma tecnologia - hardware, sistema operacional, protocolos de comunicação, linguagens de programação, etc;

- Evolução: durante seu funcionamento o sistema pode incorporar novas tecnologias;

- Possibilidade de falhas parciais: qualquer componente do sistema pode falhar sem comprometer os demais;

- Mobilidade: as fontes de informação, nós de processamento e usuários podem se mover fisicamente.

Sendo assim, um sistema distribuído não é simples de ser modelado e, portanto, sua especificação não é uma tarefa trivial, pois envolve o tratamento de muita informação. Para lidar com essa grande quantidade de informação, a ODP divide a fase de especificação do sistema em cinco modelos definidos a partir de pontos de vista, e 
também propõe um conjunto de regras para manter a respectiva consistência entre os objetos (AAGEDAL; BERE, 1997):

- Empresa: especifica o sistema em relação aos negócios da empresa, tendo como foco o propósito, escopo e políticas do sistema;

- Informação: especifica o significado das informações sendo processadas;

- Computação: especifica a distribuição funcional dos objetos e suas interfaces;

- Engenharia: especifica os mecanismos e funções necessárias para a interação dos objetos distribuídos;

- Tecnologia: especifica as tecnologias utilizadas no sistema.

Com a visão da computação, o projetista especifica quais objetos computacionais que serão utilizados para dar transparência aos mecanismos de comunicação:

- Objetos computacionais: os componentes da aplicação distribuída;

- Interface computacional: mostra todos os serviços disponíveis;

- Invocação das operações: fica transparente os mecanismos e métodos internos de chamadas;

- Especificação: desenvolve toda especificação das operações e relacionamento dos nós computacionais.

Com a visão de engenharia, o projetista especifica quais os mecanismos que irão implementar as transparências de:

- Acesso (mascara diferentes tipos de dados e formas de invocação de método entre objetos distribuídos);

- Falha: mascara a eventual falha e recuperação de um objeto;

- Localização: mascara a localização física de uma interface;

- Migração: mascara a troca de localização física de um objeto;

- Realocação: mascara a troca de uma interface por outra compatível;

- Replicação: mascara a troca de um objeto por outro que implementa a mesma interface;

- Persistência: mascara a eventual desalocação e realocação de um objeto.

Com a visão de tecnologia, o projetista especifica a tecnologia necessária para implementar o sistema modelado pelos outros pontos de vista. Devem ser 
especificados os recursos de hardware e software necessários para a implementação dos objetos definidos pelos demais pontos de vista, sendo que esses recursos podem ser padronizados, proprietários ou ambos, dependendo da política da corporação. O modelo, do ponto de vista de tecnologia, é constituído por objetos que possuem correspondência direta com os objetos do ponto de vista de engenharia.

Para o desenvolvimento do presente trabalho, abordou-se inicialmente apenas a visão de engenharia e visão da tecnologia, visto que essas duas estão diretamente relacionadas com a proposta de analisar e aplicar o contexto de middleware na área de automação, com o objetivo de atender aos requisitos da computação pervasiva.

No item 4.8. do Capítulo 4, será abordada também a visão da computação, estabelecendo uma forma de apresentação dos objetos na visão da computação, para documentar os projetos de automação.

\subsection{Visão de Engenharia}

No nível mais geral, os objetos estão fisicamente associados a um recurso de processamento, o nó - um computador, um microcontrolador com sensor ou atuador. Cada nó é controlado por um núcleo de software (uma espécie de sistema operacional ou firmware) que é responsável pela inicialização do nó, pela criação de grupos de objetos, pelo suporte a comunicação, pela criação de clusters, etc. Ainda no nó, há cápsulas que possuem memória e dispositivos de entrada e saída de hardware que compartilham o processador do nó (um processo). Na cápsula há um objeto especial, chamado gerenciador, que a controla (HÜBNER; SICHMAN; BECERRA, 2000) (RAYMOND, 1995). Uma ilustração desse modelo abstrato de objetos e seu encapsulamento encontra-se apresentado na Figura 16. 


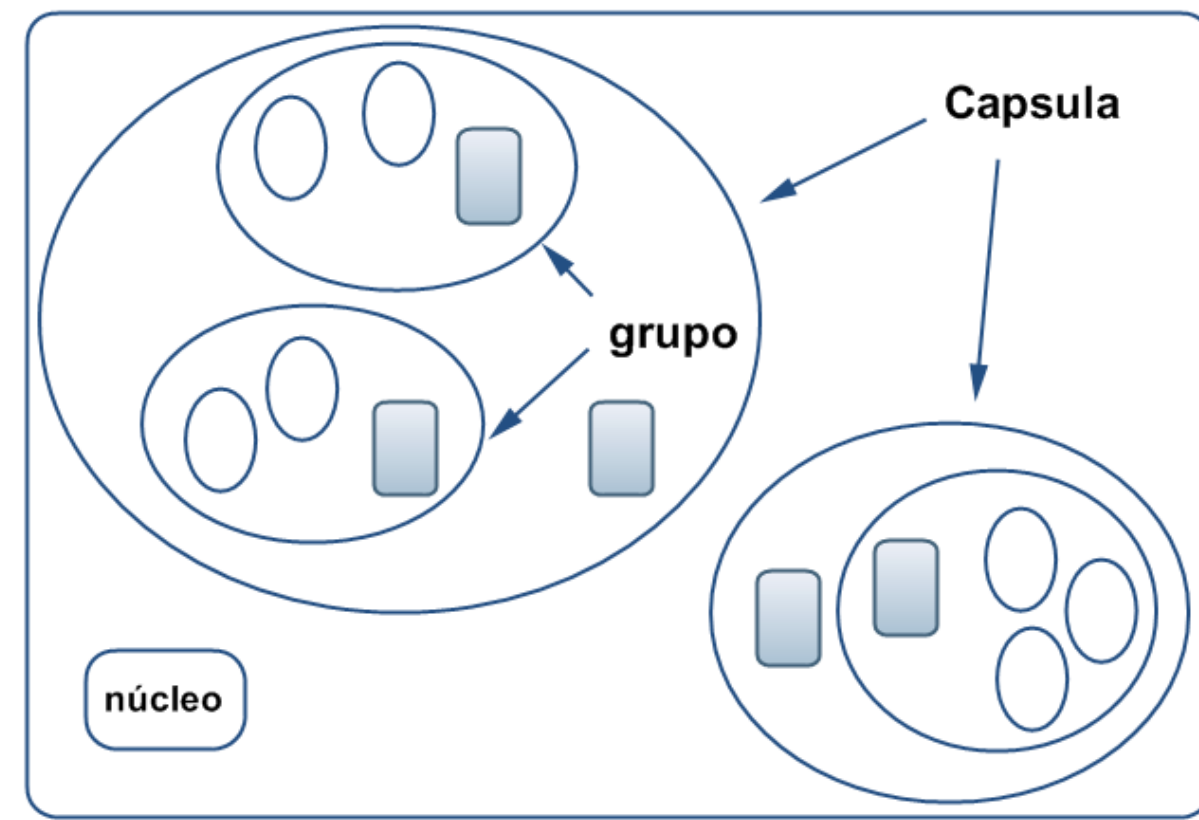

Nó

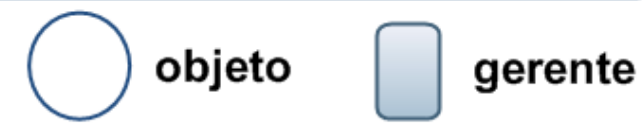

Figura 16: Organização de um nó ODP adaptado de HÜBNER, SICHMAN e BECERRA (2000).

Com esse modelo pode-se montar configurações diferentes para entender a modelagem de objetos proposto. Na Figura 17, tem-se a visão de dois nós e alguns detalhes dos mecanismos de transparência para os relacionamentos entre Objetos Básicos de Engenharia (OBE). O exemplo mostra alguns clusters e um canal formado entre duas cápsulas de um mesmo nó (FAROOQUI; LOGRIPPO; MEER, 1996) (RAYMOND, 1995). A proposta dessa Figura é mostrar transparência de protocolo e dos objetos no canal.

No caso de deslocar esses clusters, os objetos que o compõem deverão ser deslocados juntos, pois suas ligações são mais simples de serem feitas em seu conjunto.

No nó 1 na cápsula da direita também figura a idéia do canal ser utilizado por três OBEs. Nesse caso foram aplicadas as transparências para manter os relacionamentos das informações de cada um dos três OBEs no canal da comunicação. Na cápsula da direita no mesmo nó sendo apenas um OBE e do nó 2 as transparências não foram apresentadas, mas são necessários os mesmos mecanismos na formação de canais. Nota-se também que cápsulas com mesmo gerenciador no nó 1 não precisa de transporte de informação pela rede e quando o nó 1 se comunica com o nó 2 , há a necessidade do transporte da informação pela rede, pois são dois equipamentos computacionais em posição geográficas distintas. 


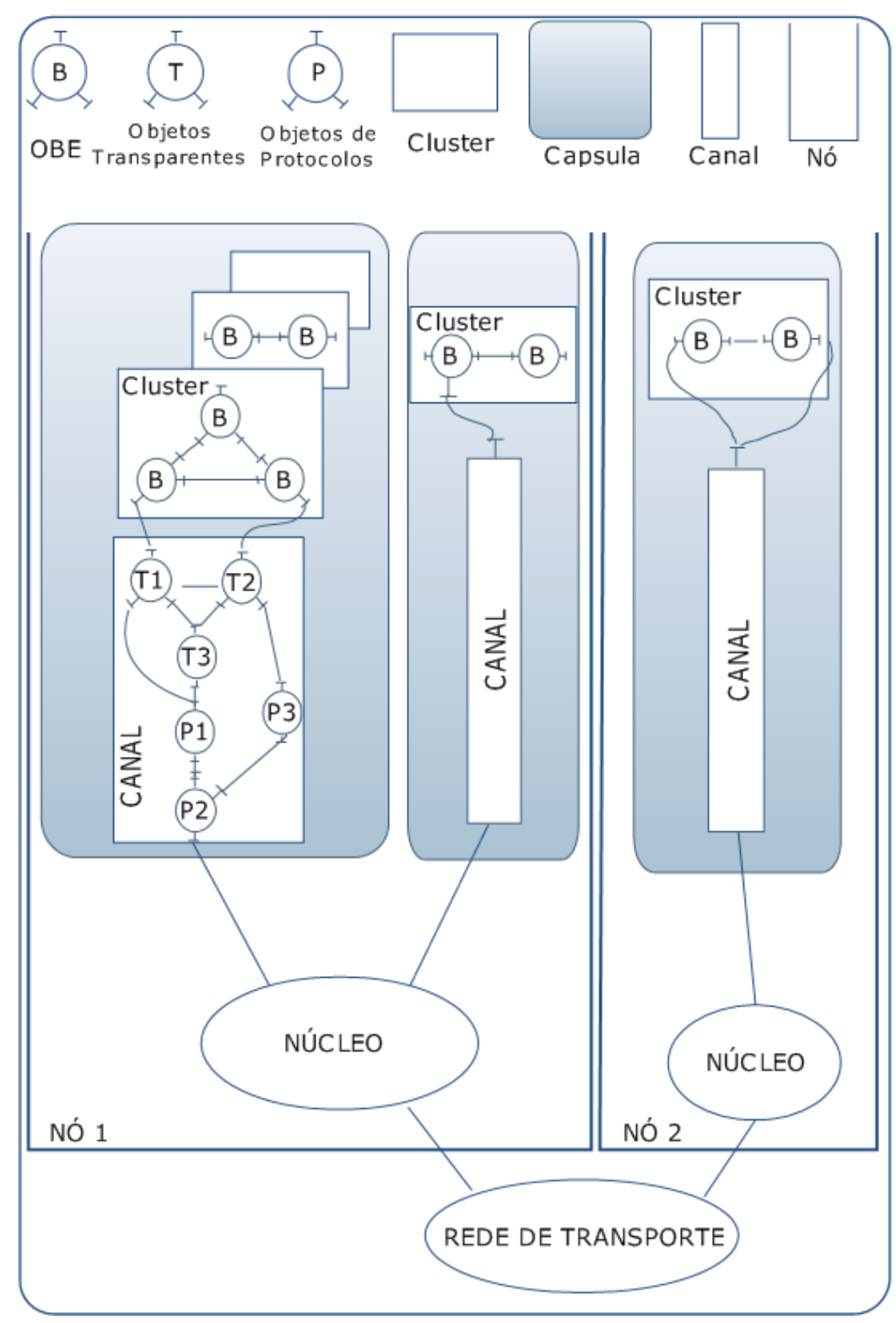

Figura 17: Visão de engenharia (FAROOQUI; LOGRIPPO; MEER, 1996).

O agrupamento de objetos em cápsulas facilita a comunicação entre eles, e por consequência facilita a comunicação entre processos oferecidos pelo nó. Cada cápsula pode conter vários objetos cliente/servidor formando agrupamentos. Os objetos de um agrupamento formam uma unidade que pode ser transferida, desativada, reativada e movida para outro nó. A comunicação dos objetos dentro do agrupamento cluster é muito eficiente, já que os objetos são criados juntos e desenvolvidos na mesma linguagem. Neste caso, a comunicação normalmente é uma invocação de método. Assim como o nó e a cápsula, cada agrupamento é controlado por um gerenciador. 
Para que objetos de diferentes agrupamentos possam interagir com as transparências mencionadas, a recomendação sugere uma estrutura para estabelecer um canal de comunicação com as seguintes camadas, esboçadas na Figura 18:

- Stub: responsável pela informação transmitida na interação;

- Binder. responsável por manter a associação entre os objetos de um canal;

- Protocolo (protocol): responsável pela manutenção da comunicação e, caso seja necessário, pela resolução de problemas de nomes serviço de diretório;

- Interceptador (interceptor): utilizado no caso em que a comunicação é com objetos de outra organização e/ou tecnologia (outro tipo de rede, por exemplo), onde há necessidade de adaptações adicionais.

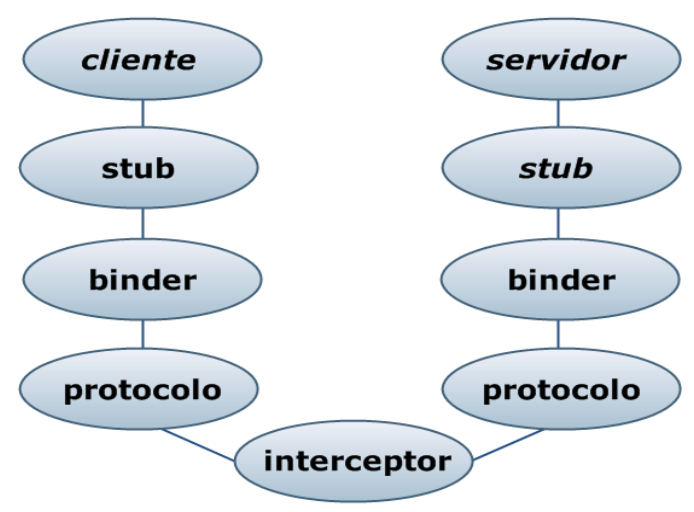

Figura 18: Canais de comunicação HUBNER, SICHMAN e BECERRA (2000). 


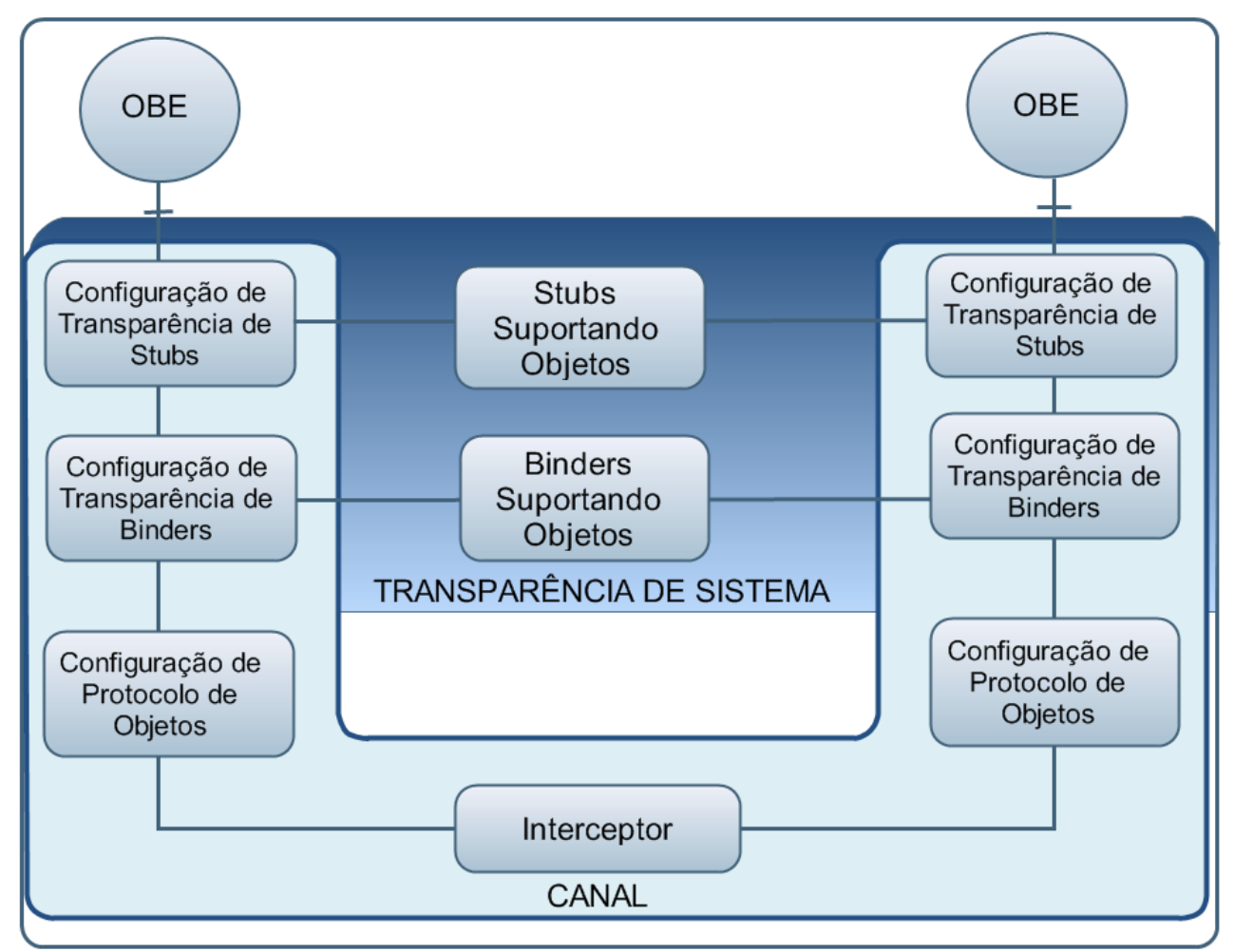

Figura 19: Mecanismos utilizados para executar um canal de comunicação.

Na Figura 18 e Figura 19 tem-se um canal montado, por interpretação da norma com autores diferentes, mostrando o grau de transparência entre o cliente e o servidor quando ocorre uma conexão. Esse mecanismo, semelhantes, deixa claro que os objetos se comunicam por canais que são instanciados após o OBE formado; em seguida o canal de comunicação se estabelece, ligando os objetos. Esse mecanismo poderá ser feito de forma estática ou dinâmica em tempo de execução.

\subsection{O contexto de middleware}

O termo middleware apareceu pela primeira vez no final de 1980 para descrever gerenciamento de conexões em software, mas passou a receber mais destaque a partir da metade da década de 1990, quando a tecnologia de rede começou a ser mais intensamente utilizada (BAKKEN, 2003).

O RM-ODP foi estabelecido entre 1995 e 1996, mesma época na qual o middleware começou a ganhar destaque no mercado, pois ambos, cada um ao seu nível, tratam de aplicação distribuída em plataformas computacionais heterogêneas. $O$ 
middleware é mais antigo e nasceu da necessidade do mercado em resolver e adaptar sistemas com aplicação distribuídas.

Cronus foi o primeiro sistema middleware de objetos distribuídos, sendo Clouds e Eden como seus contemporâneos. O RPC foi desenvolvido no início da década de 1980 por Birrell e Nelson. Rapidamente o sistema RPC foi utilizado pela Sun em seu Open Network Computing (ONC), e no Apollo's Network Computing System (NCS). A Open Software Foundation's Distributed Computing Environment (DCE), incluiu também sistema RPC, que foi uma adaptação do Apollo fornecido pela Hewlett Packard (que adquiriu Apolo). Qualidade Objetos (QuO) foi o primeiro framework de middleware criado para uso geral e extensível com qualidade do serviço de objetos distribuídos (ZINKY; BAKKEN; SCHANTZ, 1997). TAO foi o primeiro grande sistema CORBA a proporcionar qualidade de serviço, ou seja, com desempenho em tempo real, diretamente no ORB (BAKKEN, 2003).

O Message Oriented Middleware (MOM) é um método de comunicação entre componentes de software utilizado em sistemas distribuídos, sendo considerado como um tipo de middleware orientado a mensagens. Devido ao seu grande uso na década de 1990, a Message Oriented Middleware Association (MOMA) foi formada em 1993. No final dos anos 1990, o protocolo Hypertext Transfer Protocol (HTTP) se tornou freqüente em vários tipos de middleware, devido à sua transversalidade de implantação e sua capacidade de transpor a maioria dos firewalls conforme BAKKEN (2003).

O middleware trouxe novos paradigmas e serviços para ajudar a tornar mais fácil e controlável a construção e desenvolvimento de aplicações distribuídas. O termo foi associado principalmente com bases de dados no início da década de 1990, mas já na metade dessa década passou a ser utilizado em outras aplicações (BERNSTEIN, 1996) (CAMPBELL, GOULSON, KOUNAVIS, 1999). Os conceitos de middleware de hoje anteriormente foram associados aos atributos dos sistemas operacionais de rede, sistemas operacionais distribuídos, e ambientes de computação distribuída.

Uma plataforma middleware fornece o ambiente para aplicações orientadas a objetos distribuídos serem executados em tempo de execução (runtime). Ela prove os mecanismos de tratamento das conexões entre objetos, em um programa local ou entre objetos de uma aplicação que estejam distribuído em rede. Ela também fornece serviços de gestão de recursos para hospedagem lógica do programa aplicativo em tempo de execução (por exemplo: gestão de memória, sistema operacional de processos 
e threads, carregando programas a partir do disco, conforme necessário, iniciando, parando e multiplexando programas, balanceando a carga, etc). Plataforma middleware também fornece interfaces para uma ou várias formas de comunicação middleware (oneway messaging e request/respond) (LHEUREUX et al., 2004).

Uma definição de middleware é um sistema de software que executa em tempo real e que permitem um nível de interação direta entre os programas da aplicação em um ambiente distribuído de computação (LHEUREUX et al., 2004). Ele é uma camada de Software que tem a função de auxiliar no gerenciamento da complexidade e heterogeneidade típicos de sistemas distribuídos, localizando-se entre a camada do sistema operacional e a da aplicação, como mostra a Figura 20 (LHEUREUX et al., 2004).

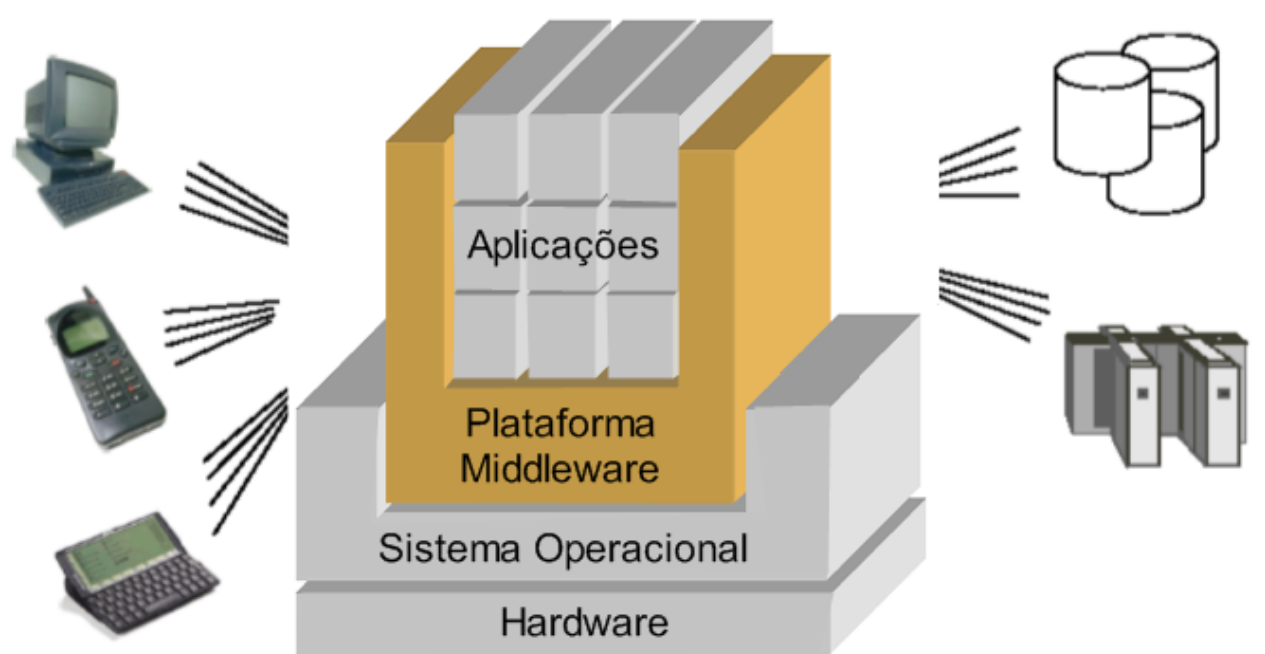

Figura 20: Representação da posição relativa de um middleware extraída de Gartner Research LHEUREUX et al (2004).

O middleware é dividido em quatro categorias, em função da abrangência das atividades que executa (BAKKEN, 2003):

- Distributed Tuples: Permite a distribuição de bancos de dados em um ambiente de rede. Uma base de dados relacionais distribuída oferece a abstração de enuplas distribuídas e é uma das formas mais utilizadas de middleware atualmente. A sua linguagem SQL (Structured Query Language) permite aos programadores manipularem conjuntos de enuplas (uma base de dados) em uma linguagem parecida com o Inglês porém com semânticas intuitivas e funções matemáticas rigorosas baseadas na teoria de conjuntos e cálculo de predicado. Bases de dados relacionais distribuídas também oferecem a abstração de uma transação. Produtos de bases 
de dados distribuídas tipicamente oferecem heterogeneidade entre linguagens de programação, porém muitos não oferecem a heterogeneidade entre as implementações de fabricantes. Monitores de Processamento de Transação (em inglês, TPMs) são comumente usados para gerenciamento ponto-a-ponto de recursos de consultas de clientes, especialmente gerenciamento de processos do servidor e gerenciamento de transações entre múltiplas bases de dados (BAKKEN, 2003). Exemplos deste tipo de middleware incluem sistemas de arquivos remotos, como os embutidos em NetWare, o Network File System (NFS) e Windows, e também incluem o acesso remoto de dados, por exemplo, Open Database Connectivity (ODBC) ou o Java Database Connectivity (JDBC), que são bibliotecas agrupadas em SGBDs como o DB2, Oracle e SQL Server;

- Remote Procedure Call (RPC): Permite que a lógica de uma aplicação seja distribuída ao longo de uma rede, permitindo que programas em sistemas remotos sejam chamados como se fossem sistemas locais. Assim tem-se: Java Message Service (JMS), ou serviços da Web (com base em Simple Object Access Protocol (SOAP);

- Message-Oriented Middleware (MOM): Permite troca de informações entre programas através de mensagens, prevê a transparência de filas de mensagens que podem ser acessadas através de uma rede. É um software que suporta um protocolo de transmissão de mensagens ou dados entre dois pontos, assim como um sistema de programação interface (SPI) para invocar o serviço de comunicação. É uma generalização do conhecido sistema de caixa de correio. É muito flexível na forma como ele pode ser configurado com a topologia de programas que deposita e retira as mensagens a partir de uma dada fila. Muitos produtos oferecem MOM filas com persistência, replicação, ou em tempo real. Comunicação mais avançada, prevê também, a segurança e garante somente uma mensagem entregue no destino. Protocolos e APls podem ser proprietárias (como por exemplo, IBM WebSphere MQ ou Microsoft MSMQ). Hoje, a comunicação geralmente é executada nos 
middlewares baseados na Internet, como os protocolos FTP, HTTP eSecure HTTP (S-HTTP), IP, SMTP ou TCP;

- Object Request Brokers (ORB): Permite que objetos que compõem uma aplicação sejam distribuídos ao longo de uma rede. Um exemplo é CORBA (Commom Object Request Broker) é uma plataforma de distribuição resultante da arquitetura OMA (Object Management Architecture) do OMG (Object Management Group) , uma organização internacional, fundada em maio de 1989 pelas empresas 3Com Corporation, American Airlines, Canon Inc, Data General, Hewlett-Packard, Phillips, Telecommunications N.V., Sun MicroSystems e Unisys Corporation. A plataforma CORBA fornece mecanismos pelos quais objetos fazem pedidos e recebem respostas em um ambiente distribuído de forma totalmente transparente $(\mathrm{OH}$ et al. 2003).

Na Figura 21 tem-se um diagrama mostrando a posição do middleware abaixo da aplicação e dentro da infra-estrutura. Observando-se apenas a camada middleware e os serviços locais e na rede tem-se o modelo apresentado na Figura 20. Uma ilustração completa e mais abstrata do contexto do middleware está representado na Figura 22 e Figura 23, nela tem-se a observação que o middleware é totalmente acessado por APIs. Tanto a aplicação quanto o sistema operacional é tratado por acesso de APIs.

A ilustração da Figura 22 apresenta uma comparação entre o modelo de referência OSI para protocolo de comunicação em relação às camadas de uma estrutura middleware. Nesta Figura, o correspondente as APIs que tratam o middleware estão na mesma posição da camada 7, ou seja, da aplicação do OSI. Esse fato está de acordo com a iniciativa de se desenvolver o RM-ODP, como foi visto, sendo o mais utilizado como possibilidades de soluções em sistema de aplicação distribuída, conforme apresentado nos parágrafos anteriores deste capítulo. 
Aplicações

Middleware

Serviços de Rede

Serviços Locais

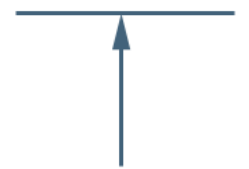

Infra-

Estrutura

de TI

(Plataforma)

Sistema Operacional e Hardware

Figura 21: Representação da estrutura de um middleware (BAKKEN, 2003).

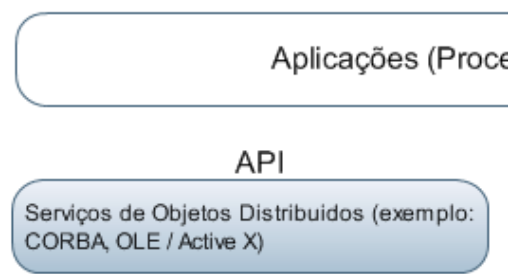

\section{$\mathrm{API}$}

Dados Distribuidos e Gerenciamento de Transação (exemplo: 2PC, XA)

\section{API}

Serviços Básicos Cliente/Servidor
(exemplo: RPC, RDA, MOM, Segurança,
Diretorios, Tempo)

\section{$\mathrm{API}$}

Serviços Programaveis de Rede

(Sockets, LU6.2, NetBIOS, TLI)

API

Serviços de Rede

Serviços de Transporte Ponto-a-Ponto

(exemplo: TCP/IP, SNA, SPXIPX, NetBIOS)

- Serviços de Comunicaçăo Física

(Ethernet, Token, Ring, FDDI, ISDN, X.25, ATM, Frame Relay, Wireless)

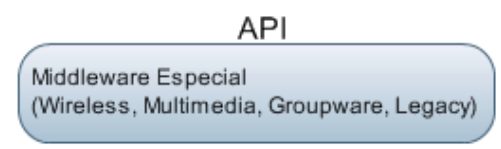

API

Middleware World Wide Web (exemplo: HTTP, HTML, CGI)

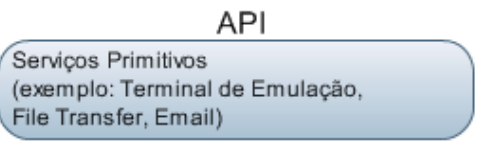

e

OSI

Camadas 6,5

OSI

Camadas

4,3 ,

2,1

Legenda usada em camadas:

Sombreamento mais Escuro = middleware

Sombreamento mais Claro $=$ geralmente não considerado como middleware

Sem sombreamento

= sem middleware

Figura 22: Arquitetura de middleware x OSI 


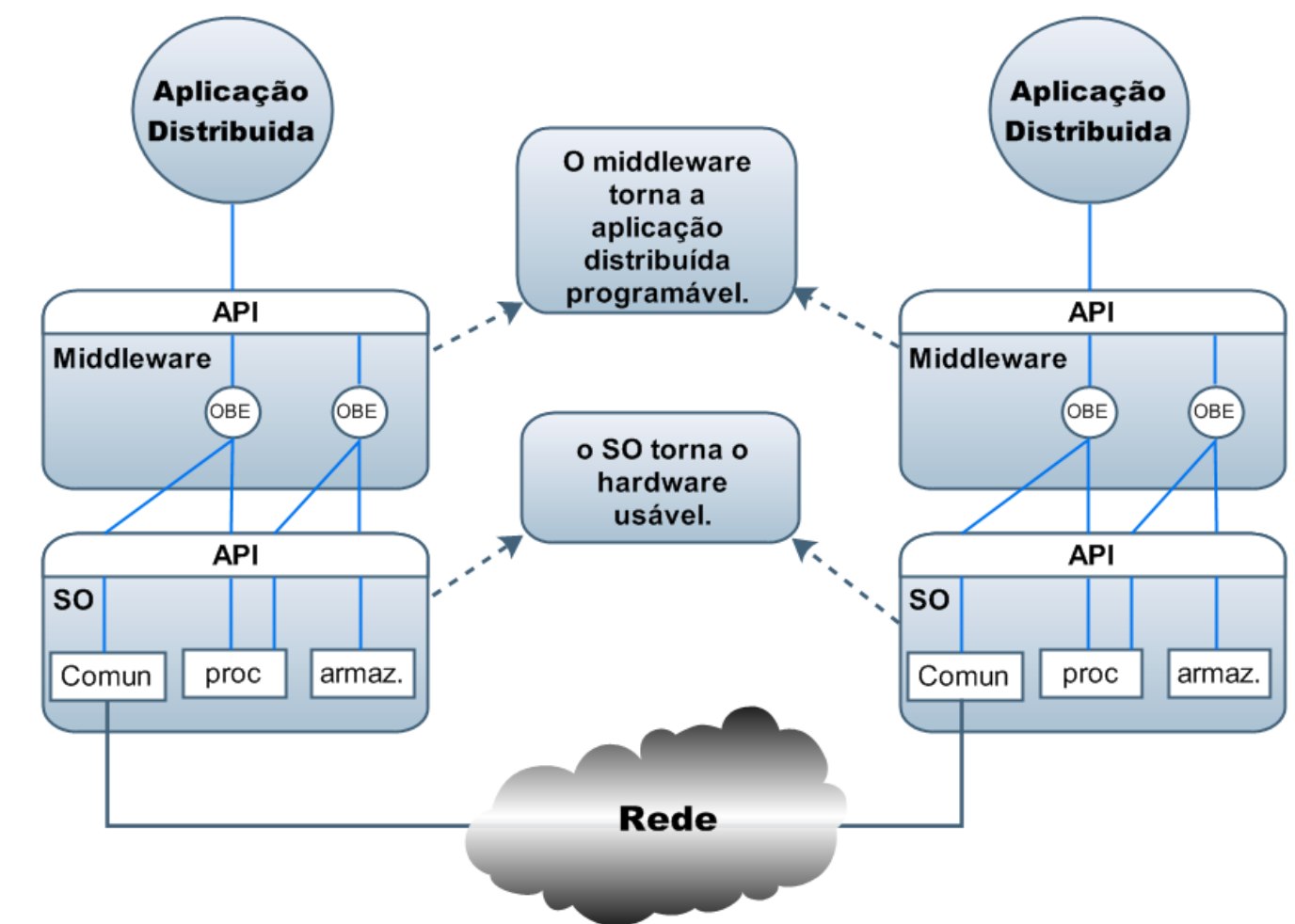

Figura 23: Contexto do middleware em ambiente de aplicação distribuída (BAKKEN, 2003).

Pode-se concluir que, o middleware é a condição necessária para que a programação distribuída seja realizada. Neste ponto da pesquisa, observa-se que as estruturas são complexas e o fato de o acesso se processar por meio de APls poderá dificultar a sua implementação em sistemas baseados em microcontroladores, utilizando esta modelagem.

Uma definição típica de sistemas operacionais embute o conceito de que ele é "o software que torna o hardware utilizável"; de modo similar, o middleware pode ser considerado como: "o software que torna programável os sistemas orientados a objeto ou aplicação distribuída" (BAKKEN, 2003).

\subsection{A associação OMG e o middleware CORBA}

A arquitetura OMA tem por objetivo reduzir a complexidade, bem como os custos e acelerar a introdução de novas aplicações distribuídas, sem que para isso fosse preciso realizar grandes mudanças. Um modelo de referência OMA foi então especificado, caracterizando os componentes, as interfaces e protocolos, resultando daí a plataforma 
CORBA (OH et al. 2003).

O intuito do OMG é ajudar o desenvolvimento e o crescimento da tecnologia de orientação a objetos. Seus princípios incluem o estabelecimento de diretrizes industriais e especificações de gerenciamento de objetos para prover uma base única para o desenvolvimento de aplicações. A adequação a essas especificações tornará possível desenvolver ambientes de aplicação heterogêneos através de diferentes plataformas de hardware e sistemas operacionais. O OMG adota uma tecnologia denominada Object Request Broker (ORB), que fornece interoperabilidade entre aplicações em diferentes máquinas em ambientes heterogêneos distribuídos. O ORB tem as seguintes características:

- Provê mecanismos pelos quais os objetos fazem pedidos e recebem respostas de forma transparente;

- Provê interoperabilidade entre aplicações em diferentes máquinas em ambientes distribuídos e heterogêneos.

CORBA é, portanto, a tecnologia de middleware ORB adotada pelo OMG. Ela define uma estrutura para que diferentes implementações de ORBs possam prover serviços e interfaces comuns para suportar clientes e implementações de objetos portáveis. Dentre os aspectos relevantes para a caracterização da plataforma CORBA, destacam-se:

- Semântica dos objetos;

- Modelo de objetos;

- Implementação de objetos.

Essa iniciativa da OMG serve para ilustrar o caminho de uma associação na área de TI, o CORBA hoje é muito utilizado por corporações e está sendo um porto seguro de outras inciativas na área de computação distribuída.

\subsection{Conclusões deste Capítulo}

Este Capítulo resume conceitos relevantes para o presente trabalho, e que serão considerados no Capítulo seguinte. Procurou-se considerar o RM-ODP como uma arquitetura para a camada de aplicação, e que estabelece canais entre objetos que podem explicar ou justificar os contextos de middleware. Reforça os conceitos de que o 
middleware é um mecanismo complexo e que se destina ao tratamento adequado e necessário à troca de informação em um ambiente de programação distribuído. Os ambientes computacionais utilizados com middleware são ambientes robustos e comuns na área de $\mathrm{TI}$, nos quais as informações são trocadas, por meio de memórias locais e acesso pela rede (LAN), com performance suficiente para as aplicações a que se propõem.

Como o middleware é o responsável pela interação entre os sistemas distribuídos e heterogêneos, deverá ser o caminho para a criação de ambientes computacionais pervasivos em automação, com devidas adequações pois estes ambientes de automação são formados por processadores e microcontroladores de pequeno porte. Esse assunto será considerado em maior profundidade no no próximo Capítulo. 


\section{Desenvolvendo Tecnologia da Automação tendo como base RM-ODP e o contexto de middleware da Tecnologia da Informação.}

Conforme discutido nos Capítulos anteriores, existem tendências na Tecnologia da Informação (TI) que, de certa forma, também se manifestam com a Tecnologia da Automação (TA), mas com uma distância temporal.

Nessas duas áreas, algumas necessidades comuns se manifestam, como a necessidade de estabelecerem padrões e com eles podem favorecer a interoperabilidade entre os sistemas, considerando sempre a abertura para permitir soluções proprietárias e com isso prover diferenças entre as propostas das diversas soluções de diferentes fabricantes.

Uma preocupação comum reside em definir regras e funcionalidades para a camada da aplicação. A especificação BACnetß, por exemplo, define vários protocolos de troca de informação nas aplicações de automação predial, e coloca duas camadas

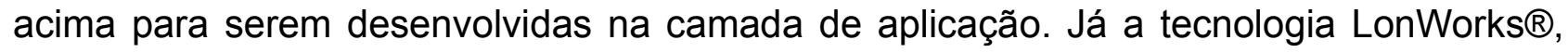

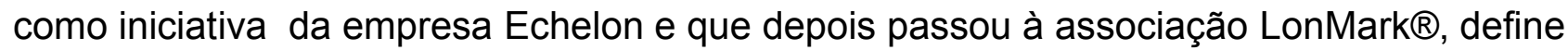
padrões para troca de informações entre os produtos de fabricantes diferentes (chamado de Perfil Funcional), utilizando seu microcontrolador NeuronChip®, que já tem embutido o protocolo de comunicação LonTalk® (norma ANSI/EIA 709.1 desde 1999).

Este Capítulo retoma os conceitos e modelos de referência ODP e OSI, e propõe uma combinação desses modelos, mostrando que o resultado dessa combinação se harmoniza com a norma ANSI/EIA 709.1, viabilizando soluções em TA que transcendem o estabelecimento de perfil funcional para produtos, possibilitando 0 desenvolvimento de programação aberta com arquitetura orientada a objetos.

Por conseqüência dessa harmonia com ANSI/EIA 709.1 é apresenta uma proposta de modelo de relacionamento dinamicamente reconfigurável entre dispositivos, transformados em objetos, de uma rede de controle LonWorks $® / E I A 709.1$, como extensão do seu modelo de (Perfil Funcional de produtos), viabilizando middleware em automação.

Além disso as ferramentas que forem desenvolvidas com base na RMODP em TI poderão ser adequadas para a TA com poucas alterações, pois ficará transparente e abstrato se o sistema é referente à TA ou TI. Pois o núcleo computacional para operar um objeto em TA passa a ser exatamente igual ao núcleo que operam os 
objetos da TI e que por conseqüência natural, pode-se desenvolver middleware para a TA e utilizar as ferramentas da TI no desenvolvimento de soluções, e vice versa. Assim, este trabalho pretende contribuir para que a TI e a TA, caminhem uma ao lado da outra, de forma mais simples e compartilhando soluções.

\subsection{Introdução}

O desenvolvimento contínuo de microcontroladores mais poderosos, e ainda com encapsulamentos com múltiplos processadores e protocolo de comunicação embutidos, favorecem o desenvolvimento de soluções com arquitetura distribuída para aplicações de controle de processo e automação.

Algumas empresas e instituições de pesquisa procuram acompanhar esses avanços criando produtos e soluções que tratam os sinais analógicos, com aplicações sofisticadas de tratamento de sinais, próximos da sua geração, eliminando interferências e ruídos, e ligando tais sensores ou atuadores inteligentes em rede, conhecida também como rede de controle de campo (ou fieldbus) (CANOVAS, 2006) (ALVES, 2001).

Alguns protocolos se destacaram para determinadas áreas como, por exemplo, o Controller Area Network (CAN) para sistemas embarcados; o ModBus para sistemas de distribuição de energia; o LonTalk®/EIA709.1 para automação predial; o Fieldbus para automação industrial; entre outros.

Essa diversidade de padrões não permite a interoperabilidade de os diversos tipos de sistemas abertos de automação. Alternativas importantes vêm sendo dadas pelo mercado, como apresentado no Capítulo 2, mas elas ainda não são suficientes para contemplar aplicações mais abrangentes, como as associadas à computação pervasiva em ambientes de automação. Em especial a automação predial e residencial deverá atender e demandar cada vez mais soluções com características computacionais pervasivas, permitindo a transparência a qualquer sistema, com o objetivo de cuidar do conforto e qualidade de vida dos usuários, sem que estas a percebam.

Neste trabalho buscou-se considerar características altamente desejáveis em sistemas de automação, como programabilidade, interoperabilidade e portanto, com produtividade, utilizando o paradigma e contextos de middleware e a adequação ao RM- 
ODP para modelar e definir novas arquiteturas de sistemas e programação. Procurou-se viabilizar o desenvolvimento em microcontroladores, produtos e sistemas de controle em automação, com características especiais de programação orientada a objeto e em multiplataformas independente do protocolo de comunicação ou firmware dos microcontroladores. É no contexto de middleware e na adequação dos modelos de referência OSI e ODP, aplicados à automação, que reside a originalidade e inovação deste trabalho de pesquisa, e que será destacada neste Capítulo.

Nos Capítulos anteriores foi analisado o estado da arte dos atuais sistemas de automação, de controle de processos e suas tendências de convergência. Decorrente dessa análise, procurou-se evidenciar os diferentes métodos e protocolos de rede de comunicação e as tentativas de padronização da informação no nível da aplicação.

$\mathrm{Na}$ área da $\mathrm{TI}$, mostrou-se que a tendência está em desenvolver cada vez mais sistemas distribuídos, que trocam informações entre objetos básicos de engenharia em um mesmo ambiente ou em ambientes computacionais diferentes. Baseados nestas modelagens, desenvolveram-se ferramentas para efetuarem estas ações. $O$ mecanismo mais importante, que procurou-se tratar com detalhes neste trabalho, foi o modelo de referencia ODP que conceitua as operações das camadas de middleware em uma arquitetura de programação orientada a objetos.

Neste Capítulo considera-se a visão de engenharia, da tecnologia e da computação do RM-ODP e o contexto de middleware para ser utilizado em microcontroladores com protocolos de comunicação de rede de controle; no Capítulo 5, coloca-se o RM-ODP aplicado na tecnologia LonWorks $₫$ integralmente, constituindo-se em uma das contribuições deste trabalho.

A tecnologia LonWorks $®$ está no mercado há mais de 18 anos, porém, até o momento, foi apenas utilizada como já apresentado no Capítulo 2. No entanto seu diferencial em relação a outros protocolos aplicados em sistemas de automação vai muito além da proposta inicial de interoperabilidade entre produtos de fabricantes diferentes e o uso de perfil funcional para o desenvolvimento desses produtos.

Este trabalho propõe uma modelagem e uma arquitetura que poderá unificar os contextos de middleware utilizados na TI com o modelo de referência OSI, estendido pela adequação ao ODP, e utilizar essa adequação como modelo no desenvolvimento dos protocolos de comunicação de rede de controle na TA. Desta abstração, modela-se um novo conceito de módulos de automação que não mais deverá 
ser tratado como apenas o perfil funcional de um determinado equipamento ou produto, mas será tratado como a apresentação da interface das informações disponíveis como cliente ou servidor do(s) objeto(s) computacional(is) de engenharia, que poderá ser um produto ou apenas objeto(s) simples do software da aplicação distribuída instanciado junto ao(s) dispositivo(s).

Isso facultará o desenvolvimento de sistemas novos de automação que poderão estar voltados para atender as especificações da computação pervasiva, pois será claro a existência do computador unificado pervasivo, tratando todos os objetos computacionais, distribuídos e instanciados em dispositivos de automação na planta automatizada, como se fossem objetos instanciados em um imenso computador formado pelos dispositivos distribuídos, com uma única aplicação distribuída ou várias aplicações distribuídas.

A aplicação que antes era separada e interoperável passará a ser considerada como uma aplicação única com várias atribuições funcionais em plano único, sem necessitar da configuração hierarquizada como até agora é configurado e passará a operar totalmente voltado ao contexto e se comportar e configurar os vários sistemas agentes tratando operações de "siga-me com as configurações do usuário".

\subsection{O contexto do middleware para automação}

Com o que foi descrito no Capítulo 2, é de se supor que os produtos de automação em um ambiente de rede de controle devem se agrupar como ilustrado na Figura 24. Nessa rede, observa-se equipamentos comuns em uma instalação, sendo cada

um desses produtos, pequenos ambientes computacionais, constituídos de microcontroladores interligados pela rede de controle. 


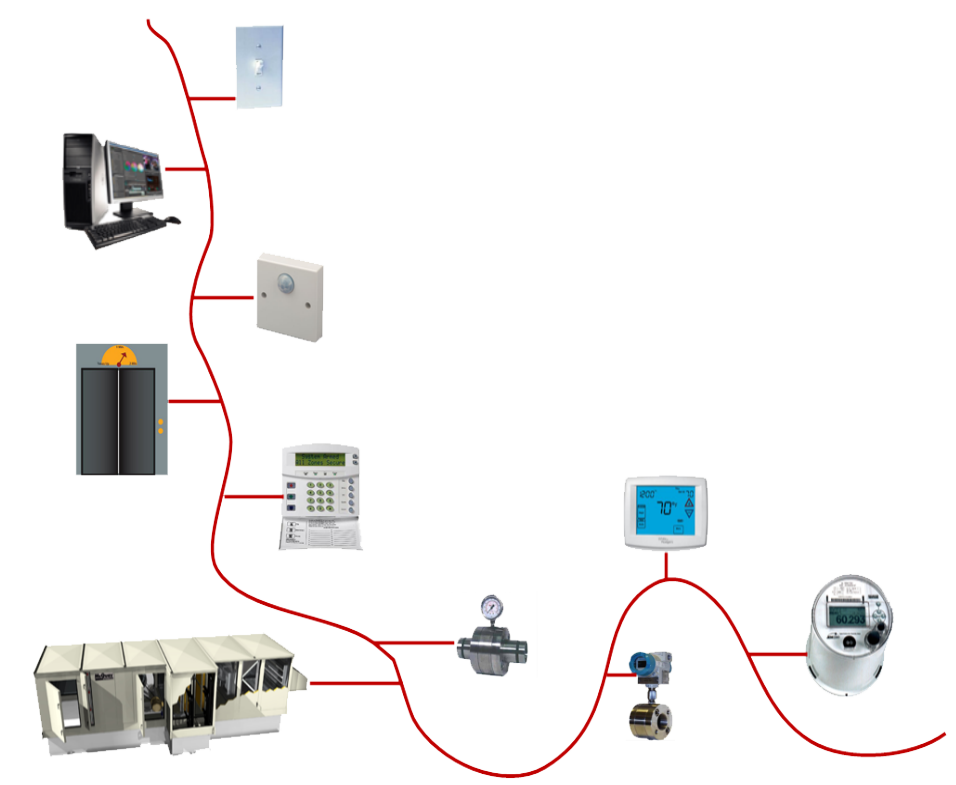

Figura 24: Um barramento de rede de controle com diversos equipamentos de automação.

Esses equipamentos possuem uma maior simplicidade quando atuam apenas em uma saída ou entrada digital, como no caso de uma lâmpada ou interruptor, e podem chegar a níveis altos de complexidade quando usam display ou mostradores numéricos, teclados, saídas ou entradas analógicas, ou controladores PWM, PCM, dentre outros periféricos mais sofisticados.

Em uma rede de controle de automação, seja ela predial ou industrial, e independente da complexidade do equipamento, existe, na sua grande maioria, um ambiente computacional pequeno, com memória e processamento adequados à necessidade do controle ou monitoramento a que se propõem. Normalmente contendo microcontrolador com memória interna e os periféricos mínimos necessários para a leitura de sensor ou sinais analógicos ou digitais para tratar saída para atuadores, como válvulas, motores, entre outros.

Sendo assim, tomando como base o que está ilustrado na Figura 25, observa-se a direita um ambiente computacional HOT2 formado por um microcontrolador básico de um sistema de automação. Nele tem-se a conexão com a rede feita pelo transceptor na camada física do modelo de referencia OSI. No topo, ligado a camada da aplicação tem-se o representativo da camada da aplicação como sensor ou atuador. Este é o ambiente computacional admitido como comum na TA e que vai-se considerar dentro deste trabalho e apresenta a condição de comunicação em rede de controle e processador e memórias adequadas para executar as atividades de leitura de sensor ou 
de escrita de estados lógicos ou analógicos para tratar um atuador.

No lado esquerdo da mesma figura tem-se o ambiente computacional de $\mathrm{TI}$, apresentado pelo contexto de middleware utilizado no capítulo anterior. Para a seqüência da analise do que tem em comum entre estes dois ambientes computacionais, será simplificado o ambiente HOST1 até chegar ao ponto deste se equiparar ao ambiente HOST2, deixando em evidência apenas os caminhos de conexão entre os objetos que se interligam por meio da rede de controle conforme apresentado na Figura 27.

Esta visão simplificada, considerando apenas os canais de comunicação, irá se justificar posteriormente, quando serão analisados estes sistemas de comunicação e adequados os seus mecanismos, tomando como base o modelo de referência ODP e o resultado ser aplicado diretamente nos microcontroladores dos dispositivos de automação.
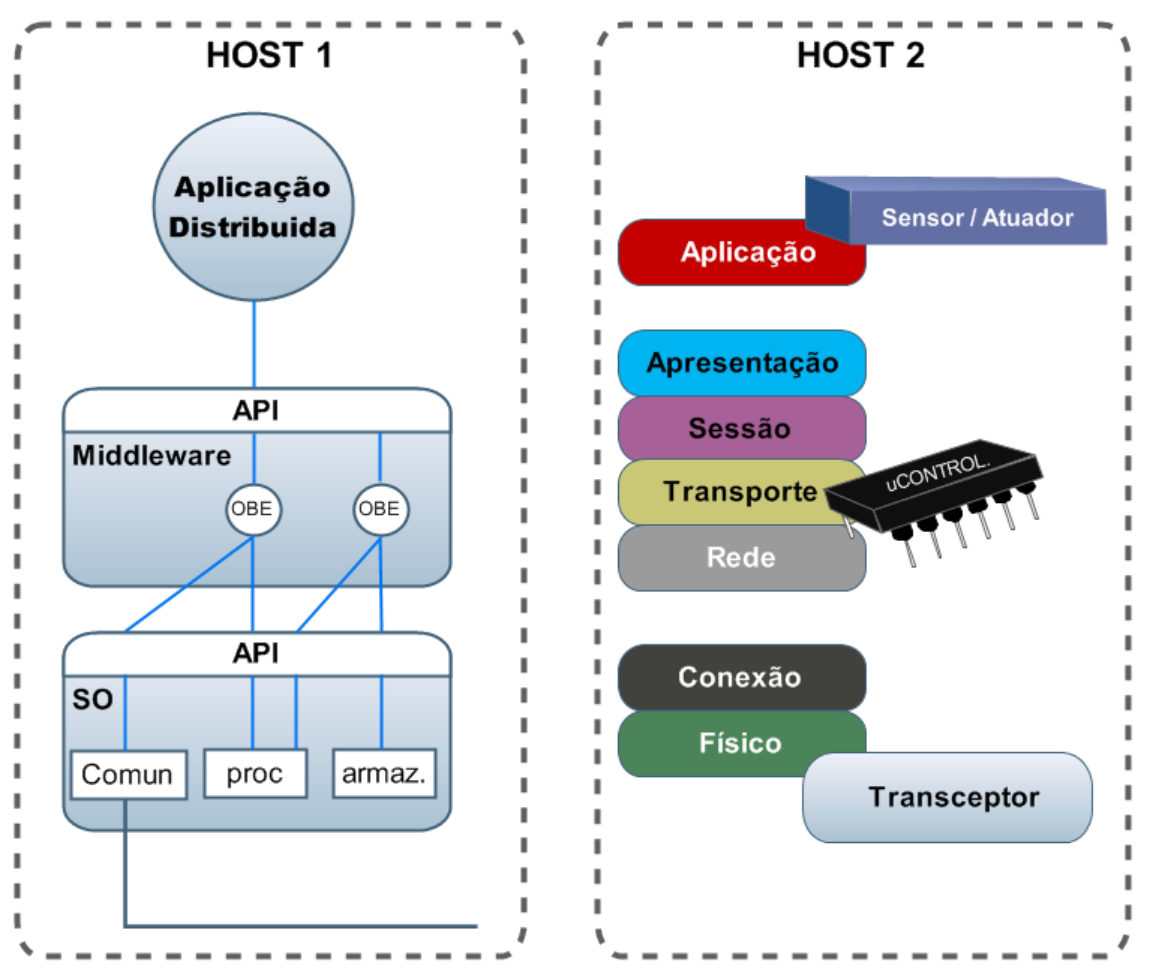

Figura 25: Comparação entre o ambiente computacional de TI e um microcontrolador de TA 


\subsection{A Visão de engenharia do RM-ODP no contexto de middleware}

Considerando uma aplicação distribuída e aberta com arquitetura orientada a objetos, como proposto pela RM-ODP, pode-se observar detalhes no contexto de middleware e na formação dos canais entre os objetos básicos de engenharia (OBE)s, conforme ilustra a Figura 26.

O middleware cria e também destrói, os objetos e canais de comunicação entre os objetos de uma aplicação distribuída. Mas neste trabalho só será considerado a formação dos canais entre os objetos e na recomendação ODP, considerando apenas o canal entre objetos, seria como criar o stub e o bind em um momento e desfazê-los em outro momento, de forma dinâmica e em tempo de execução.

Os canais de comunicação, como descrito na visão de engenharia ODP, estabelecem os mecanismos necessários para que um cliente faça acesso ao, armazenamento, procedimento ou comunicação ao servidor, sendo formado um canal quando se estabelece a conexão entre os objetos, e havendo o transporte de informação entre os dois objetos básicos de engenharia, como sugerido pela recomendação.

Em um computador hospedeiro de uma aplicação distribuída em objetos, existirão vários $\mathrm{OBEs}$ se comunicando por meio da área de memória e dos recursos pertinentes ao ambiente computacional do computador hospedeiro. Portanto, em uma aplicação orientada a objetos distribuídos, tudo se processa e se resolve no próprio ambiente computacional em que a aplicação estiver sendo executada. Desta mesma forma o middleware deverá tratar tabelas locais de memória; contudo, quando são utilizados ambientes computacionais diferentes, ele deve acrescentar o tratamento do protocolo e interceptador que fazem as adaptações adicionais necessárias e mantém a transparência da rede de comunicação. Na Figura 27 são apresentados dois ambientes computacionais ligados por uma rede de controle e sem roteador, gateway ou qualquer outro equipamento interceptador, por não precisar de adaptações quando em uso de uma rede comum aos dois ambientes computacionais. 

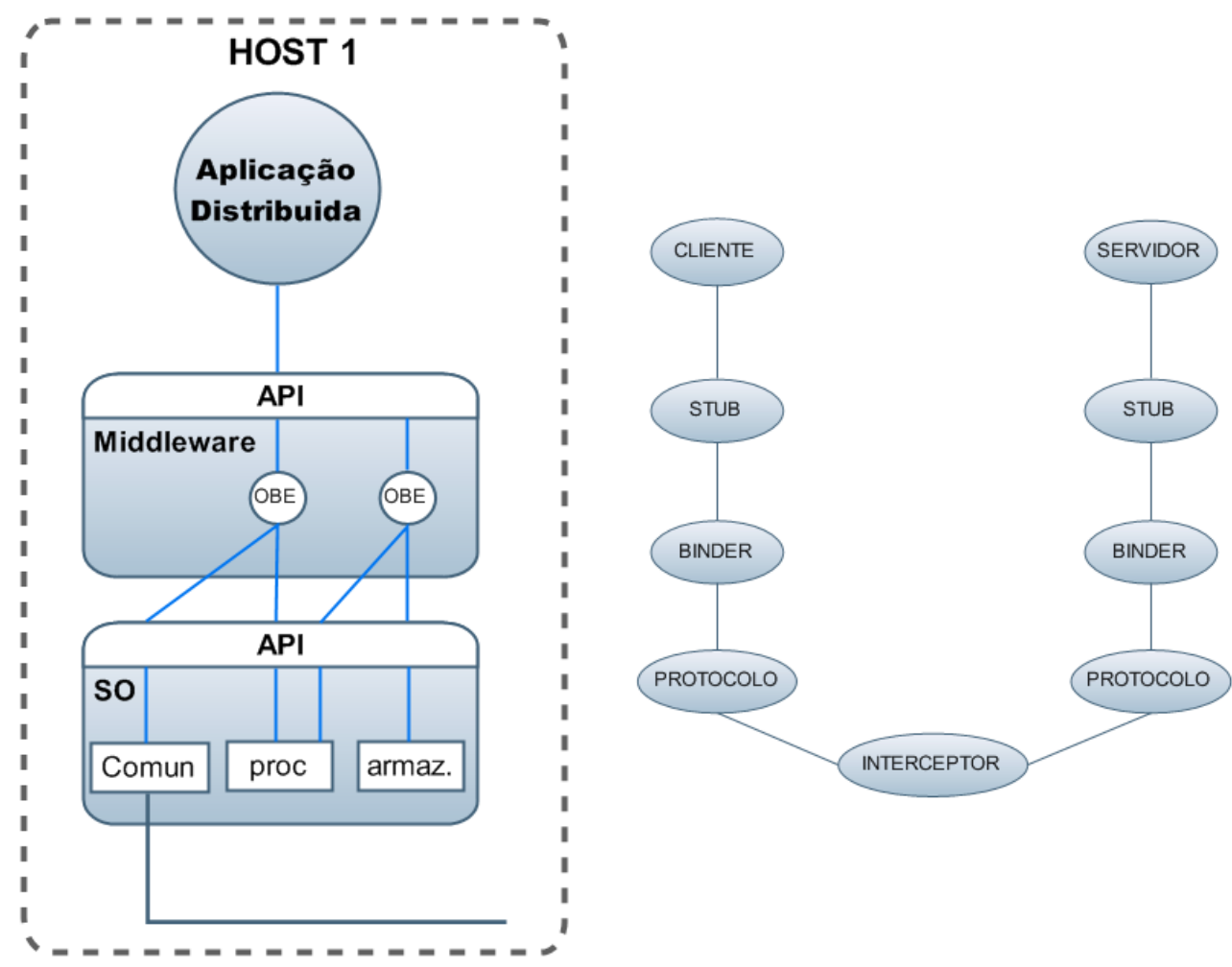

Figura 26: Middleware e Canal do modelo de referência ODP

Neste trabalho explorou-se os objetos de engenharia distribuídos em ambientes computacionais distribuídos, e observou-se apenas os OBEs que estabelecem canal de comunicação por meio da rede de comunicação, como ilustra a Figura 26, que destaca o acréscimo das camadas da recomendação OSI para estudar o processo de comunicação de rede, quando da criação de canal entre OBEs em ambientes diferentes e conectados através da rede de controle comum a eles. 


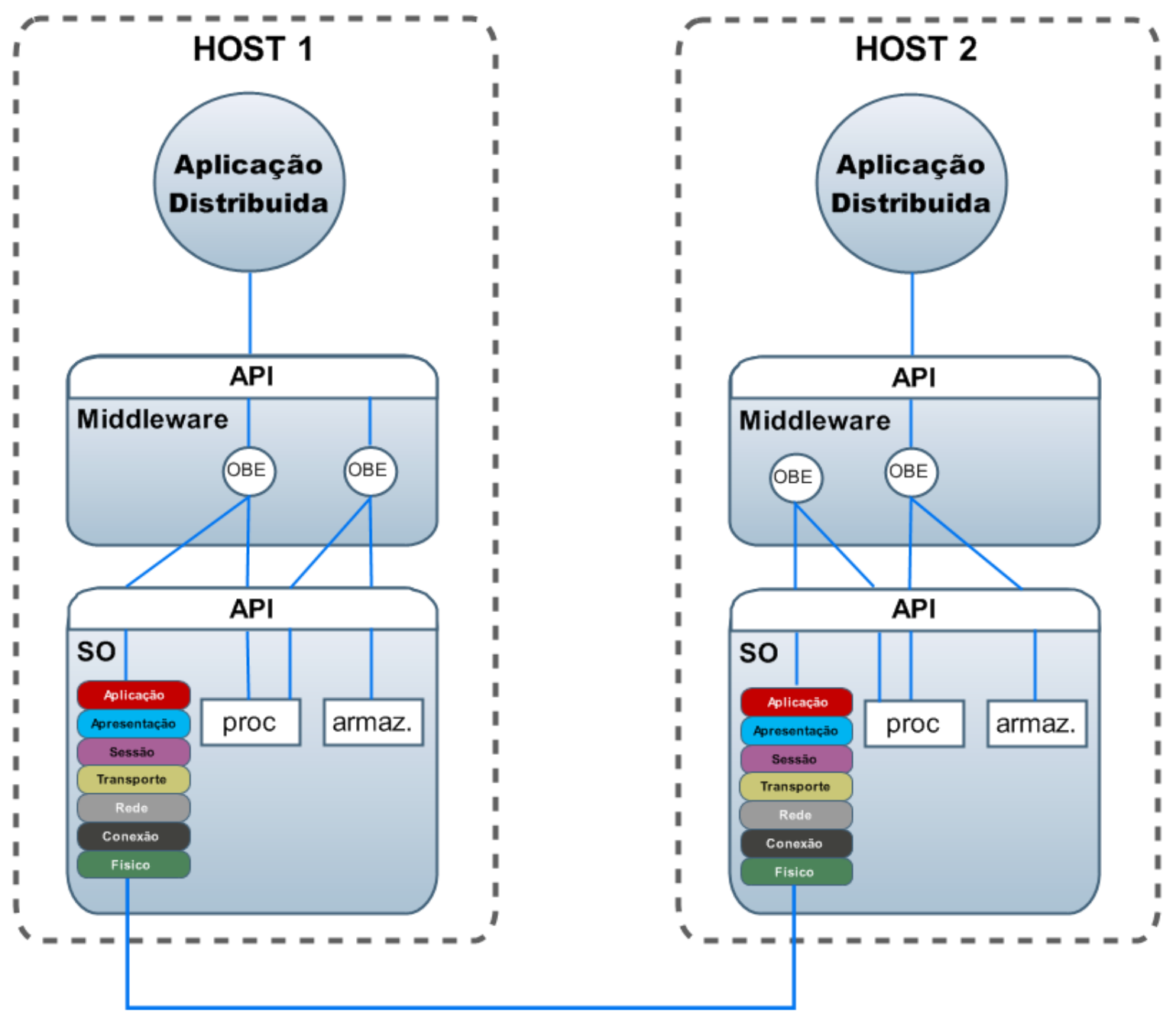

Figura 27: Discretizando as operações dentro do contexto middleware

Assim, tem-se as sete camadas do modelo de referência OSI associado ao SO do computador sendo o acesso aos serviços de comunicação feito através de APIs.

\subsection{Criando os mecanismos ODSIP.}

Para apresentar a proposta de adequação dos dois modelos de referencia, ODP e OSI, e formar com essa adequação um novo modelo que justifique a formação dos canais de comunicação entre OBEs, distribuídos em rede de comunicação, foi desenvolvido primeiro a visão de engenharia ODP e em seguida foi desenvolvida a visão de tecnologia ODP. A primeira visão irá definir a adequação proposta e a segunda irá dar uma idéia de como poderá ser implementada essa adequação em uma tecnologia 
de comunicação.

Para diferenciar esse modelo de referência composto pela aplicação do ODP nas camadas abaixo da camada de aplicação do modelo de referência OSI, será adotada a sigla Open Distributed System Interconnection Processing (ODSIP).

Como o ODSIP irá definir uma forma de endereçamento diferente e promovido através de tabelas internas e gerenciados pela própria rede, neste documento será adotado para indicar o método de "endereçamento interno". Para diferenciar do "endereçamento externo" comum em protocolos de comunicação, que é criado e tratado pela camada de aplicação. Nos protocolos de comunicação é normal ser definido endereço de destino e endereço da origem, além de providenciar todo os mecanismos de respostas e confirmação de envio e recebimento das mensagens.

No caso do ODSIP todo o tratamento de endereços será feito internamente pelo sistema operacional operando em conjunto com as camadas do OSI e tabelas propostas por este modelo proposto neste trabalho.

\subsubsection{Visão da Engenharia ODP na criação do ODSIP}

A Figura 49 ilustra na parte interna como é definido um canal ODP entre OBEs, na parte externa mostra o modelo de recomendação OSI já equiparando as camadas OSI com as camadas do ODP que possibilitam a transparência entre sistemas.

Assim sendo, tomando como base a Figura 49, o stub, que é responsável pela informação transmitida ou recebida na interação entre os objetos implementados na camada da aplicação será tratado na camada de apresentação, por ser a camada mais próximo da camada da aplicação. Para isto defini-se um campo com referência numérica (índice) que deve ser estabelecido sempre que criado uma informação variável (data) em um OBE na camada da aplicação e a camada de apresentação ao transportar a informação variável (data) usa esse campo com a referência numérica (índice) para relacionar a informação a ser transportada ao objeto respectivo da aplicação.

Dessa forma é uma relação direta entre a informação e o objeto que usa a informação pelo campo número de referência (índice) criado pra cada (data) informação do OBE respectivo. Quando um objeto atualiza sua informação na camada de aplicação, a camada de apresentação recebe essa atualização (data) no campo correspondente 
apontado pelo número de referência (índice) e pode repassar a informação para as camadas abaixo. Quando a camada de apresentação tem atualização da informação (data), vinda das camadas abaixo, repassa ao objeto da aplicação correspondente o campo da informação (data) apontado pelo número de referência (índice) correspondente.

Ainda na camada de aplicação, também se justifica criar um campo que registre a direção da informação, que indicará se é uma informação (data) de saída (servidor) ou de entrada (cliente) do objeto básico de engenharia, esse campo de um bit, informa se a informação (data) de rede é entrada IN ou saída OUT .

O binder, responsável por manter a associação entre os objetos dentro do canal, será tratado pela camada sessão por estar logo abaixo da camada apresentação e acima das demais camadas que definem os demais processos do protocolo dos objetos. Deverá ser uma atividade gerenciada através da própria rede e que irá definir uma referência numérica (seletor) para referenciar a informação (data) que será transportada pelo protocolo dos objetos.

Sendo que esta referência numérica (seletor) deverá ser única e exclusiva para identificar apenas um canal em toda a rede ou no mínimo ser sempre diferente para todos os canais de um mesmo nó endereçado contendo vários OBEs.

Isso implica em estabelecer um método de endereçamento de nós que os identifiquem na rede de forma exclusiva e que depois desse endereçamento se estabeleça o seletor correspondente as ligações entre OBEs distribuídos nestes nós em rede.

Esse mecanismo deverá ser implementado por mensagens específicas de gerenciamento de rede, que devem identificar o endereço dos nós de origem e destino da informação e com isso criar a conexão entre os canais, definindo o seletor para cada canal de transferência de dados entre OBEs e executar junto ao sistema operacional ou firmware de um dispositivo nó os tratamento dos campos sugeridos que implicam em construir e dar manutenção em tabelas em memória local de cada nó. 


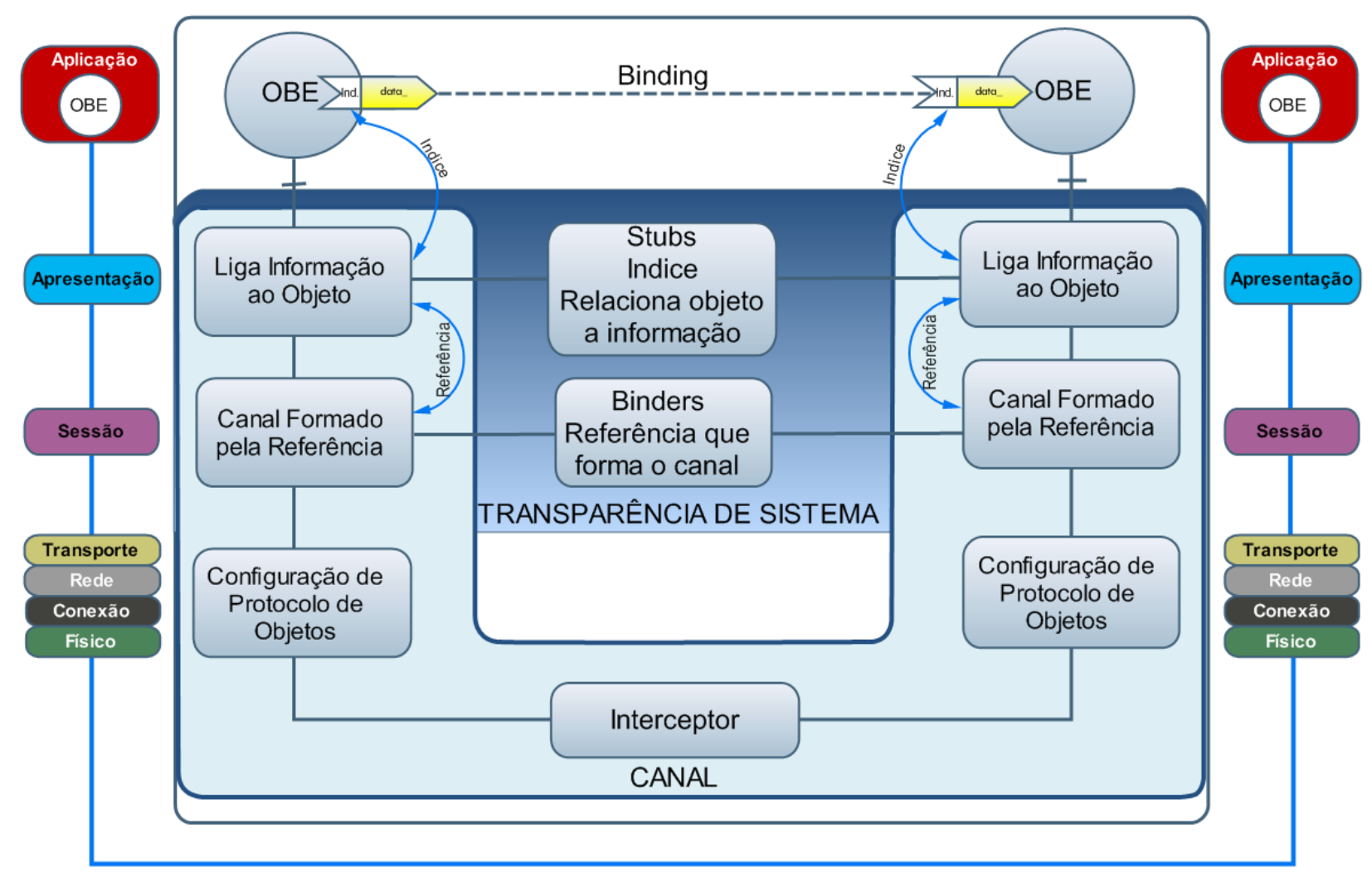

Figura 28: Modelar a recomendação ODP as camadas OSI

\subsubsection{Visão da Tecnologia ODP na implementação do ODSIP}

A Figura 29 apresenta a visão da tecnologia, mostrando como pode ser implementado os mecanismos ODSIP proposto no item anterior. Nesta figura está apresentado duas tabelas para cada nó. Sendo que a estrutura das tabelas são as mesmas para cada nó. Uma tabela intitulada como "tabela de configuração de Variáveis" e uma outra tabela intitulada de "tabela de endereços".

Poderia ser implementado outra tabela para definir domínios diferentes, e nesse caso teria um conjunto de tabelas, para configurar variáveis e para endereços, para cada entrada de domínio diferente que fosse definido. Outra tabela que poderia ser acrescentada e dimensionada também seria a tabela com os endereços de memória que apontam para o início do campo da informação (date) para cada (índice) correspondente.

Neste trabalho só foi apresentada as duas tabelas principais para que seja entendido as possibilidades multiplas que podem ser implementadas na tecnologia para atender ao que foi solicitado na modelagem ODSIP.. 
$\mathrm{Na}$ tabela de configuração de variáveis os campos importantes para a implementação do ODSIP são: campo do valor numérico INDICE, SELETOR, DIR e ENDEINDX. Sendo que o INDICE será definido quando da compilação da aplicação e a camada de apresentação quando tem uma informação (date) na rede repassa para a aplicação nos endereços de memória correspondentes a este índice. Embora a informação (date) seja a mesma para nós diferentes podem estar em índices diferentes para cada OBE.Nesta Figura, o índice está assinalado pela cor azul, na coluna index da tabela de configuração de variável.

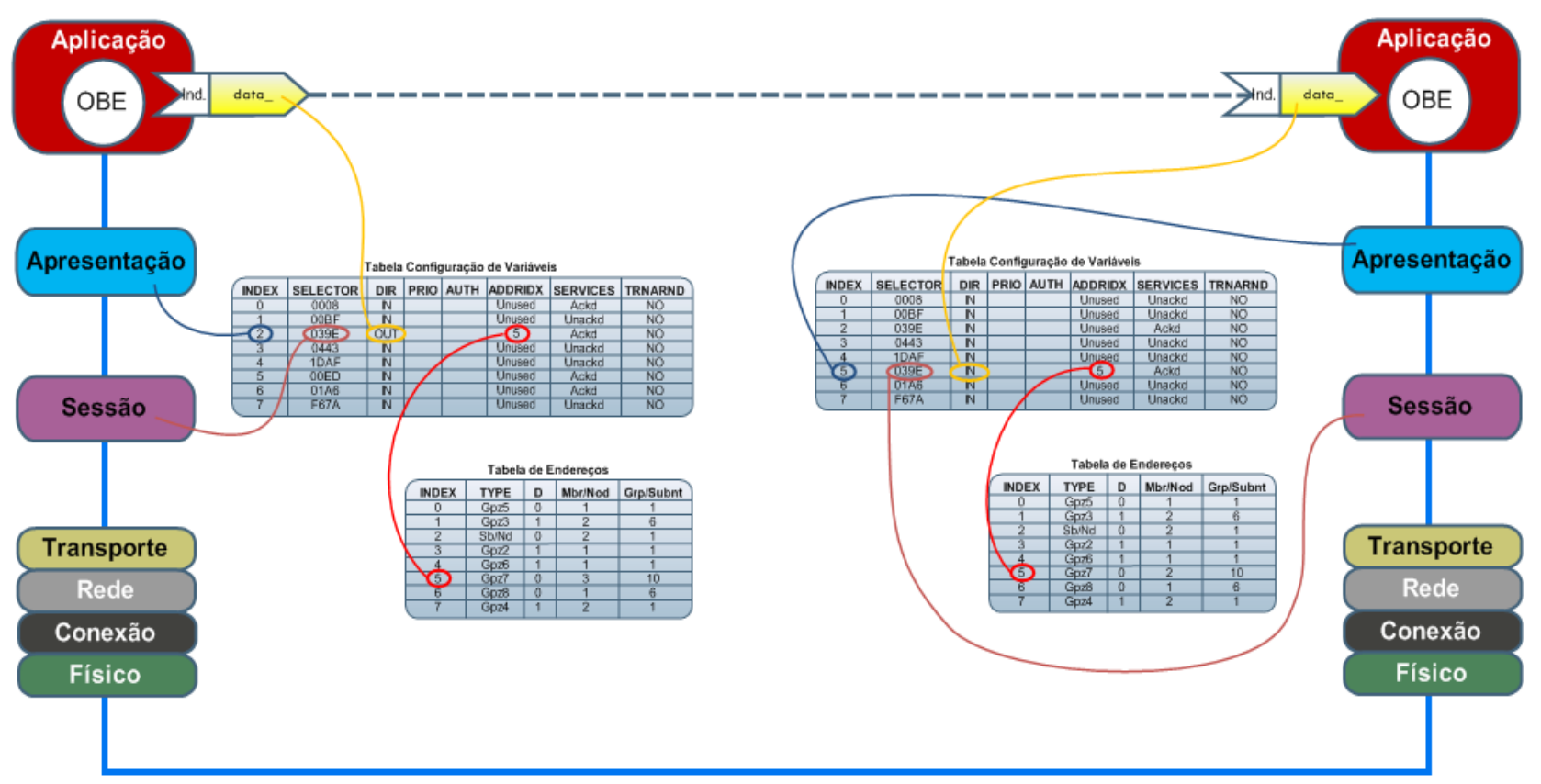

Figura 29: Visão de Engenharia da implementação proposta

Na Figura 29 está assinalado pela cor amarela, na coluna DIR (direção) na tabela de configuração de variável. Esse campo é importante para quando for feito o trabalho de ligação entre os OBEs verifica neste campo quem manda a informação e quem recebe para poder alimentar as tabelas de endereços de forma conveniente. Por exemplo se o endereçamento for grupo, ou subnete/nó, ou outros.

Na Figura 29 está assinalado pela cor violeta, na coluna seletor da "tabela de configuração" de variável em relação ao índice da "tabela de endereços". Em cor vermelha esta apresentada a ligação entre a "tabela de configuração" da variável com a "tabela de endereço" do destino da mensagem. Assim com esse mecanismo fica estabelecido todas as relações entre os OBEs e conclui o canal.

Assim, quando um frame de mensagem na rede chega na sessão, ela relaciona e identifica a "referência" seletor com o "índice" da informação e repassa para a 
camada apresentação no índice correspondente, e a camada de apresentação repassa para a camada da aplicação. No sentido inverso a aplicação repassa para a apresentação a informação com o "índice" correspondente, assim a apresentação repassa a "referência" com o (seletor) correspondente para o transporte e assim chega na rede o frame correto que é encaminhado para o endereço do nó correspondente.

O protocolo da recomendação ODP, responsável pela manutenção da comunicação, é o próprio protocolo da rede de controle. O interceptador será o gateway ou roteador, para o caso de adequações adicionais em função de mudança de rede, meio físico, ou de tecnologia. Portanto, no caso mais simples, não há necessidade, destes dois últimos detalhes da recomendação, pois tudo é tratado como rede de controle única.

Assim, adequando o contexto de middleware, levando em consideração a recomendação RM-ODP estabelecida dentro da recomendação OSI, pode ser apresentado no ambiente computacional distribuído, como ilustra a Figura 30.

A camada da aplicação, da recomendação OSI, assume os OBEs da camada do middleware junto com as tabelas alimentadas pelas camadas, apresentação e sessão, como ilustra a Figura 30. Isso porque essas duas camadas irão realizar os mecanismos de conexão entre os OBEs, que são tratamento de tabelas, como visto, além das atividades pertinentes da recomendação OSI.

As camadas do modelo de referência OSI, são estabelecidas para que um sistema de comunicação possa ser separado, em suas atividades principais; todavia, pode-se acrescentar, outras atribuições além das atividades principais recomendadas, que se façam necessárias para o desenvolvimento da solução pretendida.

Portanto serão atribuídas mais atividades nas duas camadas, 5 e 6 , e as quatro camadas abaixo, da sessão, são preservadas e consideradas sem alteração à recomendação, e permanecem sendo executadas pelo SO do ambiente computacional. O tratamento conjunto dessas camadas e os campos e tabelas deverão ser implementados junto ao sistema operacional ou firmaware de microprocessadores. 


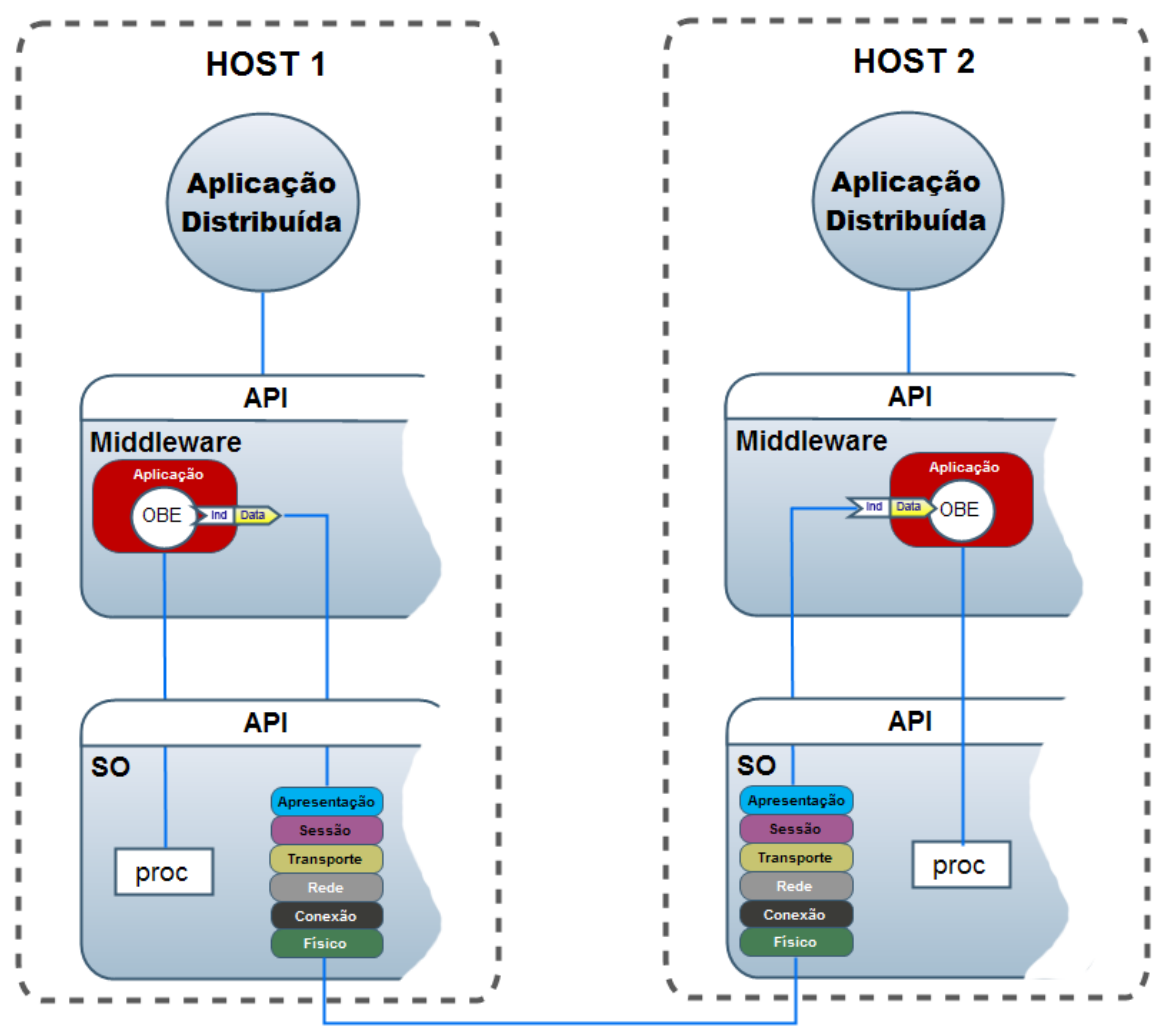

Figura 30: Contexto de middleware incorporado com o modelo OSI e ODP apenas no canal de comunicação pela rede

No ambiente computacional de $\mathrm{Tl}$, deve-se manter a idéia de acessos pelo intermédio de APIs. No caso, a API do SO acessa as 4 ou 6 camadas inferiores do modelo de referência OSI, e a API do middleware acessa a aplicação que são OBEs ao mesmo tempo que acessa as tabelas de configuração de variáveis e de endereços da rede. Isso é resolvido na implementação do driver e a respectiva API para o tratamento adequado de uma Network Interface Card (NIC) específica para essa rede de controle.

Por outro lado, como o ambiente computacional em um microcontrolador é reduzido, o acesso aos seus recursos de processamento, memória e dispositivos de entradas e saídas é feito de forma direta, sem o uso de APIs. Os programas que executam a aplicação em microcontrolador, também tratam da configuração dos registros iniciais e definem os parâmetros iniciais dos dispositivos que controlam a aplicação. Normalmente o fabricante de um microcontrolador deixa disponível toda a documentação necessária para o entendimento das funções e como deve ser feito o acesso direto à biblioteca quando presente.

Para representar o mesmo contexto de middleware, mas aplicado em ambientes computacionais diferentes, como o computador de $\mathrm{TI}$ e microcontroladores de 
TA, pode ser considerado como exemplo, a Figura 31. Nesta figura nota-se a perfeita harmonia dos dispositivos desenvolvido com base no modelo ODSIP. Nesta Figura está representado três implementações de dois OBEs em cada microcontrolador, representando cada um um microcontrolador com atividade(s) diferente(s), como se fossem diferentes dispositivos, que estariam compondo uma aplicação distribuída.

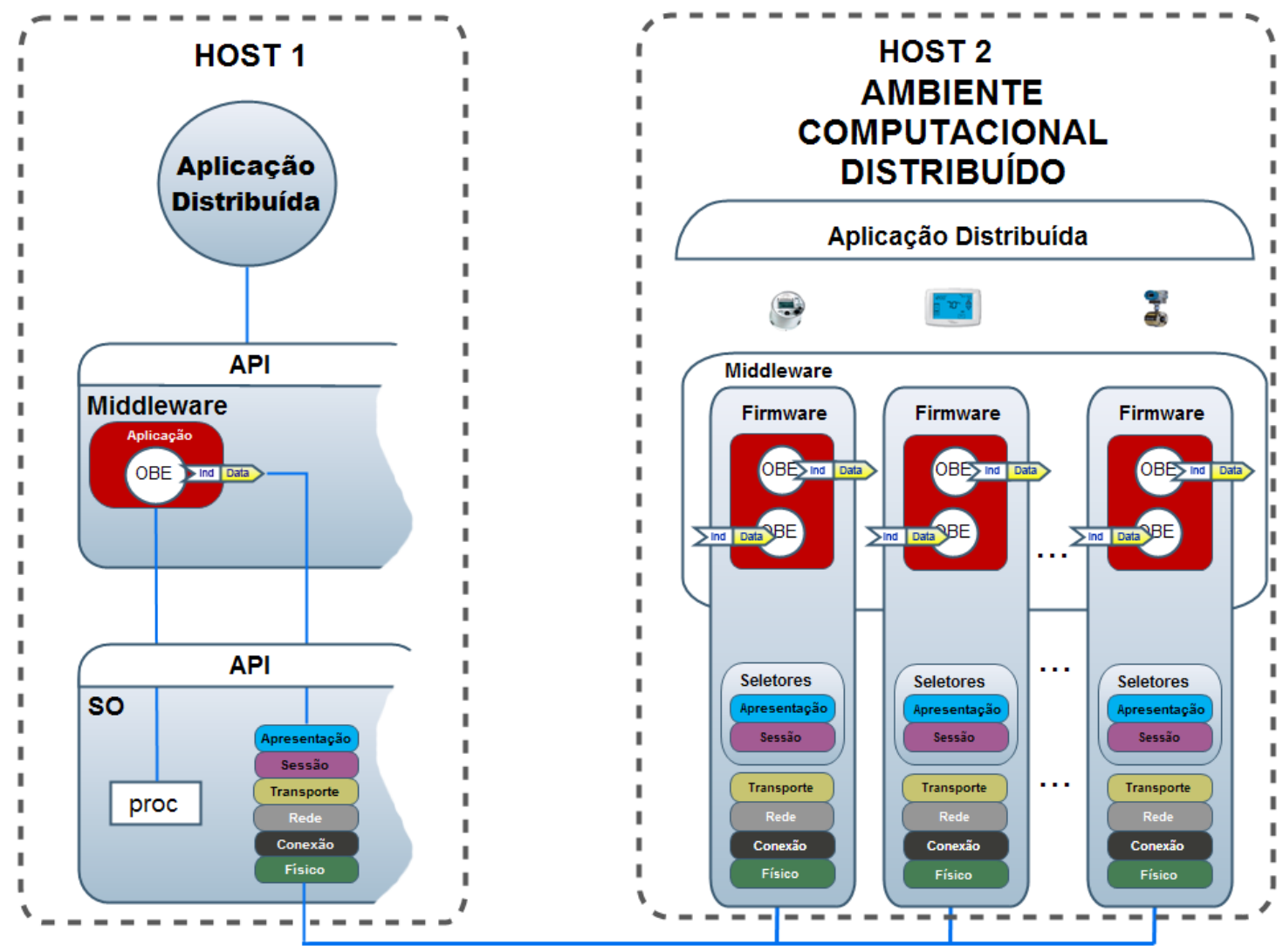

Figura 31: O contexto de middleware aplicando ODSIP

O ambiente computacional do Host1 é de TI, e o ambiente computacional distribuído do Host2 é de TA. Portanto, no ambiente de TA esta demarcado o middleware ODSIP contendo os OBEs dos microcontroladores presentes para executarem em seu conjunto uma aplicação distribuída, mantendo o contexto de middleware entre os ambientes de TI e TA.

Essa abstração do contexto de middleware é importante para se perceber que o middleware de TI não vai ser o mesmo para TA, pois não vai ficar no meio, e sim fora envolvendo os objetos, mantendo a idéia abstrata de controle do que pode ser criado de objetos e ligar ou desligar, cada um dos canais possíveis de serem criados ou combinados para uma aplicação.

Constatando-se esta diferença entre TI e TA pode-se inferir que os 
ambientes de automação com essa coerência podem conter objetos dos mais variados tipos de serviços em uma rede de controle e o conjunto formado pelos relacionamentos entre os objetos é que irão executar uma aplicação.

Esta aplicação do ODSIP em microcontroladores com estes mecanismos implementados no protocolo de comunicação irá facultar aplicações abertas em automação totalmente distribuídas em objetos. O hardware de um dispositivo de automação além da atividade prevista pelo seu fabricante, também poderá hospedar outros objetos para serem associado aos outros objetos de forma dinâmica e assim trocará os aspectos de controle mediante determinadas combinações, em função do contexto, por exemplo, em função da presença de um usuário.

Assim qualquer microcontrolador na rede será tratado e desenvolvido de forma independente e o conjunto é que será o resultado da aplicação como um todo. Conforme será abordado, considera-se que um microcontrolador pode ter um ou mais objetos. Estes podem estar implementados em uma aplicação simples, composta apenas por um objeto ou complexa e ter vários objetos que se completam integralmente, dentro do mesmo ambiente microprocessado, ou que se compõem com vários outros objetos nas aplicações distribuídas na rede de controle, como ilustra a Figura 32.

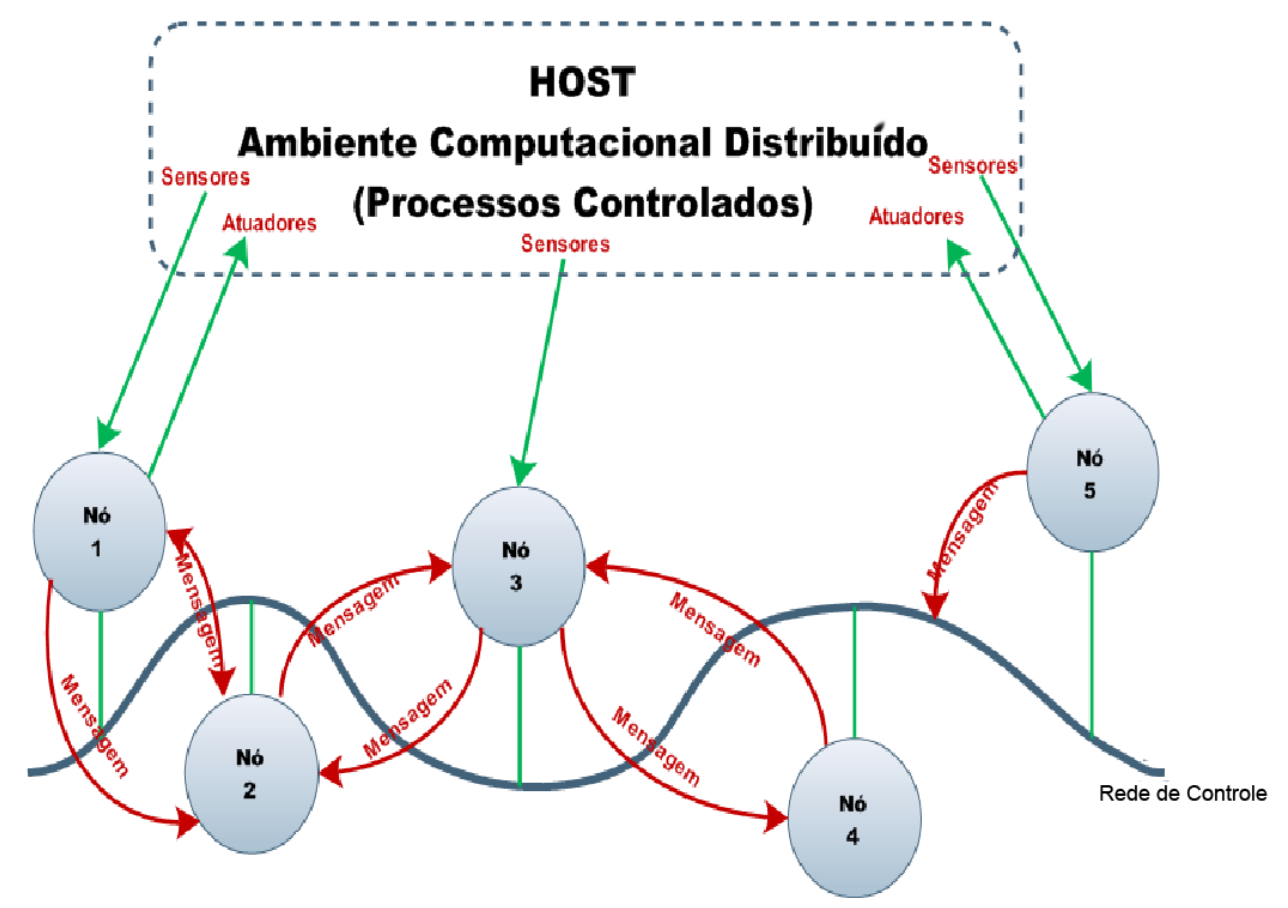

Figura 32: Produtos de Automação com Objetos instanciados e interligados em tempo de execução 


\subsection{Visão da Computação ODP em projetos de automação.}

Como conseqüência natural do mecanismo ODSIP tem-se o fato de se poder utilizar as demais visões da recomendação ODP para o desenvolvimento de soluções em sistemas abertos de automação.

$\mathrm{Na}$ visão da computação, por exemplo, o objeto básico de engenharia pode ser representado por seta, com a direção estabelecendo se é cliente ou servidor. Se estabelecido um retângulo para um objeto ou vários objetos combinados para desenvolvimento de um produto ou solução de engenharia, as setas dos objetos estabelecidas dentro deste retângulo, na direita o que é servidor, e na esquerda o que é cliente. Pode-se representar um projeto de automação totalmente desenvolvido apenas observando e ajustando este representativo das interfaces dos objetos básicos de engenharia, dos dispositivos ou da aplicação, como apresentado na Figura 33.

Isso irá facilitar e agilizar o desenvolvimento da aplicação, pois pode ser desenvolvido em tudo, sem a necessidade de se estabelecer onde será instanciado tais objetos. Apenas ao final do projeto se estabelece onde serão instanciados os respectivos objetos com toda a aplicação distribuída concluída e até testada.

Com o mecanismo ODSIP fica claro que a interface faculta um grau de transparência de todo o mecanismo e também simplifica o desenvolvimento do software a ser implementado no objeto, como apresentado na Figura 33.

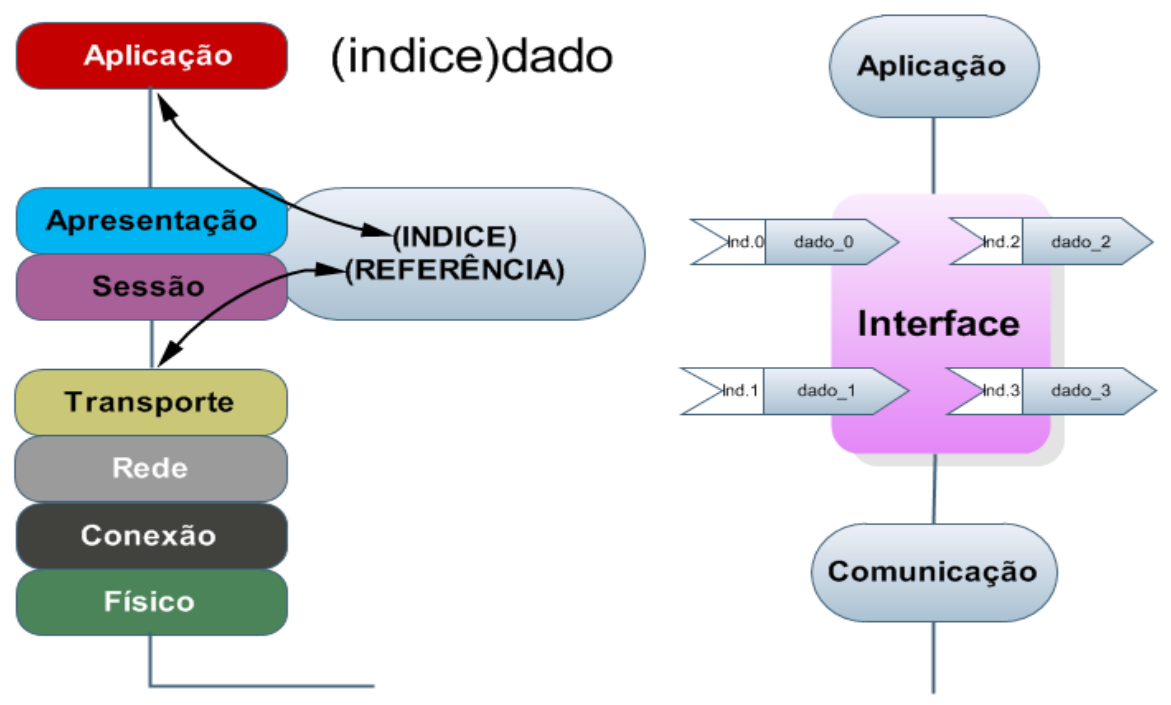

Figura 33: Mecanismo ODSIP esclarece a operação do objeto apenas pela representação gráfica da sua interface 
Como o canal é estabelecido também com a direção da informação, identifica se entrada (cliente) ou saída (servidor) na comunicação, tem-se assim, na interface do objeto, uma seta apontando se é uma variável de saída ou uma variável de entrada. Desta forma para cada uma delas será criado um índice (liga a variável à aplicação) e uma referência de rede (liga um objeto ao outro objeto). Sendo a direção da seta, a indicação de quem é o cliente(s) e quem é o servidor(es) em cada canal formado. Na Figura 33, à direita, é mostrada uma interface de um objeto ou quatro objetos num cluster e pode ser identificado como o perfil funcional do conjunto.
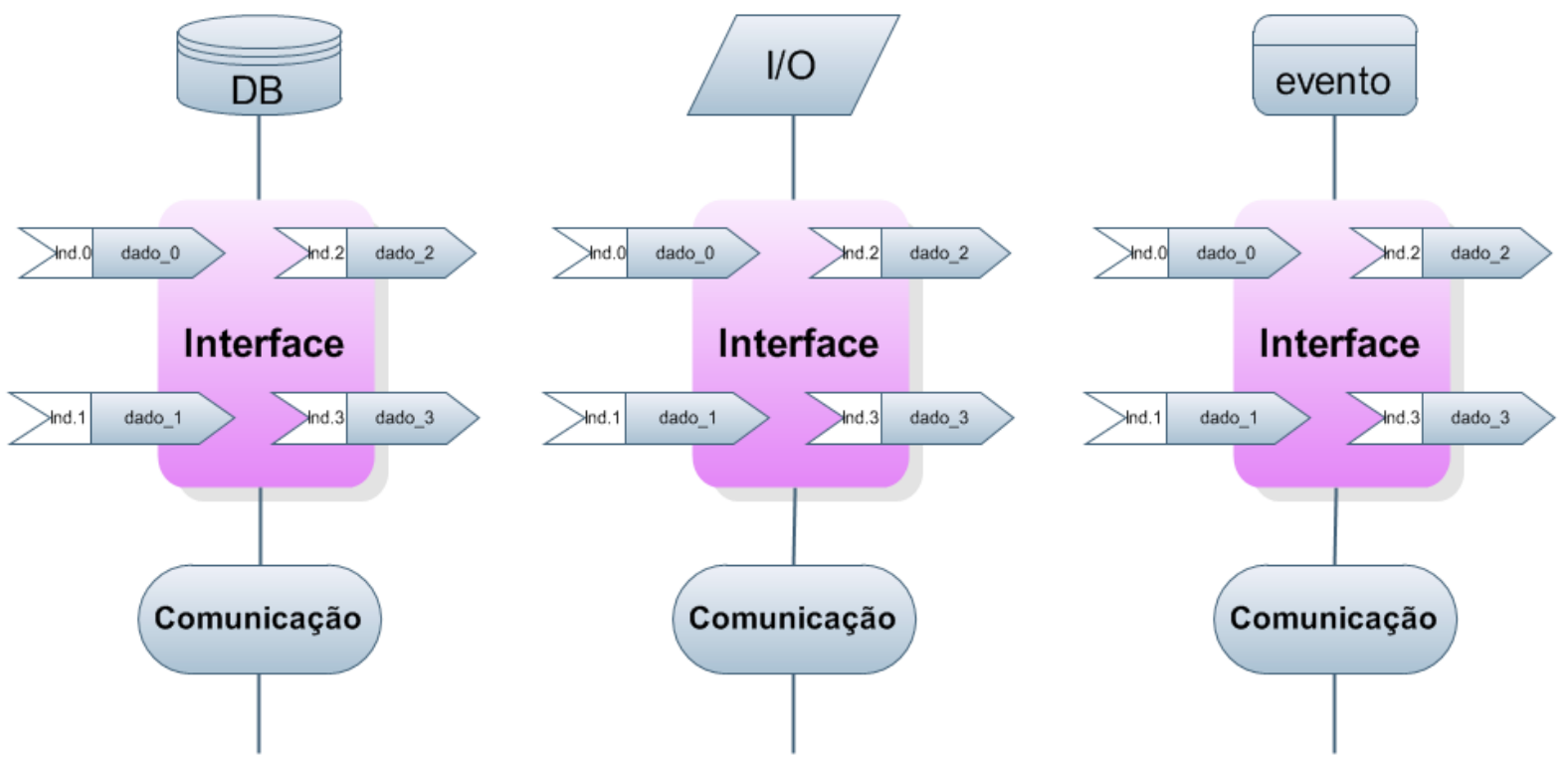

Figura 34: Objetos ou aplicações representadas pela sua interface

Desta forma, o ambiente computacional proposto para uma automação deverá ser formado por objetos, como ilustrado na Figura 34. Sendo possível representar qualquer objeto, ou ambiente computacional de uma aplicação, apresentando apenas as interface. Em uma aplicação de automação, haverá muitos objetos básicos de engenharia, que estarão instanciados em vários produtos, dentro do(s) ambiente(s) computacional(is) da automação. Assim, essa representação funcional dos objetos pelas suas correspondentes interfaces irá facilitar desenvolver e imaginar as necessidade e finalidades do middleware ODSIP para definir a aplicação distribuída da automação.

Sendo assim, pode-se considerar que qualquer tipo de objeto será possível de ser projetado com base nesse modelo. Isso significa que pode-se ter a representação de objetos com várias setas de entrada e saída ou apenas uma seta de entrada ou saída. Isso dependerá da complexidade de cada objeto instanciado no 
microcontrolador.

Partindo das considerações e modelos apresentados, pode-se revisar os ambientes de automação e sua rede de controle e passar a considerá-los como sendo um ambiente único computacional, no qual cada microcontrolador na planta poderá implementar uma aplicação completa, ou apenas instanciar objeto(s), e que eles poderão ser interligados entre si de forma dinâmica, por meio da rede de controle, com aplicativos fazendo o contexto de middleware ODSIP, como o exemplo ilustrado da Figura 35.

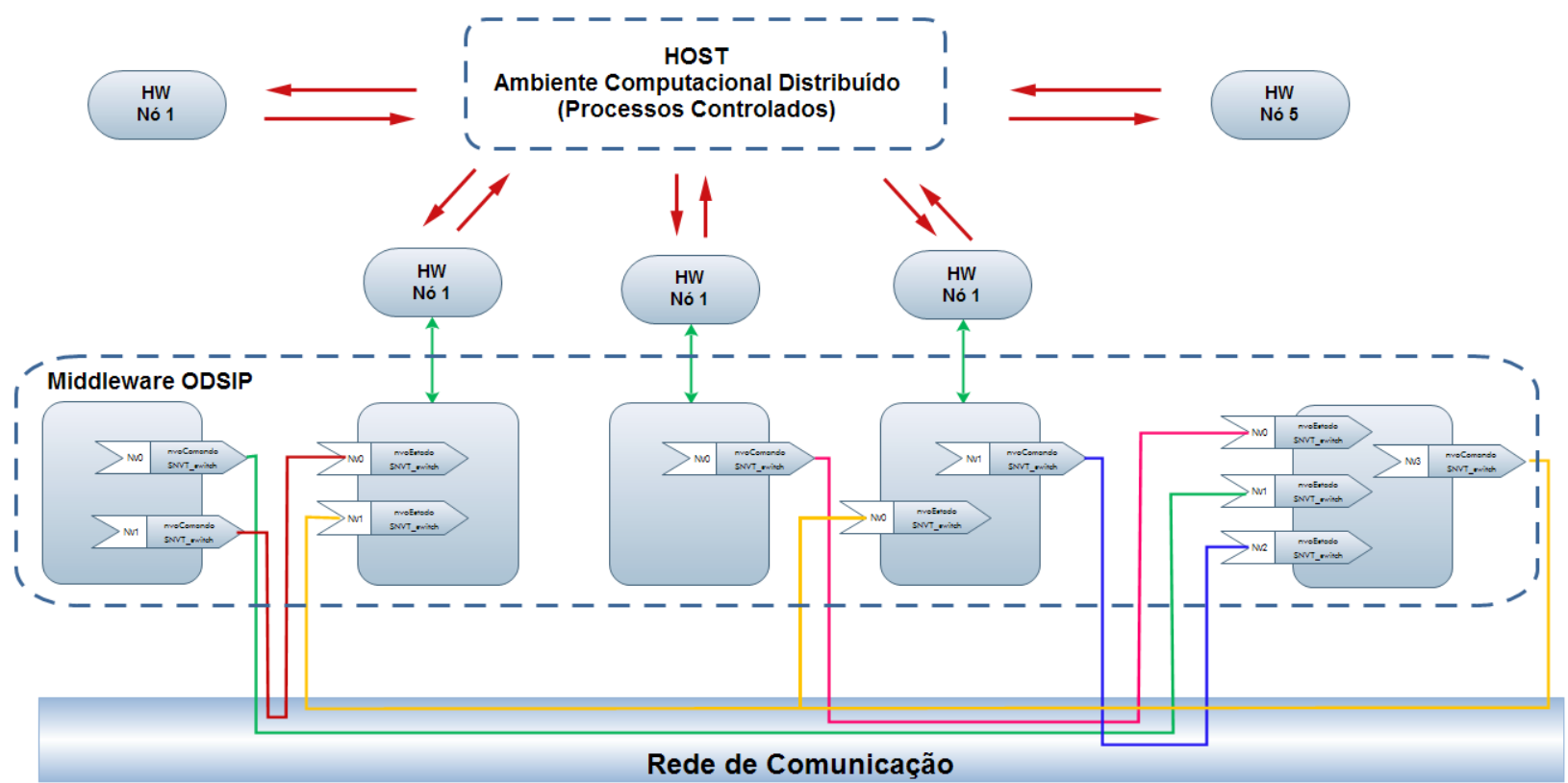

Figura 35: Visão da computação de um sistema de automação

\subsection{Como representar o contexto do middleware ODSIP de automação.}

O contexto de middleware estabelece um sistema operacional, uma camada middleware e sobre essa camada uma outra camada da aplicação, como foi ilustrado na Figura 20, quando se analisa sob a óptica de $\mathrm{TI}$, mas necessita de ajustes na tentativa de definir o contexto middleware ODSIP de automação, pois um produto ou pequena aplicação implementada em microcontroladores são transformados em apenas 
objetos isolados, como ilustrado na Figura 36 ou Figura 37, e não incluem o middleware ODSIP neles, mas fora deles.

Nestas Figuras está demarcada a camada (seletor) sobre a rede de controle e esta camada esta envolvida pelo firmware, e sob o software da aplicação (objetos) com acesso direto ao hardware. O seletor é tratado pelo firmware, assim como as seis camadas inferiores do modelo de referencia OSI. A camada 7, que é aplicação, compõe os objetos envoltos de todo o firmware, que além de tratar as camadas que tratam o (seletor), também executa as operações diretas de entradas e saídas disponíveis no hardware do microcontrolador.

O contexto de middleware ODSIP de automação, com mecanismos de tratamento do seletor é um contexto claro na sua atividade e ação, mas não esta no meio, e sim na planta automatizada de forma abstrata, envolvendo os objetos e seus seletores disponíveis para este componente ou componentes abstratos, para criarem e desfazerem objetos e os canais de comunicação entre estes objetos de tal forma a prover e configurar uma aplicação a partir dos objetos que estarão disponíveis. Todo o gerenciamento do seletor será executado por meio da rede de controle. Assim, ele pode estar no computador da rede ou ser objetos instanciados nos produtos da rede com o modelo de negócio que estabelece os critérios da aplicação.

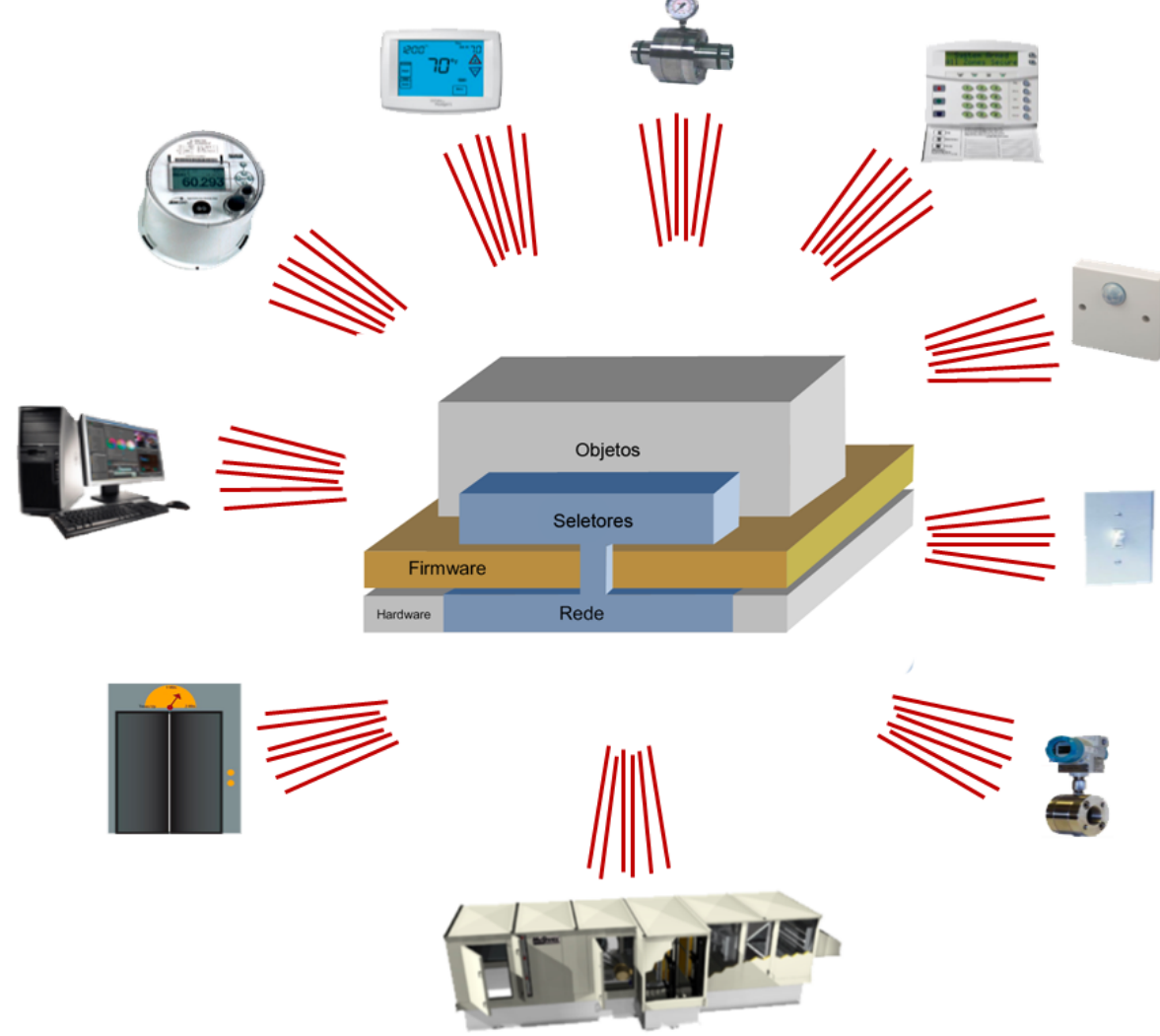

Figura 36: Visão do seletor na área de automação 
Como foi visto no Capítulo 3, o "middleware é o que torna uma aplicação distribuída programável". Isso porque tanto no próprio ambiente computacional quanto fora deste, o middleware ODSIP estabelece o relacionamento e conexão, além de criar os objetos de engenharia distribuídos, seja na aplicação local ou distribuída em outros ambientes computacionais, a exemplo do CORBA, que é middleware, cria e instancia os objetos no mesmo ambiente ou em outro ambiente de forma distribuída Ele mantém a completa transparência de todos os mecanismos de conexão e comunicação entre os objetos de uma aplicação.

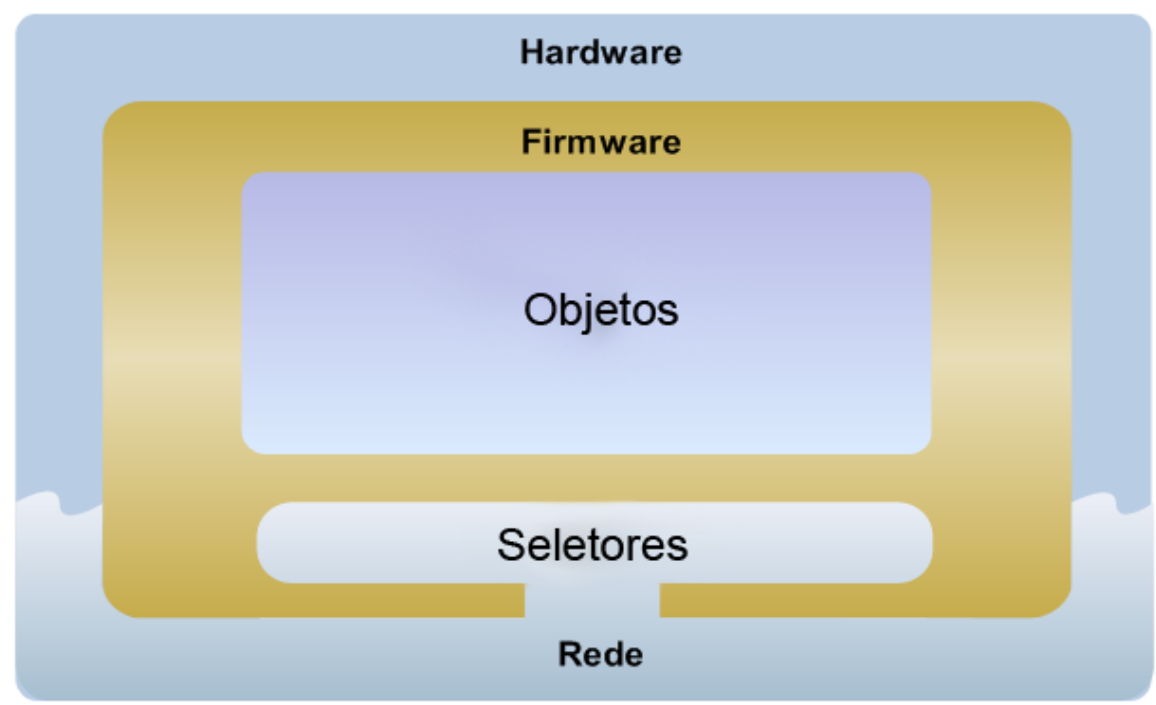

Figura 37: A camada seletor em um microcontrolador

Uma representação do contexto de middleware ODSIP esta na Figura 38 e mostra, na área central, o middleware e ao seu redor os nós com os seletores envoltos na rede de controle. 


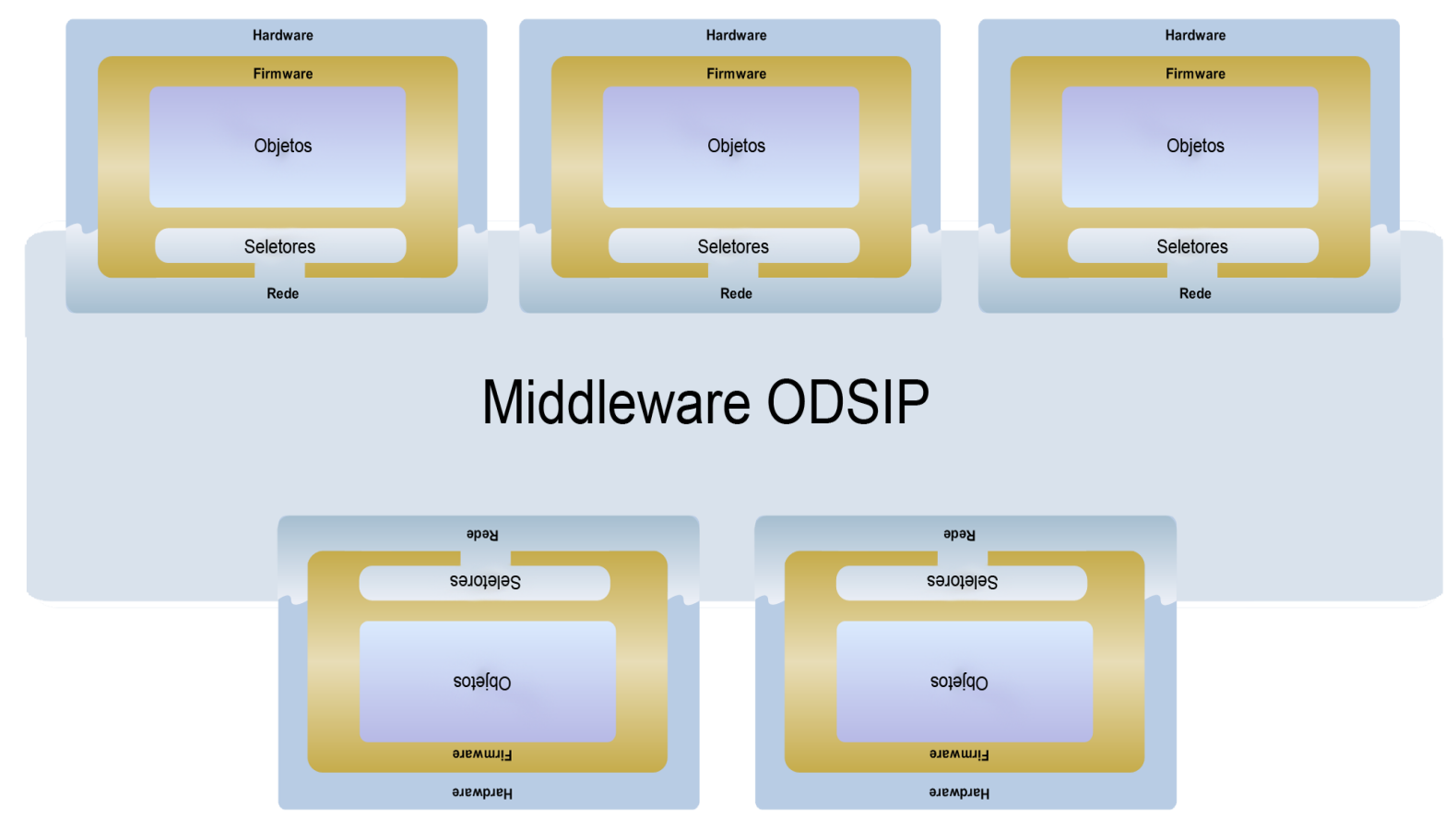

Figura 38: O contexto do middleware ODSIP em Automação

Pode-se destacar que o ODSIP elimina a necessidade de conhecer os endereços de destino no momento em que se cria uma aplicação distribuída, pois este mecanismo elimina a necessidade de definir o endereço de destino para as mensagens quando se desenvolve a aplicação, e cria outro mecanismo (seletor) que atribui o(s) endereço(s) de destino da mensagem no momento que for realizar uma aplicação. Como ele abstrai a necessidade de endereçamento, faculta a possibilidade do desenvolvimento de aplicações com arquitetura orientada a objetos em projetos de automação. Em contrapartida, determina a necessidade do middleware ODSIP, a parte ou contido na planta como objeto(s), para estabelecer o relacionamento entre os objetos e compor a aplicação. Esse software middleware ODSIP pode ser desligado da planta se o relacionamento entre seus objetos, for estático, depois de estabelecido uma primeira vez, a aplicação não se altera. Mas deverá ser ligado novamente na planta quando da necessidade de fazer manutenção dessa aplicação, para alterar procedimentos, adicionar ou eliminar componentes.

Como a proposta deste trabalho está diretamente vinculada à realização de plantas de automação que interagem à mudanças do contexto, criando ambiente computacional pervasivo que permite que interfaces próximas de um usuário seja utilizada por qualquer sistema, deverá ser utilizado middleware ODSIP permanente na planta automatizada, pois ele deverá alterar o relacionamento entre os objetos e o comportamento da planta, por conseqüência disso. 
O ambiente computacional desenvolvido com ODSIP tem o limite estabelecido pela da capacidade de endereçamento de todos os nós da planta deverá ser compreendido como sendo um grande computador operando com processamento concorrente e paralelo, com um clusters de processadores.

No Capítulo seguinte será apresentada a tecnologia LonWorks $®$, identificando-se nela a implementação do ODSIP nativo e criado desde 1989, mas que até o momento, LonWorks $®$ é utilizada como uma tecnologia que trouxe interoperabilidade entre produtos de diferentes fabricantes, por apresentar o perfil funcional destes produtos e utilizar as ferramentas LonMaker ${ }^{\mathrm{TM}}$ ou NL220, para criar uma aplicação ligando as variáveis de rede do perfil funcional de um produto ao outro para criar a aplicação do cliente, o que em função da abordagem nova deste trabalho o identifica como sendo aplicativo middleware ODSIP de operação manual.

\subsection{O que muda com aplicações middleware ODSIP.}

Por meio dos modelos apresentados até estão, pode-se caracterizar um sistema automatizado de uma forma diferente e competente para atender aos novos requisitos da computação pervasiva, pois qualquer objeto de automação poderá estar instanciado em um microcontrolador, ou microcomputador e ser ligado ao outro objeto presente em outro microcontrolador ou computador ligado por meio da rede de controle. É natural que quando o objeto estiver nele mesmo terá outras ferramentas de chamada de métodos ou bind tournaround.

As redes de controle tem expandido sua abrangência em muitas áreas, e com o que se está propondo neste trabalho, tem-se outras atribuições para a rede de controle, que deve-se utilizar com esse novo paradigma criado, pois elas serão responsáveis diretas, pela eficiência do relacionamento das informações em um ambiente distribuído, e mantendo o nível de transparência adequado.

A tecnologia da automação poderá evoluir para soluções mais audaciosas de modelagem, como foi visto, nas soluções adotadas e praticadas na tecnologia da informação com a especificação de arquitetura CORBA, e certamente será possível, a partir deste trabalho, iniciar uma nova etapa no desenvolvimento de sistemas de automação para atender aos requisitos de computação pervasiva. 
Tudo que foi apresentado poderá ser desenvolvido para criar conexões, entre objetos das aplicações distribuídas, com orientação ao contexto e caminhar e acompanhar os usuários, levando seus banco de dados e configurações, nos vários equipamentos distribuídos em todo o edifício.

Além disso, poderiam ser estudados e aplicados novos métodos de gerenciamento e relacionamento entre os dispositivos, permitindo conexões voláteis e automatizadas. Nesse ponto, podem ser abordados diversos tipos diferentes de arquiteturas como: centralizadas, nas quais há um concentrador de informações que gerencia todos os dispositivos da rede; parcialmente centralizados, nas quais há a divisão de subconjuntos da rede como um todo, que são gerenciados por dispositivos responsáveis cada qual pelo subconjunto que the cabe; e totalmente distribuídos, nos quais o gerenciamento é realizado par a par mediante a necessidade de conexão.

Com base nesse tema dentro do contexto desta pesquisa, Cunha (2008) desenvolveu a sua dissertação de mestrado na qual foi analisada a possibilidade da aplicação de outro conceito de TI na área de TA, o conceito de sistemas multi-agentes, para a realização da conexão automatizada entre esses dispositivos sem a necessidade de um dispositivo ou programa centralizador responsável por realizar esse processo.

Nesse trabalho é apresentada a semelhança entre um sistema multiagente na área de $\mathrm{Tl}$ com os sistemas de automação distribuídos em rede e com a tecnologia LonWorks ${ }^{\circledR}$. E a partir dessas semelhanças, é proposta uma implementação de agentes nos dispositivos de automação, levando-se em conta todos os conceitos empregados nos agentes de software.

Também são analisadas as duas diferentes classes de agentes de software, agentes cognitivos e agentes reativos, verificando-se qual desses modelos mais se enquadra no objetivo dessa dissertação. Devido às características da solução desejada e dos dispositivos de automação que possuem memória reduzida e menor capacidade de processamento em relação aos computadores, optou-se pela utilização de agentes reativos, por se enquadrarem nessas características.

Dessa forma, criou-se uma camada de software adicional, o agente, na camada de aplicação, que engloba a aplicação original do dispositivo e que é responsável por realizar a conexão de todas as variáveis necessária para que a aplicação original do dispositivo possa ser executada. Após essas conexões terem sido realizada, a camada adicional, referente ao agente reativo, deixa de operar e inicializa a operação padrão do dispositivo, conforme ilustra a Figura 39. 
E como conclusão, tem-se o fato de que a utilização de conceitos de sistemas multi-agentes contribuiu para a eficiência da solução proposta para a realização de conexões automáticas, apresentando muitas vantagens em relação ao processo padrão, como: velocidade da configuração; confiabilidade do processo; continuidade de execução da aplicação.

Do ponto de vista desse trabalho, pode-se concluir que foi desenvolvido um sistema simplificado de um middleware ODSIP, englobando uma parte de suas funções. Na verdade englobou apenas a característica de fazer e desfazer as conexões entre os objetos.

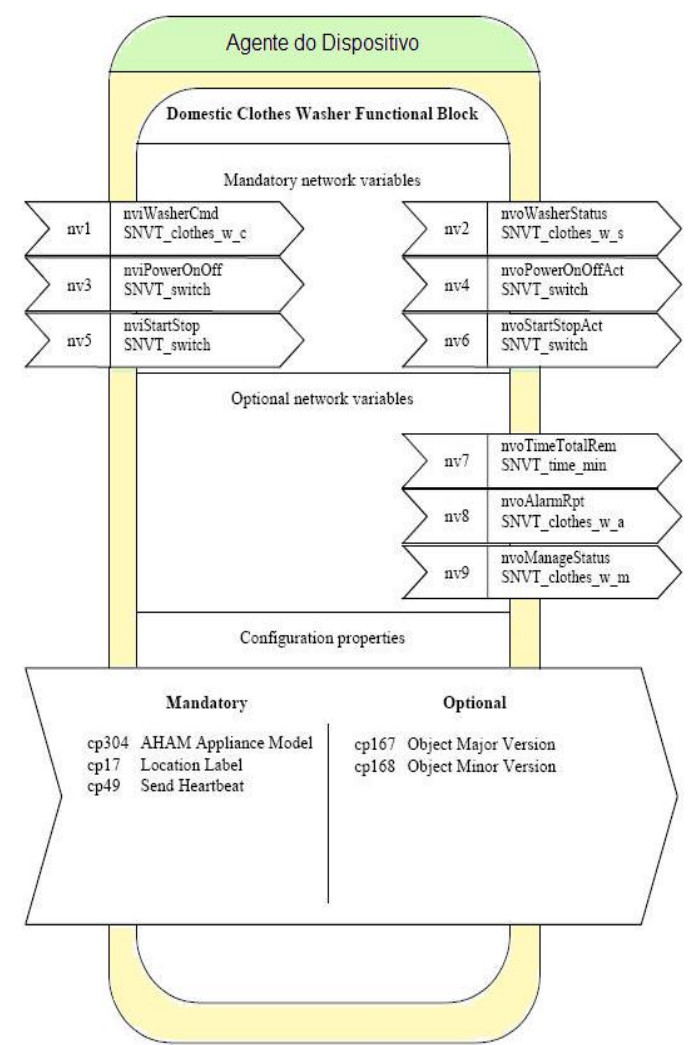

Figura 39: Camada agente de um dispositivo. (CUNHA, 2008).

No entanto ele destaca que é possível a sua ampliação para um middleware ODSIP completo, conforme descrito nos Capítulos anteriores. Mas o mais importante, foi um prova de conceito para a utilização proposta, nesse trabalho, de referências propostas pelo ODP, porém aplicado nas camadas cinco e seis do modelo de referência OSI, ou seja, validando o sistema ODSIP, mostrando a viabilidade para o desenvolvimento de middleware ODSIP em automação. 


\subsection{Visão nova de sistema de automação desenvolvido por orientação a objetos}

A nova visão de automação proposta está em admitir que os produtos não mais terão, apenas e tão somente, seu perfil funcional, mas também serão hospedeiros de objetos que podem ou não serem utilizados como parte do perfil funcional do produto a quem estão instanciados fisicamente e que podem não estar ligados logicamente ao produto original.

Portanto, para nova visão proposta, deve-se considerar que qualquer dispositivo de entrada ou saída irá disponibilizar o espaço não ocupado, tanto em processamento como em memórias disponíveis no seu microcontrolador, para que possam ser instanciados objetos que farão parte da aplicação, que traz a solução para o uso do conjunto de equipamentos, que compõem uma determinada automação conforme pode-se observar na Figura 40.

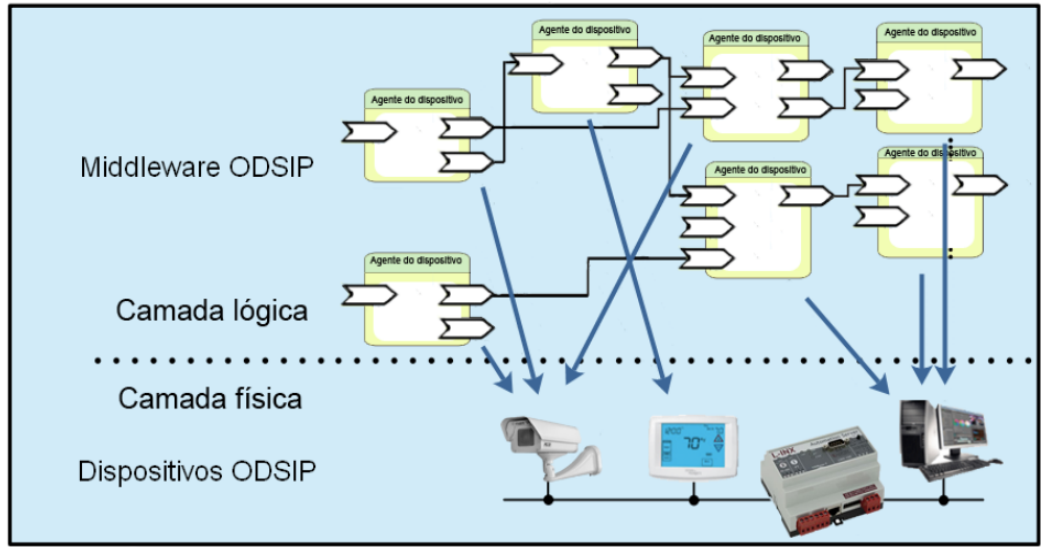

Figura 40: Diversos objetos instanciados nos hardwares. .

A automação poderá ser de apenas uma máquina com poucos sensores e atuadores ou ser uma planta de um edifício com muitos sensores, atuadores e computadores para exercerem, em seu conjunto, várias atividades de controle e processo. 


\subsubsection{0 ambiente físico}

Todo o ambiente físico será determinado pelos equipamentos distribuídos em uma planta ou equipamento automatizado. Portanto será determinado posição física em função de suas atribuições técnicas de conexão com a aplicação, pois está diretamente relacionado aos recursos de seu hardware.

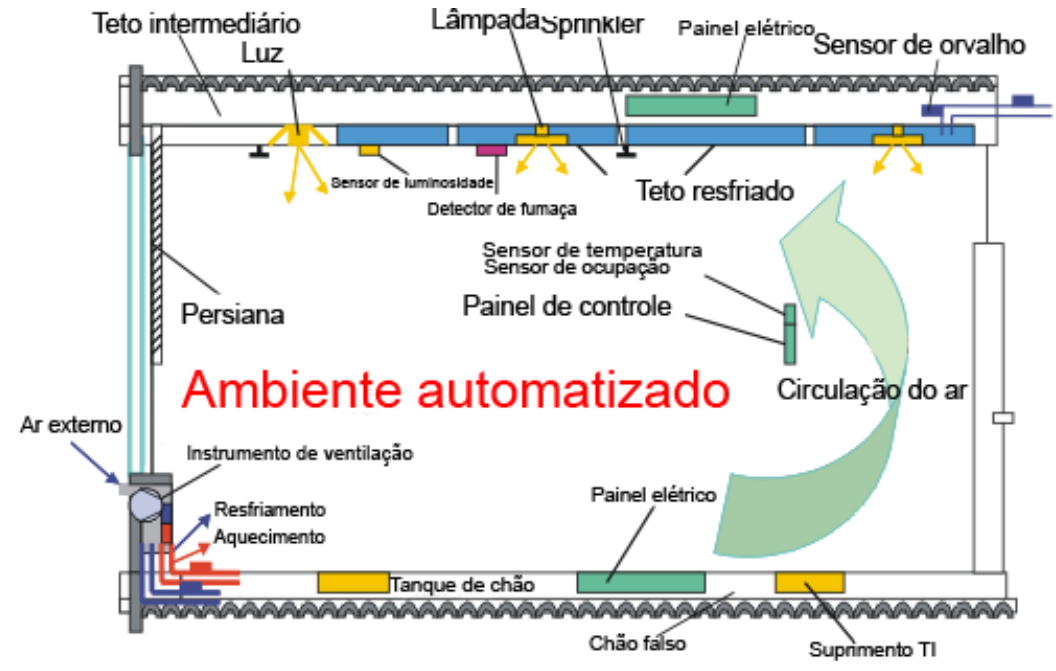

Figura 41: Funcionalidades que dependem de um hardware associado..

$\mathrm{Na}$ Figura 41 pode-se observar diversos sensores e atuadores distribuídos pelo ambiente automatizado, assim como alguns comportamentos que decorrem de sua atuação.

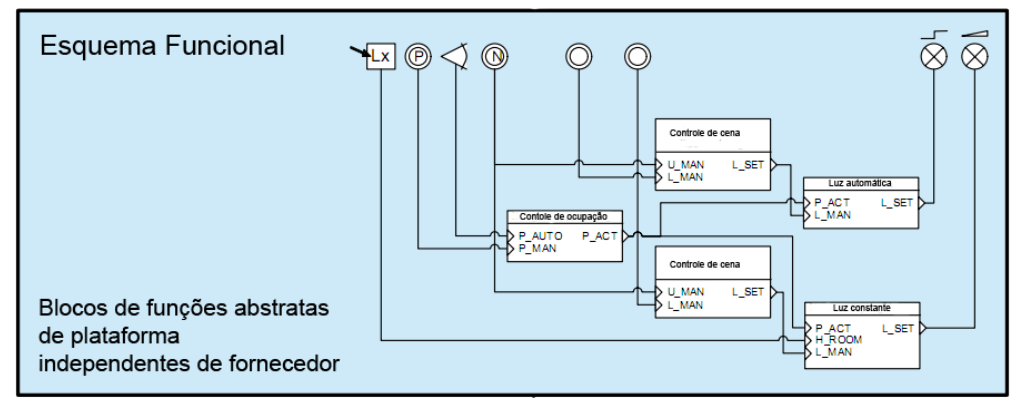

Figura 42: Dispositivos físicos atrelados diretamente ao hardware.

Esses sensores e atuadores necessitam de um dispositivo de hardware, que por sua vez, definem o ambiente físico mínimo para que o ambiente seja automatizado. Além disso, existem comportamentos que também podem exigir um hardware associado, como por exemplo um sensor lógico que faz a sua medição conforme a leitura de diversos sensores diferentes. Como exemplo disso, tem-se um BTU meter em uma planta de ar condicionado, cuja medição depende de sensores de 
temperatura e vazão distribuídos pelo sistema. Cada um desses dispositivos físicos podem ser diretamente mapeado em um objeto atrelado ao seu respectivo hardware conforme mostra a Figura 42.

Portanto o ambiente físico é definido apenas pelos equipamentos de controle no ambiente automatizado, não se levando em conta os dispositivos lógicos associados ou a interconexão entre eles.

Com a aplicação do middleware ODSIP poderiam ser colocados objetos que encontram elementos importantes para um determinada operação e se conectam a estes de forma automática e utilizem esses serviços, antes isolados.

Também poderiam ser aplicados dispositivos lógicos conforme a ociosidade de um hardware. Por exemplo, poderia-se utilizar processamento e memória disponível em um determinado hardware para executar objetos puramente lógicos, como o próprio caso do BTU meter citado.

\subsubsection{Ambiente lógico}

Será definido por todos os objetos distribuídos na planta e que poderão estar ou não instanciados em vários dispositivos físicos da rede, mas que nesse ambiente serão representados somente suas interações lógicas, pela visão computacional do projeto como se pode observar na Figura 43.

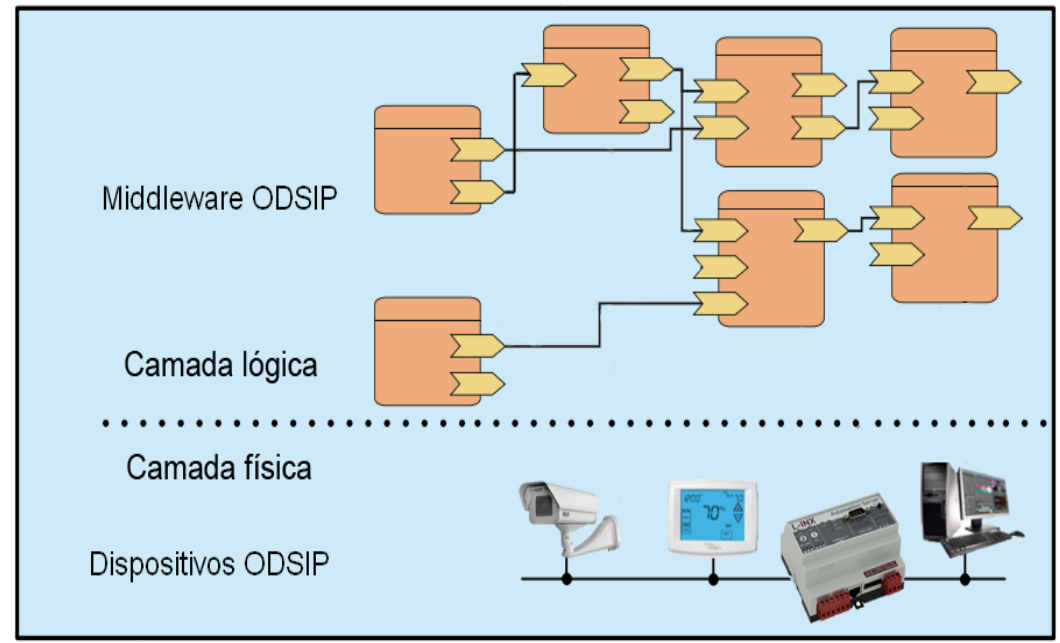

Figura 43: Interligações lógicas dos objetos.

Pode-se fazer uma analogia dessas interligações lógicas a fios virtuais 
entre as entradas e saídas das interfaces dos objetos, que produzem o resultado final da aplicação em seu conjunto. Esse resultado será como o de um esquema de um painel elétrico, porém os fios irão interligar o relacionamento das informações que trafegam na rede e executam o cenário dinâmico dos prováveis projetos.

\subsubsection{Ambiente de rede}

Este ambiente é formado pelos equipamentos de entrada e saída de comunicação em barramento. Essa parte deverá ser estabelecida em conformidade com as características técnicas de conexão dos transceptores de rede e as possibilidades de variar a topologia.

Como qualquer protocolo tem a possibilidade de utilizar os mecanismos que foram definidos neste trabalho, poderá ser desenvolvido uma rede mista com vários protocolos diferentes, e tratados da mesma maneira. Assim, um se interliga ao outro por meio de roteadores para alterar o meio físico de um em relação ao outro, como se fossem apenas repetidores de sinais.

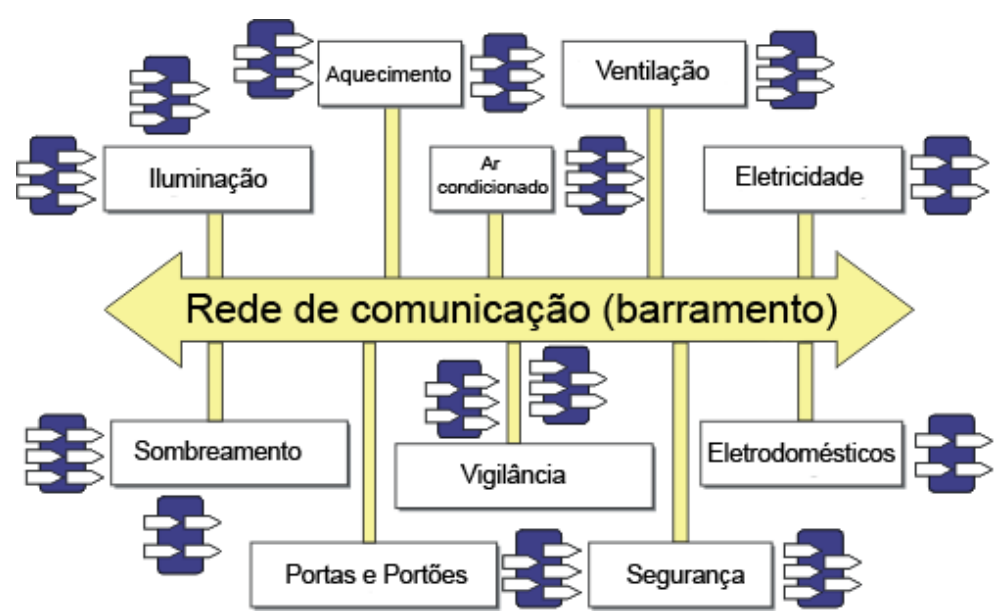

Figura 44: Ambiente de rede abstraído como um barramento de objetos.

Do ponto de vista lógico, os objetos estarão diretamente conectados entre si e estará invisível para o desenvolvedor da aplicação quais protocolos e tipo de meios estarão sendo aplicados para cada caso. Na Figura 44 pode-se observar como será o ambiente de rede abstraído conforme proposto pelo modelo ODSIP.

Atrelando à visão de ambiente físico, ambiente lógico e ambiente de rede baseados no modelo ODSIP os conceitos de sistemas multi-agentes, tem-se uma 
comunidade de agentes interagindo no mesmo ambiente, de forma totalmente dinâmica e ainda com a capacidade de se transferirem entre os objetos de hardware distribuídos. Características essas, inerentes de um ambiente pervasivo a ainda não explorados pelos sistemas de automação atuais.

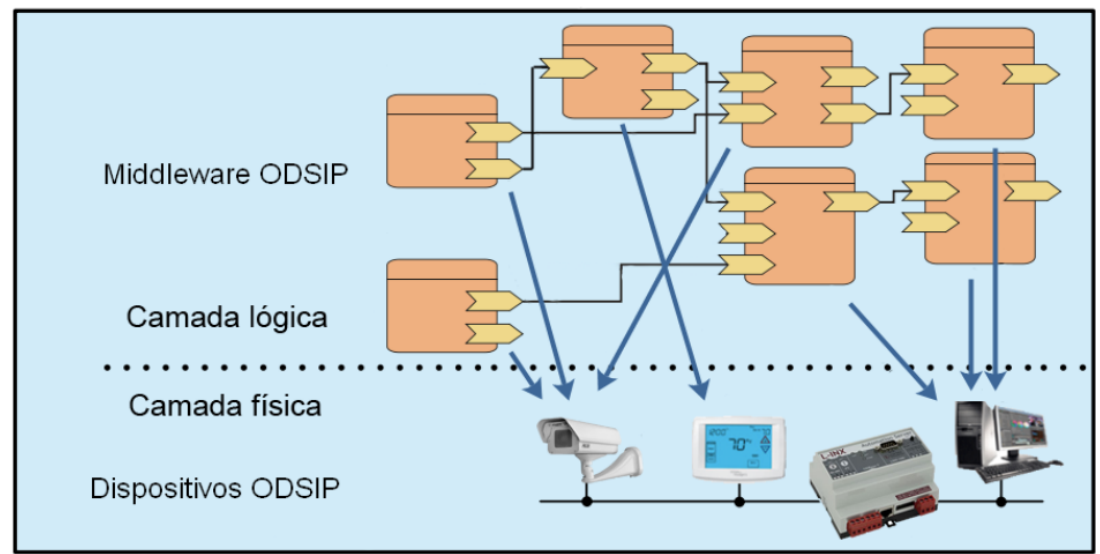

Figura 45: Ambiente de automação ODSIP acrescido dos conceitos de sistemas multi-agentes.

Na Figura 45 pode-se observar que os agentes podem ser instanciados em qualquer um dos dispositivos físicos, conforme o hardware, ou seja, os sensores e atuadores atrelados a eles e a quantidade de processamento e memória disponível. Por fim, também pode-se observar as interligações entre os agentes, ressaltando que essas ligações podem ser feitas e desfeitas em tempo de execução.

\subsubsection{As possibilidades de middleware em automação com ORBs}

Como foi visto no Capítulo 3, o middleware CORBA tem modelagens para aplicar todo o tratamento de solução de ligação entre objetos e até mesmo de instanciar e apagar o objeto em tempo de execução.

Talvez de início não se tenha maneiras diretas de instanciar e depois eliminar objetos com as tecnologias existentes para microcontroladores, mas fica de uma forma conceitual essa possibilidade, pois abrirá ainda mais a abrangência das aplicações. Mas podem hoje ser desenvolvido e instanciados os objetos em tempo de programação e depois ligar ou não tais objetos.

Portanto com a modelagem idealizada pode-se desenvolver aplicações com interação dinâmica e praticamente exercer as atividades de ORB encontrando 
determinados objetos e fazendo suas interligações de forma automática.

\subsection{Conclusão deste Capítulo}

Identificou-se que um aspecto de destaque da tecnologia LonWorks ${ }^{\circledR}$ é 0 seu protocolo de comunicação, que contém o mecanismo seletor. Este protocolo foi estabelecido como a norma EIA 709.1, e vem sendo utilizado com sucesso em diversos controladores, como ARM7 e MC 68360. O potencial para a adequação de toda a recomendação ODP constitui-se em um passo muito grande a favor da computação pervasiva para ser aplicada em automação. Como resultado prático desse trabalho, temse a viabilização da execução de bindings dinâmicos em sistemas de automação que utilizam a norma EIA 709.1, e justifica de forma concreta as possibilidades de criar ambientes de automação com os requisitos da computação pervasiva. Desenvolveu-se uma extensão de pequenos aplicativos (objetos), como se fossem middlewares ODSIP, que instanciados em uma planta de automação, faz e desfaz dinamicamente as conexões entre objetos ou produtos, em tempo de execução, e transforma os ambientes automatizados, em diferentes cenários, adequando-os às mudanças no contexto.

Este Capítulo destaca os caminhos de convergência e unifica as tecnologias tomando como base a rede de controle distribuído em automação. Como resultado, os sistemas de automação passam a estar capacitados a operar no contexto de computação pervasiva, até estão considerados, apenas, no contexto da TI. Com a iniciativa deste trabalho, tem-se possibilidade de tratar sistemas de automação com ferramentas mais adequadas aos sistemas da $\mathrm{TI}$ e evoluir mais rapidamente com a automação ao ponto de poder alcançar os progressos que já se atingiram na área de TI.

Sistemas de automação que adotarem a modelagem proposta poderão se acomodar e se adequar a outras modelagens e ferramentas propostas pela OMG, que eram até aqui, apenas utilizadas na análise e construção de sistemas de computação. 


\section{A Tecnologia LonWorks ${ }^{\circledR}$ e o middleware ODSIP de Automação}

A tecnologia LonWorks $®$ é utilizada até então na versão original da forma como foi criada pelo fabricante Echelon. Como resultado deste trabalho espera-se que as considerações sobre novas possibilidades de uso da mesma possa contribuir para o desenvolvimento de novos tipos de projeto de automação, com arquitetura orientada a objetos distribuídos e que atenda aos requisitos de automação pervasiva.

Este Capítulo apresenta a tecnologia LonWorks ${ }^{\circledR}$, dando o enfoque apresentado no Capítulo anterior, assimilando os mecanismos do middleware ODSIP e apresentando um novo modelo para projetos para o desenvolvimento de sistemas de automação.

A tecnologia LonWorks ${ }^{\circledR}$ vem se destacando em relação a outras tecnologias de automação desde sua criação, por incorporar os conceitos de interoperabilidade, objetos distribuídos, além de disponibilizar ferramentas para a construção de sistemas de automação, como o LonMaker ${ }^{\mathrm{TM}}$, recursos estes que viabilizaram o que outras tecnologia não possibilitavam: executar Object Request Brokers (ORB) com operação manual. Assim, a tecnologia LonWorks ${ }^{\circledR}$ será discutida em relação aos requisitos do middleware ODSIP, evoluindo para soluções que atendem aos requisitos de computação pervasiva, como foi visto nas soluções comumente adotadas em TI. Também serão discutidas algumas iniciativas em desenvolver uma arquitetura semelhante a CORBA para sistemas de automação.

Considera-se, assim, a possibilidade de se viabilizar a implementação metódica de sistemas de automação que possam atender aos requisitos da computação pervasiva, considerando-se a orientação ao contexto e o acompanhamento dos usuários em ambientes, levando seus bancos de dados e configurações nos vários equipamentos distribuídos nos locais em que ele passa, como considerado no trabalho de Cunha (2008), no qual uma breve citação na programação orientada a agentes e multi-agentes foi efetuada. 


\subsection{A Tecnologia LonWorks $\AA$ e a norma EIA 709.1}

Quando a Echelon lançou a tecnologia LonWorks $®$, ela disponibilizou aos projetistas todo um conjunto de recursos para o desenvolvimento de aplicações nela baseadas. Um desses recursos incluía um equipamento robusto e completo para o desenvolvimento de redes, denominado LonBuilder ${ }^{\mathrm{TM}}$, que era composto de software de desenvolvimento para a criação dos aplicativos de cada nó e para associar as informações, variáveis de rede, entre os nós criando a rede efetivamente. Essa plataforma incluía roteadores e software para acompanhar e analisar o tráfego e desempenho de uma rede desenvolvida (ECHELON CORPORATION, 2003a).

O passo seguinte foi a evolução desse recurso para um mais completo, denominado NodeBuilder ${ }^{\mathrm{TM}}$, destinado ao desenvolvimento de nós isoladamente, e o software LonMaker ${ }^{\mathrm{TM}}$ para criar as conexões entre os nós, originando, assim, redes de controle (ECHELON CORPORATION, 2003b).

Muito do sucesso dessa tecnologia se justifica pela forma que foram colocadas no mercado as ferramentas que facilitavam o trabalho de desenvolvimento de novos sistemas, aproveitando todo o potencial de modularidade entre os produtos desenvolvidos nesta tecnologia, permanecendo transparentes os mecanismos proprietários da Echelon até 1999.

Quando esses mecanismo ficaram claros para o mercado foi fundada a associação LonMark $\circledast$ que se justificou criando a interoperabilidade entre produtos de fabricantes diferentes. Dela surgiram as padronizações do meio físico e lógico, a padronização das Variáveis de Rede (NV) que se tornaram Standard Network Variable Type (SNVTs).

Isso é importante destacar no contexto deste trabalho, uma vez que explica o fato de que por razões de padronização, outros potenciais da tecnologia deixaram de ser explorados. Por exemplo, iniciativas diferentes do uso do LonMaker $^{\mathrm{TM}} \mathrm{e}$ seu banco de dados LonWorks Network Services (LNS), que serão abordados neste Capítulo. A idéia desta pesquisa é estender algumas formas de utilização dessa tecnologia, seguindo os conceitos de middleware ODSIP, apresentados no Capítulo anterior. Assim, propõe-se que se desenvolvam projetos e produtos desvinculados do padrão hoje estabelecido, com uma nova perspectiva de programação, com arquitetura orientada a objetos, para produtos e equipamentos. 
A seguir serão expostos os mecanismos do LonTalk® e algumas das partes relevantes do software LonMaker ${ }^{\mathrm{TM}}$, propondo-se ao final uma mudança de paradigma de criar aplicação apenas utilizando ferramentas e operação manual e passar a atender o objetivo proposto neste trabalho, que é desenvolver produtos que se auto configuram ou OBEs que possam ser instanciados em produtos acabados e que possuem ainda capacidade de processamento e memória para opera-los.

\subsection{A operação do LonTalk $®$ na rede de controle LonWorks $®$}

Antes de se considerar os detalhes de estruturas de tabelas da tecnologia é importante estudar o frame do protocolo de comunicação básico, ilustrado na Figura 46, que mostra a representação do encapsulamento dos sete níveis do protocolo, sendo a camada 5 e 6 o detalhe mais importante a destacar. Esse campo é o responsável por levar ou trazer a informação como referência ao canal de comunicação que se formou entre dois ou mais dispositivos presentes na rede.

A Echelon deu o nome nesse campo de seletor da variável de rede e explica que não se pode repeti-lo em nenhum outro canal de comunicação no mesmo dispositivo. Isso se deve ao fato de que se um produto possuir um mesmo seletor para mais de uma variável, ele não conseguirá distinguir para qual delas está destinada uma mensagem recebida.

Além do seletor, a tecnologia LonWorks $®$ também controla, em tabela, o endereço do nó, origem e destino. Isso multiplica o potencial do seletor, que pode ser formado por uma menor quantidade de dígitos que o estabelecido, pois os dígitos tem a função de diferenciar os seletores dentro de um grupo pequeno de nós, e não a rede toda. 


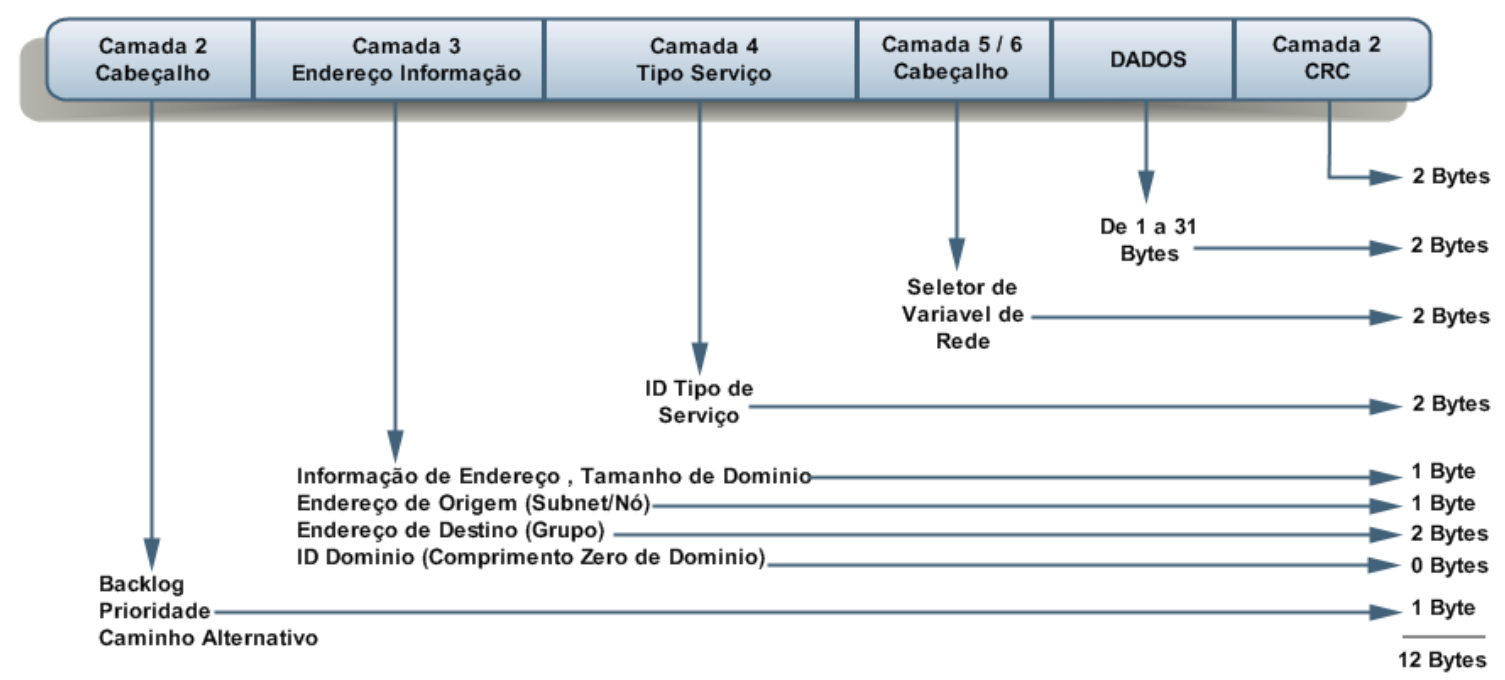

Figura 46: Frame de comunicação do protocolo LonTalk® ou norma EIA 709.1 adaptado de ECHELON CORPORATION (1997).

Desta forma, na rede LonWorks $₫$, o seletor poderá não ser único, pois qualquer nó poderá repeti-lo na construção de seus canais, desde que não seja para uso em um mesmo grupo de nós.

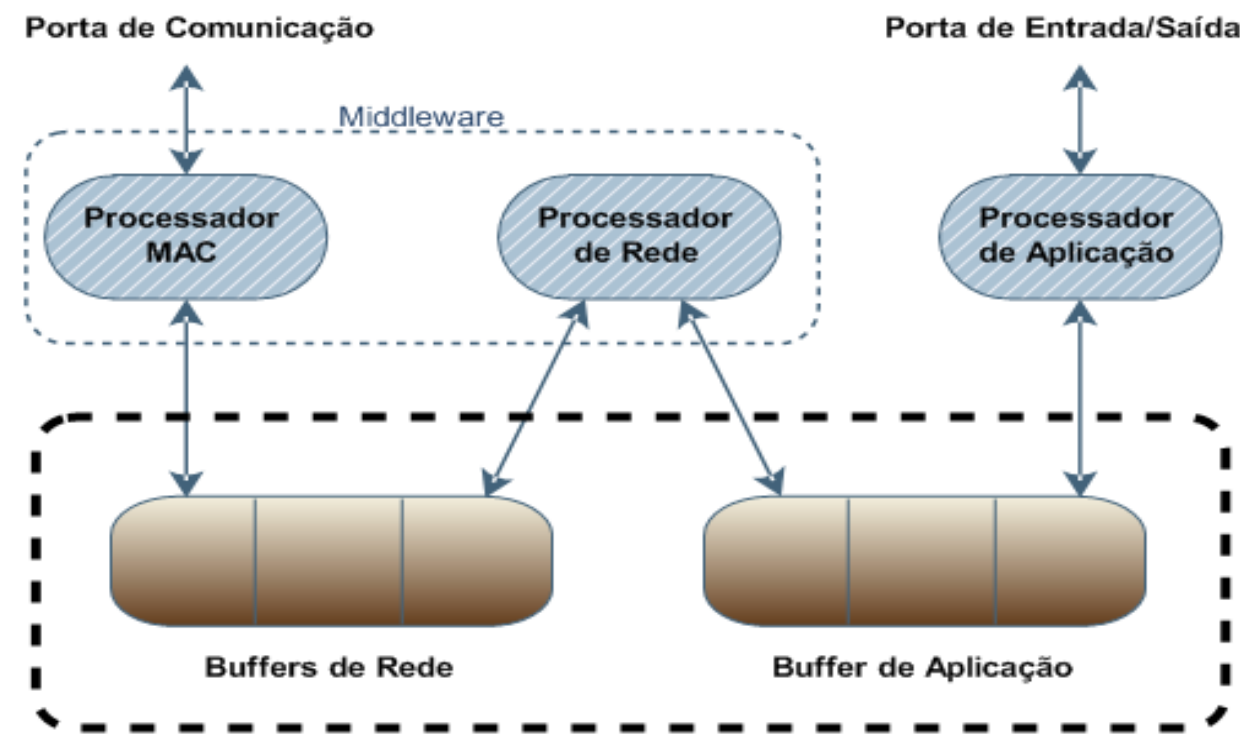

Figura 47: Alocação de memória e tratamento dos processadores de um NeuronChip ${ }^{\circledR}$ adaptado de ECHELON CORPORATION (1997).

O NeuronChip $®$ é na verdade o encapsulamento de três processadores que trabalham em paralelo e compartilham a mesma Unidade Lógica e Aritmética (ULA). Cada um desses processadores trata de uma parte do banco de memórias do microcontrolador, como ilustra a Figura 47.

O processador MAC trata da interface com a rede, o processador da aplicação trata com a interface da aplicação, e o processador da rede trata de executar o compartilhamento entre o buffer da aplicação e da comunicação. 
Neste ponto, pode-se deduzir que o responsável em tratar o seletor e índice é o processador de rede, no momento em que a variável é recebida pelo nó. Nesse instante, o processador de rede atualiza a variável em um buffer correspondente e assim chama o método de tratamento da variável. Por esse motivo, marca-se os dois processadores como sendo o mecanismos do tratamento especial, que disponibiliza o seletor para a operação do middleware ODSIP, discutido no Capítulo anterior.

Em manuais referentes à tecnologia LonWorks ${ }^{\circledR} \quad(E C H E L O N$ CORPORATION, 1995b) (MOTOROLA, 1997), pode-se encontrar informações que permitem concluir:

- Sempre que uma variável de rede é criada, é registrado na tabela "configuração de variáveis" no NeuronChip $®$, no índice respectivo dessa variável, os dados de configuração referentes aos critérios e atributos de rede para essa variável.

- O dado referente ao seletor é preenchido com 0x3FFF se for índice 0, a primeira a ser criada, e vai decrescendo à medida que outras variáveis forem sendo criadas e o índice for aumentando.

- Em um nó simples, com o NeuronChip® executando a aplicação, esse índice máximo será de 62 variáveis, pois é o máximo possível no nó.

- Em um nó MIP (Microprocessor Interface Program), esse número de variáveis de rede pode chegar ao máximo de 4095 variáveis de rede.

Quando uma variável de rede é ligada a outra variável de rede, através de ferramentas de gerenciamento de rede LON, por exemplo o LonMaker ${ }^{\mathrm{TM}}$, acontece:

- O seletor referente a essa variável é criado, e também é registrado no nó que ela é uma variável de saída. O mesmo ocorre em quaisquer outros nós que recebam essa variável como entrada:

- Se a ligação for apenas entre dois nós, Um para Um, a operação finaliza colocando na "tabela de endereços" do nó de origem a informação do endereço do nó de destino.

- Se a ligação for de um nó para vários outros nós, Um para Vários, então é uma ligação de GRUPO. Neste caso as informações específicas desse grupo são armazenadas em todos os seus integrantes.

Quando o sistema está em operação normal e configurado como 
apresentado acima, o nó passa a trabalhar com o seletor, ou seja, as camadas de apresentação e sessão combinam as atividades de tratamento do relacionamento entre o seletor e índice de cada variável para transferir seu conteúdo:

- Quando ocorrer atualização pela rede de controle, o valor é repassado para a camada da aplicação. Assim, a aplicação pode executar um método ou função imediatamente (on demand) ao recebimento da mesma.

- Quando ocorrer uma atualização pela camada de aplicação, o valor é repassado para a camada de transporte. Assim, os mecanismos do protocolo de rede fazem chegar ao objetivo, considerando o seletor que acompanha a variável de rede.

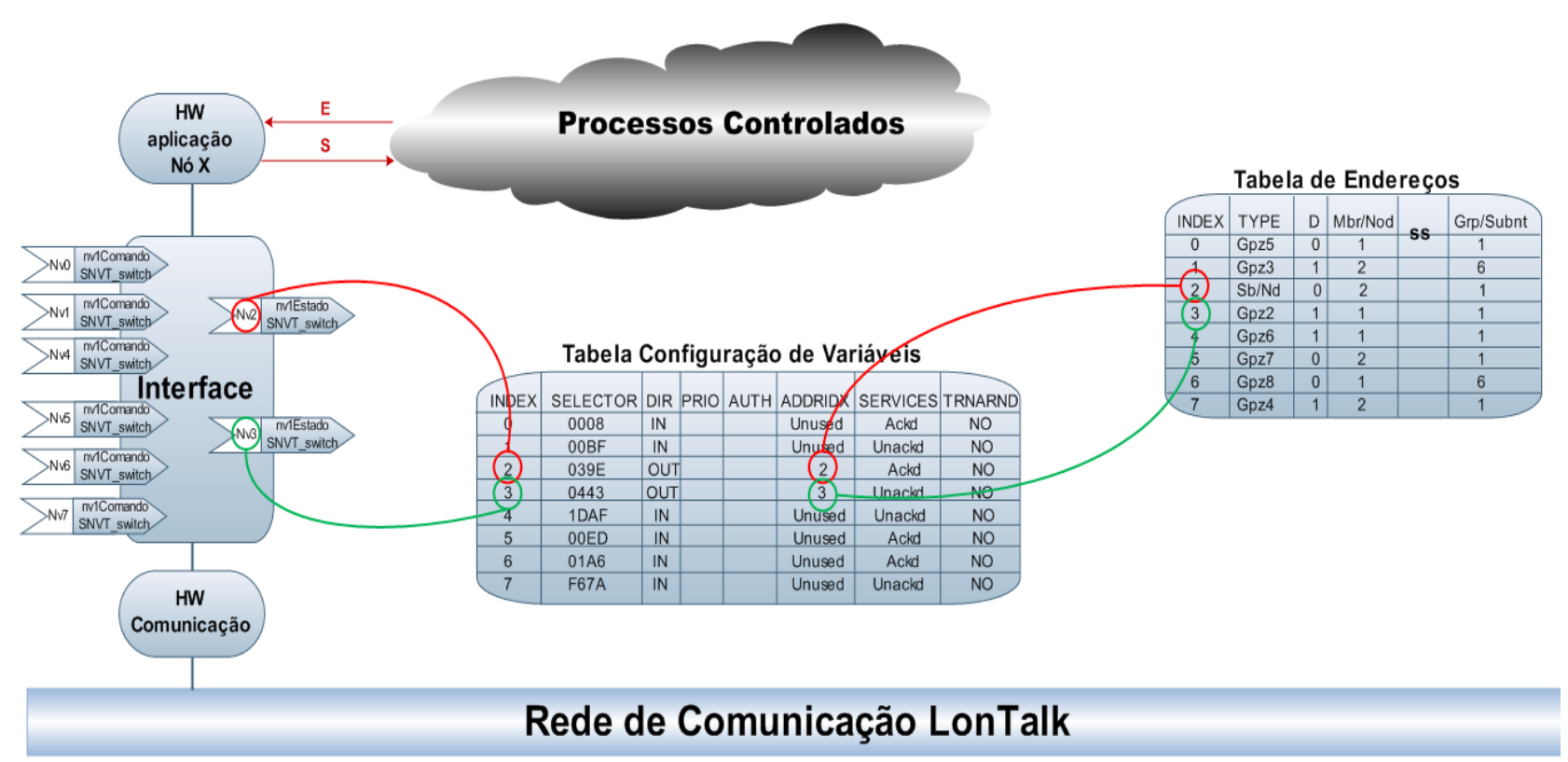

Figura 48: Tabelas internas de um NeuronChip $\AA$

Na Figura 48 tem-se destacadas as tabelas que são utilizadas em um nó LonWorks ${ }^{\circledR}$ depois da operação binding.

Pode-se observar o conteúdo da tabela "configuração de variáveis" e o conteúdo da "tabela de endereços" de um nó LonWorks $®$.

- INDEX = é a referência da variável e é definido no momento de sua criação.

- $\quad$ DIR = é a definição da direção da variável: "IN" de entrada, ou "OUT" de saída.

- SELETOR = é um número criado por uma ferramenta de comissionamento, como por exemplo o LonMaker ${ }^{\mathrm{TM}}$. Ele define o 
canal de comunicação entre os nós da rede.

\subsection{A operação do LonMaker ${ }^{\mathrm{TM}}$ através do LonTalk®.}

Conforme já destacado, o LonMaker ${ }^{\mathrm{TM}}$ é um recurso muito importante no contexto da tecnologia LonWorks ${ }^{\circledR}$. Por meio dele determina-se os endereços lógicos de cada nó presente na rede, e se estabelece as ligações entre os vários dispositivos inteligentes distribuídos em uma rede. Mas toda essa definição é realizada por meio de um processo manual, pelo projetista do sistema de automação (ou usuário integrador).

A versatilidade do LonMaker ${ }^{\mathrm{TM}}$ é decorrente do uso do banco de dados LNS, que o LonMaker ${ }^{\mathrm{TM}}$ cria e mantém atualizado da rede que controla. Quando se inicia o desenvolvimento de uma aplicação, o LonMaker ${ }^{\mathrm{TM}}$ pode ser utilizado no modo offline, que permite desenvolver todo o banco de dados de um projeto completo. Depois que a rede de controle é construída com os nós, o banco de dados LNS é incorporado no local, realizando-se a tarefa de comissionamento, que consiste em se criar o endereçamento lógico de cada um dos nós fisicamente, com o que foi previamente estabelecido no banco de dados na operação offline. Logo depois do comissionamento, a planta entra em operação, pois os equipamentos iniciam as interações de informações e a aplicação se concretiza efetivamente. Pode também, ser feita toda uma instalação diretamente na planta, no modo online, definindo-se um a um os nós e ligando-se as suas variáveis de rede.

Em qualquer um destes casos, todas as atividades são feitas pelo usuário integrador, que interage com o software LonMaker ${ }^{\mathrm{TM}}$ para criar a aplicação do sistema.

No caso de substituição ou alteração de produtos na rede criada, entra a figura do usuário mantenedor, que com o LonMaker $^{\mathrm{TM}}$ ele altera e faz substituições de uma maneira simples, sem precisar ter acesso ao projeto completo do sistema, pois no banco de dados LNS está com todo o repositório de objetos e ligações entre tais objetos pertinentes a planta automatizada. Assim, resta ao usuário mantenedor identificar o produto, pressionando o botão do pino de serviço do equipamento a ser substituído, e o LonMaker $^{\mathrm{TM}}$ se incumbe de ligar e configurar o novo componente no lugar do anterior que apresentou defeito.

Quando o usuário operador utiliza o LonMaker $^{\mathrm{TM}}$, este é configurado e 
programado como um sistema supervisório, diferentemente dos dois casos anteriores, permanecendo conectado à planta e exibindo telas gráficas, por meio das quais o operador navega e acompanha as leituras de todas as variáveis do processo, e executa comandos especialmente definidos na aplicação para o funcionamento adequado da planta automatizada.

\subsubsection{Mensagens de gerenciamento, diagnósticos e aplicação}

Para o LonMaker ${ }^{\mathrm{TM}}$ exercer todas as atividades descritas, ele executa uma série de comandos na rede de controle. Complementando os serviços de mensagens de aplicação, o protocolo LonTalk® fornece serviços de gerenciamento de rede para instalação e configuração de nós, carga de softwares e diagnósticos da rede.

Mensagens de gerenciamento e diagnóstico de rede podem ser enviadas usando-se o serviço de Requisição/Resposta (exceto para o modo on-line, modo off-line e no modo acesso rápido "wink", na qual são entregues ao processador da aplicação não tendo resposta associadas a elas). Mensagens de gerenciamento de rede que não tenham resposta associadas podem também ser entregues com outra classe de serviço, denominadas Reconhecimento (Acknowledged), Não Reconhecimento (Unacknowledged) e Não Reconhecimento/Repetição. Estas mensagens são: Responder à Solicitação (Query), Atualização de Domínio, Licença de Domínio, Atualização de Chave, Atualização de Endereço, Atualização de Grupo de Endereços, Atualização da Configuração da Variável de Rede, Modo Definição do Nó, Escrita em Memória, Recálculo de CheckSum, Refrescamento da Memória e Zeramento do Status. Se o endereçamento difundido (broadcast) for usado com serviço de Reconhecimento ou Requisição/Resposta, somente o primeiro reconhecimento ou resposta poderá ser tratado.

Mensagens de Variáveis de Rede serão enviadas para atualização das variáveis de rede de saída (updating network output variables) no programa de aplicação e são implicitamente recebidas através das variáveis de entrada da rede na mesma conexão. A varredura (polling) das variáveis é implementada com o serviço de requisição/resposta.

Mensagens de Aplicação e Atualizações de Variáveis de Rede são enviadas na classe ou serviço especificado. Note que muitas mensagens de 
gerenciamento e diagnóstico de rede podem ser autenticadas. Autenticação nunca se aplica a mensagens para ID Solicitante (Query), Resposta ao Solicitante, Status do Solicitante ou Proxy.

Mensagens de Roteador são usadas pelos nós de gerenciamento de rede para configurar outros nós que irão executar imagem de sistema para roteadores especiais. Eles não serão úteis para nós de aplicação, os quais irão retornar com resposta de falha.

\subsubsection{A norma EIA 709.1 é o protocolo LonTalk®.}

A norma ANSI/EIA 709.1 foi desenvolvida pela empresa Adept Systems Incorporated (ASI) em 1998, a pedido da Echelon, apresentando uma implementaçãomodelo para o protocolo LonTalk® para ser executado no microprocessador MC 68360 da empresa Motorola.

Até o estabelecimento da norma EIA 709.1, a única implementação do protocolo LonTalk® disponível estava no NeuronChip®. Logo depois da publicação da norma, a Echelon tornou o protocolo LonTalk® aberto para implementação em qualquer processador. Em um esforço para facilitar a implementação mais rapidamente para outros processadores, Echelon contratou a Adept Systems Incorporated (ASI) para desenvolver e documentar um software em Linguagem C para o MC68360, para servir de base para o entendimento da especificação do protocolo. Com essa implementação, o LonTalk® foi apreciado e aprovado como um protocolo padrão por várias organizações de normas industriais e controle. Um requisito essencial para estas organizações de normas abertas é uma especificação completa do protocolo a ser padronizado.

A implementação desta referência foi desenvolvido a partir de uma descrição funcional do protocolo LonTalk®. Não foi disponibilizado para referência o código-fonte do programa em Linguagem Assembly do Neuron C. Esta implementação contribui para o adequado entendimento do protocolo (ECHELON CORPORATION, 2009).

Com a norma e a implementação de referência, a empresa austríaca LoyTec vem desenvolvendo produtos baseados na plataforma ARM7, uma das mais recomendadas para roteadores e switches para redes LonWorks ${ }^{\circledR}$ (LOYTEC, 2009). 
A Própria ASI também lançou alguns produtos (roteadores e produtos programáveis com PIC da Microchip), baseados na norma que ajudaram a desenvolver.

A partir de 1999 outras empresas lançaram produtos em outras plataformas, porém referenciados como compatíveis com a norma EIA 709.1, uma vez que a Echelon é proprietária dos direitos de palavras com as letras LON, pois foi ela que registrou Local Operating Network (LON) em 1989 e é a única que pode usá-la.

Assim, todas as aplicações do middleware ODSIP poderão ser utilizadas com essas e outras plataformas que aparecerem no mercado. $O$ importante é considerar o fundamento do middleware ODSIP discutido no Capítulo anterior, vinculado ao protocolo e portanto, à norma ANSI/EIA 709.1, e que este protocolo carrega os mecanismos aqui estudados, incluindo a abertura para o desenvolvimento de extensões, elaborados dentro da recomendação ODP.

Algumas limitações podem ser observadas na tecnologia LonWorks $\AA^{\circledR}$ que podem não existir em implementações em outras plataformas que seguem a tecnologia LonWorks ${ }^{\circledR}$, mas não avaliadas no presente trabalho.

Como exemplo, a condição de criar e desfazer bindings dinâmicos funcionou conforme o esperado em diversos projetos (que serão apresentados no Capítulo 6); contudo, instanciar objetos de forma dinâmica só funciona se os demais objetos presentes no nó pararem de funcionar no momento desse processo. Isso por que existe a necessidade de ser feito um recálculo do CRC toda a vez que a área de aplicação é alterada em um nó NeuronChipß.

Já executar essa operação no ARM7 funciona corretamente, pois este foi implementado com multithreads e permite essa operação com sucesso.

\subsection{Comparando categorias do middleware de TI com ODSIP de automação.}

Neste item considera-se a tabela com as quatro categorias de middleware $\mathrm{TI}$ e essas categorias aplicadas ao middleware ODSIP, similares ao LonMaker ${ }^{\mathrm{TM}}, \mathrm{NL220}$ e outros que poderão ser criados em decorrência deste trabalho. 


\subsubsection{Distributed Tuples}

Elas permitirão a distribuição de bancos de dados em um ambiente de rede de automação, com uma NIC ou aplicação MIP com o NeuronChip $®$, que permite montar e distribuir até 4095 variáveis. Estas variáveis criam triggers para acesso direto a tabelas de bancos de dados, normalmente quando o ambiente computacional for de $\mathrm{TI}$, como é o caso em que se utiliza um PC LonTalk® Adapter - PCLTA em computador. Se o ambiente computacional for de TA, pode-se usar diretamente memórias de massa como cartões MMC, entre outras soluções.

Para a plataforma ARM7 da LoyTec poderá criar banco de dados de até 65535 variáveis com aplicação direta do L-Core, que é um ambiente computacional muito poderoso e já tem inclusive implementado soluções OPC (LOYTEC, 2009).

Os sistemas supervisórios atuais não utilizam os recursos de meddleware nem conexões bindings estáticos e menos ainda bindings da forma dinâmica por ignorar as propriedades que foram levantadas neste trabalho. É mais comum o sistema supervisório utilizar a tecnologia de request_response. Isto deve-se ao fato de que o protocolo LonTalk® é utilizado apenas como sendo um protocolo de comunicação comum, ignorando os mecanismos de middleware que foram apresentados.

Por meio de rotinas, o sistema supervisório realiza a leitura da variável no campo e, com a resposta, ele alimenta seus relatórios e telas do sistema de supervisão.

A nova proposta para um sistema supervisório deverá ser feita com operações on demand. Assim, aumenta-se a eficiência do sistema supervisório, que apenas receberá do campo o que de fato teve alteração, e com essa alteração processará atualização das telas, relatórios e banco de dados.

A partir deste trabalho pode-se: trabalhar com software orientado a agentes e multi-agentes; e desenvolver e montar ferramentas para acompanhar o crescimento das bases dos agentes cognitivos.

Lembrando que os agentes cognitivos (BDI) possuem três bases e que poderão estar distribuídas de forma controlada e acompanhadas no seu crescimento e multiplicação em uma planta automatizada:

- Com os dados da base de crenças, onde o agente guarda tudo o que infere e conhece do meio ambiente, dos outros agentes, de si mesmo, etc; 
- Com os dados da base de desejos, onde ele possui todos os objetivos que pretende atingir e que gostaria de realizar, podendo adicionar novos ou retirar antigos;

- Com os dados da base de intenções, gerada através do conjunto das duas anteriores aplicadas à regras de decisão, onde o agente guarda as atitudes que deverá executar.

O avanço aqui proposto é de utilizar programação distribuída em objetos e com possibilidades de tratar localmente em cada nó da rede qualquer armazenamento e manutenção de dados.

\subsubsection{Object Request Brokers (ORB)}

Eles permitem que objetos que compõem uma aplicação sejam distribuídos ao longo de uma rede. Essa característica é a mais importante e foi destacada com detalhes neste trabalho.

É de se supor que se pode desenvolver dispositivos agentes e multiagentes que tratem as conexões entre os objetos de engenharia, em tempo de execução e, com isso, tornar um sistema completamente dinâmico e operar em conformidade com cenários diferentes ao longo do dia ou dependendo do contexto da ocupação de usuários.

Essa característica faculta atuar em áreas de automação, como na área de automação residencial que alteram os cenários de controle, que antes eram impossíveis de serem tratadas, pois se praticava apenas as conexões estáticas e definidas pelo banco de dados LNS como foi visto no Capitulo 2.

A partir desta pesquisa, deve-se considerar o LNS como sendo um ORB manual. As ferramentas, LonMaker ${ }^{\mathrm{TM}}$ ou NL220 por exemplo, quando conectadas na rede, fazem a tarefa de middleware ODSIP manual, ligam ou desligam os objetos e suas relações em conformidade de acordo com a vontade do integrador.

Também pode-se montar ferramentas para acompanhar o crescimento das bases dos agentes cognitivos. Tratar agentes reativos e distribuir inteligência em uma rede de controle com mais facilidade e dinamismo, como pode-se exemplificar com os programas sendo executados em máquinas especializadas, e que se moldam para cenários diversos. Este também será um novo diferencial para acompanhar as 
implementações de computação pervasiva em rede de controle de automação.

\subsubsection{Message-Oriented middleware (MOM)}

Este processo é o grande destaque da tecnologia LonWorks $®$, que foi criada inicialmente com os mecanismos de binding estático e poderá ser mais abrangente se utilizar os bindings dinâmicos além de outras plataformas que se podem usar junto, como foi visto no Capítulo 2.

Este é o diferencial do protocolo LonTalk®/EIA 709.1 em relação às demais tecnologias, que se baseiam em protocolos de comunicação que só trabalham com mensagens explicitas e por isso devem definir fonte e destino da mensagem em tempo de compilação.

No protocolo LonTalk® faz-se desnecessário compilar uma aplicação com o conhecimento do dispositivo que utilizará as saídas ou entradas das variáveis dessa aplicação. Isso pode ser definido pelo integrador, que utilizando ferramentas externas consegue executar o binding em tempo de execução e fazer as integrações de forma conveniente utilizando os recursos de cada componente de rede.

\subsubsection{Remote Procedure Call (RPC)}

RPC faz com que a lógica de uma aplicação seja distribuída ao longo da rede, permitindo que programas em sistemas remotos sejam chamados como se fossem sistemas locais.

Essa atribuição também se faz presente na tecnologia LonTalk®. Os fabricantes de produtos utilizam este atributo para a montagem de seus equipamentos distribuídos, agregando a vantagem de compartilhar uma aplicação com a outra.

Este atributo é valorizado na automação predial, pois vários equipamentos, que são distribuídos fisicamente, conseguem interagir por meio desta particularidade, que foi visto aqui como atributo de um middleware ODSIP. 


\subsection{Conclusões deste Capítulo}

Neste Capítulo discutiu-se como a tecnologia LonWorks $®$ pode ser utilizada na aplicação dos preceitos de middleware ODSIP, discutidos nos itens anteriores, agregando uma visão tecnológica aplicada à tecnologia de automação.

Cabe esclarecer que alguns conceitos que antes eram entendidos como sendo de interoperabilidade, agora passam a ser entendidos como particularidades apresentadas pelo contexto de middleware ODSIP, e abrem possibilidades de criação de aplicações distribuídas, com arquitetura orientada a objetos e não somente a interoperabilidade entre perfil funcional de produtos.

Apresentou-se um modo de aplicação em automação dos conceitos de middleware ODSIP apresentados neste trabalho de forma direta por meio das tabelas e das possíveis interações, ora com a rede quando executando bindings, ora com a camada da aplicação quando executando mensagens com endereçamentos explícitos. Fica aberta a possibilidade de que este mesmo processo possa ser aplicado a outros protocolos de comunicação. Ao se aplicar esses mesmos mecanismos a outros protocolos de automação, eles passarão a se comportar como sistemas middleware ODSIP, podendo ser utilizados em conjunto com o LonTalk ${ }^{\circledR}$. Outra opção seria desenvolver e aplicar outros processos que disponibilizem os mesmos mecanismos.

Apesar de ser possível o desenvolvimento de novas tecnologias de automação, neste trabalho mostrou-se que é possível ajustar o protocolo existente a essa nova visão. Assim, ele deixa de ser utilizado apenas como protocolo para troca de informações sem padronização e passa a utilizar mensagens mais curtas, com informações padronizadas e enviadas apenas sob demanda. 


\section{Estudos de casos}

A comprovação prática das propostas deste trabalho teve sua origem em projetos de pesquisa, apoiados por meio do programa "Projetos de Inovação em Pequenas Empresas - PIPE" da Fundação de Amparo à Pesquisa do Estado de São Paulo - FAPESP (projetos 03/0443-6 e 05/5604-6), com a participação do autor e da empresa Conceito Tecnologia, no período de 2003 à 2009. O projeto é intitulado "Sistema Distribuído de Comunicação Telefônico Privado - SDCTP", e atingiu a meta de oferecer serviços de telefonia sobre uma rede distribuída de controle e automação LonWorks ${ }^{\circledR}$.

Além disso, o SDCTP integra-se com um sistema de automação predial baseado na mesma tecnologia, atuando em seus dispositivos e configurações como se fosse uma Interface Homem-Máquina (IHM), semelhante a qualquer sistema supervisório, só que neste caso atuando por intermédio dos ramais telefônicos, com respostas audíveis dos comandos e com comandos do teclado do ramal utilizado.

\subsection{Projeto do Sistema Distribuído de Comunicação Telefônica Privado}

O SDCTP é constituído por vários módulos com inteligência distribuída, para realizarem enlaces telefônicos e se complementam em funcionalidade de tal forma a exercer todos os serviços de telefonia e os serviços complementares de controle de automação predial. Além disso, como a sua estrutura foi toda baseada no middleware ODSIP na comunicação, ele foi desenvolvido com características de um sistema pervasivo, tendo em todas as suas interfaces a função de atender a todos os sistemas implementados. Isso possibilitou tratar vários sistemas inter-relacionados, listados adiante.

Cada um dos módulos que o constituem, tem uma propriedade de controle chamada Telefonia Modular Inteligente Distribuída (TMID) que é o cerne da tecnologia de distribuição dos processos de controle de enlaces telefônicos. Esse controle é montado dentro de cada um dos módulos principais de telefonia, sendo:

- Módulo de Linha Tronco (MLT): responsável em conectar o Public System Telephony Network (PSTN) com o ambiente interno do 
SDCTP que é LonWorks ${ }^{\circledR}$ e seu protocolo LonTalk.

- Módulo de Tronco E1 (ME1): responsável por receber até 32 canais da PSTN e repassar cada um desses canais em canais separados de telefonia tronco, atuando como $32 \mathrm{MLTs}$ em um barramento LonWorks ${ }^{\circledR}$. Esse módulo torna-se necessário em grandes corporações, nas quais a PSTN não liga vários pares de linhas telefônicas, mas um único par com 31 linhas telefônicas digitalizadas e o $32^{\circ}$ canal com toda a sinalização e sincronismos destas linhas.

- Módulo Terminal Telefônico Digital (MTD): responsável pela interface do mundo LonWorks $₫$ com cada um dos usuários dessa telefonia de forma digital. Este módulo, em conjunto com outros módulos MLT ou MTD, permite uma comunicação telefônica funcionar fim-a-fim.

- Módulo Terminal Telefônico Analógico (MTA): responsável pela interface do ambiente LonWorks ${ }^{\circledR}$ com os aparelhos telefônicos analógicos convencionais. Esse módulo é o ponto de conexão de telefones comuns e tem propriedades para gerar os sinais de linha (ocupado, entre outros) para um telefone comum operar normalmente. Do outro lado, ele suporta toda a comunicação LonWorks ${ }^{\circledR}$ com o seu módulo interno comum TMID, que todos os dispositivos SDCTP possuem.

- Módulo de Resposta Audível (MRA): responsável por gerar as mensagens necessárias ao atendimento de uma chamada e também a manter e operar com precisão toda uma árvore de menus audíveis, os quais serão transportados pela rede LonWorks $₫$ para qualquer módulo de interface, com a PSTN ou com os usuários, através do MTD ou MTA.

- Módulo Gatekeeper (MGK): é um módulo especial, pois ele foi concebido para realizar o roteamento entre a rede LonWorks $₫$ e a rede TCP/IP ou Internet/Intranet presente em prédios corporativos. Com essa atividade deverá realizar todas as operações necessárias para compor os vários canais de comunicação LonWorks ${ }^{\circledR}$ dentro do domínio TCP/IP de forma a ficar transparente ao sistema SDCTP, se está utilizando a rede LonWorks $₫$ simples ou ainda encapsulando a rede LonWorks ${ }^{\circledR}$ dentro de TCP/IP, por meio da norma EAI 852. 
Poderá, com isso, utilizar todo o potencial da tecnologia TMID criada para o SDCTP. Esse módulo é o responsável por complementar e ampliar o potencial do SDCTP para ser utilizado em grandes corporações e interagir diretamente com o barramento corporativo TCP/IP. Ele tem o potencial de interligar canais de MLTs ou MTD/MTA distribuídos com o backbone TCP/IP da corporação. Basicamente é utilizado toda a mesma rede TCP/IP de uma corporação para enviar voz da telefonia e seus controles de enlace juntamente com os processos de automação predial.

As interações entre os módulos (MTD, MTA, MLT, MRA, MGK e ME1) durante a execução das funcionalidade que o sistema oferece, tendo como foco as funcionalidade relacionadas à telefonia e a automação predial, constituem-se numa solução que se enquadra nos conceitos de computação pervasiva. Por exemplo, o sistema procura o usuário e toca a campainha do telefone mais próximo a ele, ou seja, o sistema acompanha o movimento do usuário. Isso porque o sistema de automação, com detetores de presença e leitores de transponder no crachá do usuário, atua diretamente no banco de dados do usuário e o acompanha em toda a planta. Esse projeto trouxe a necessidade de novas ferramentas para tratar conexões entre objetos de uma forma não convencionada pela tecnologia.

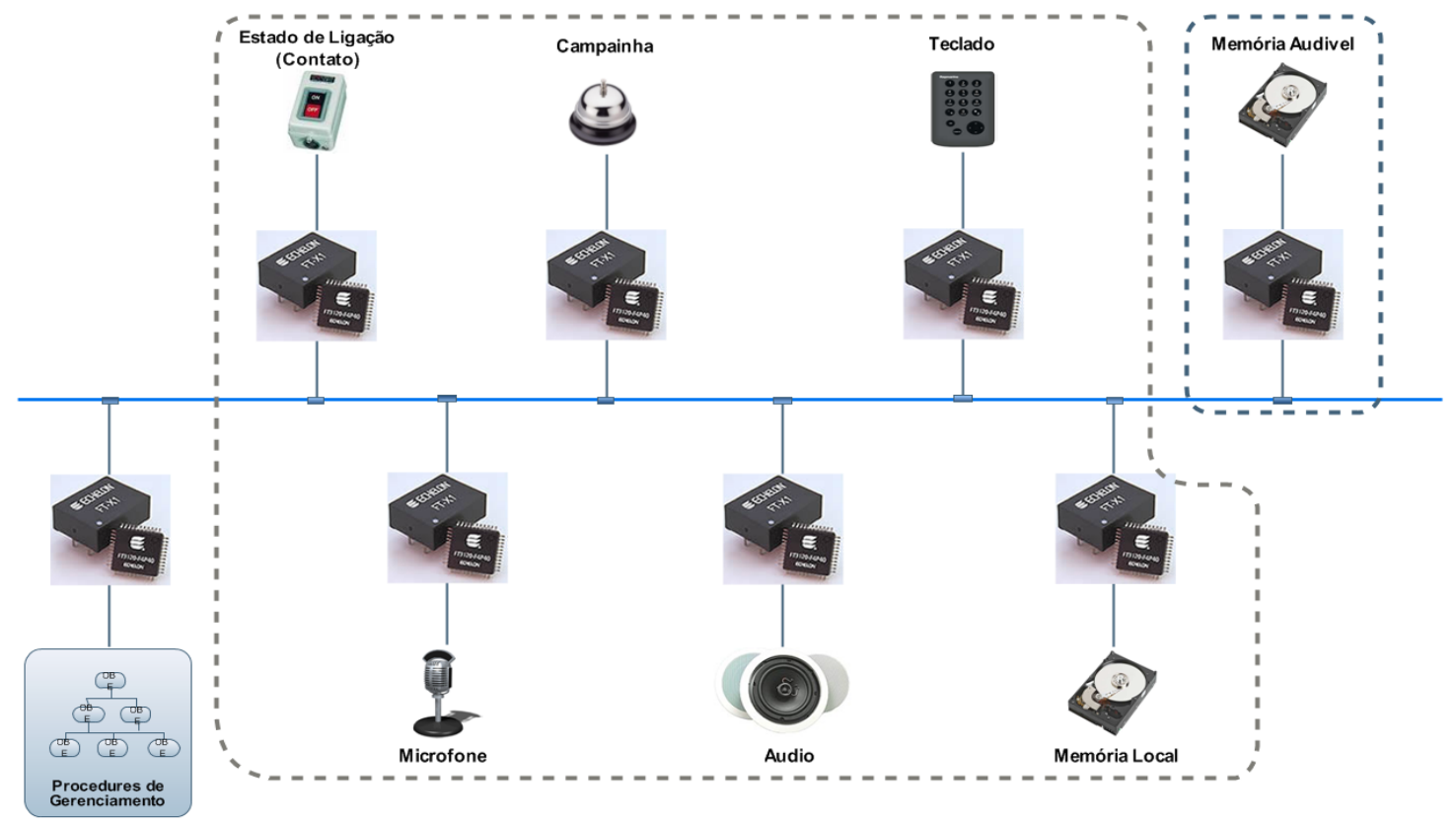

Figura 49: O Barramento de controle destacando o MTD em suas partes principais

Como as interfaces de display do telefone são tratadas pelo middleware 
ODSIP, os produtos de automação mostram mensagens diversas aos usuários, como exemplo a temperatura ambiente, ou o nome da pessoa mais próxima, chama para o intervalo do café, alem de outras informações do sistema de TI.

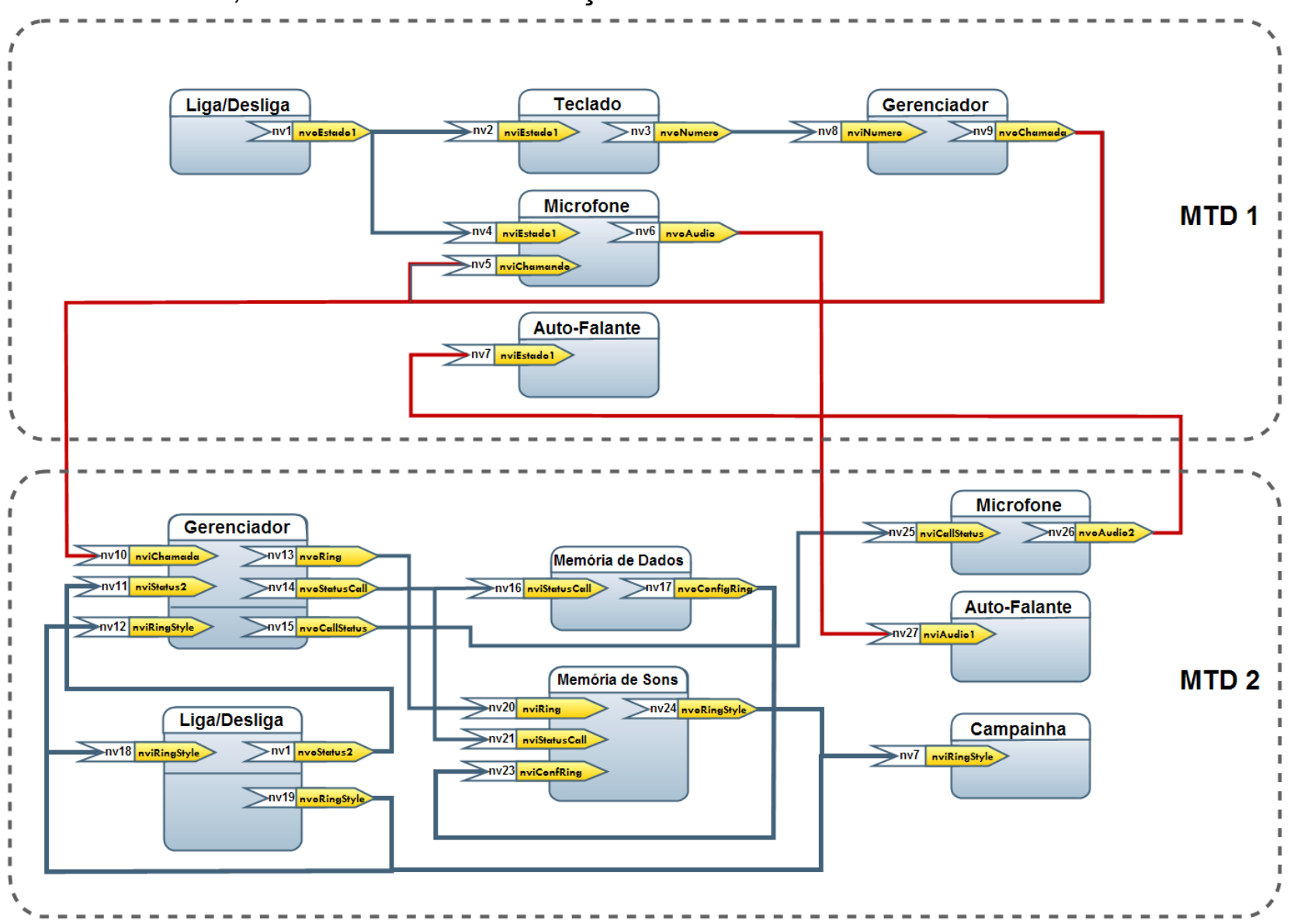

Figura 50: Visão da Computação de um enlace telefônico através de MTDs

Este projeto só foi possível de ser realizado em função dos mecanismos de middleware ODSIP, pois foram desenvolvidos objetos (linhas vermelhas na Figura 50) que ligam e desligam entre si para executarem o enlace de comunicação de voz, em tempo de execução. Este processo de enlace envolve sempre operações dinâmicas de conexões.

Um dos pontos pesquisados nesse projeto foi a proposição de uma solução baseada no método de programação orientado a agentes (ZAMBONELLI; OMICINI, 2004; SHOHAM, 1991), capaz de se auto-gerenciar, de forma dinâmica, em um ambiente previamente configurado. Esta solução deu origem ao projeto de pesquisa de mestrado de Cunha (2008).

Este ambiente computacional pervasivo de automação e computação está convergindo para uma solução de sistema de comunicação pervasivo e agrega valores importantes para automação, tais como: 
- Configuração e customização;

- Controle de acesso ao sistema;

- Localizador de usuários (sem anunciação);

- Seguidor de chamadas automático;

- Toques personalizados;

- Gravação de recados na rede;

- Envio de recados pré-gravados (mala-direta);

- Reconhecimento da origem de chamadas simultâneo com outras chamadas entrantes;

- Registro (log) das ligações recebidas e das ligações efetuadas;

- Utilização de chamadas personalizadas (com descarga pela web);

- Execução de serviços disponíveis em centrais Central de Programa Armazenado (CPA);

- Reconhecimento da origem de chamadas associado com Customer Relationship Management (CRM);

- Controle de acesso predial;

- Controle de ponto de funcionários;

- Monitoramento e acompanhamento da ronda de guardas;

- Sistema de alarme patrimonial;

- Controle de segurança abrindo telefones ramais para ouvir ambientes;

- Posicionamento ideal no Hall dos elevadores sabendo os andares a serem atendidos. 


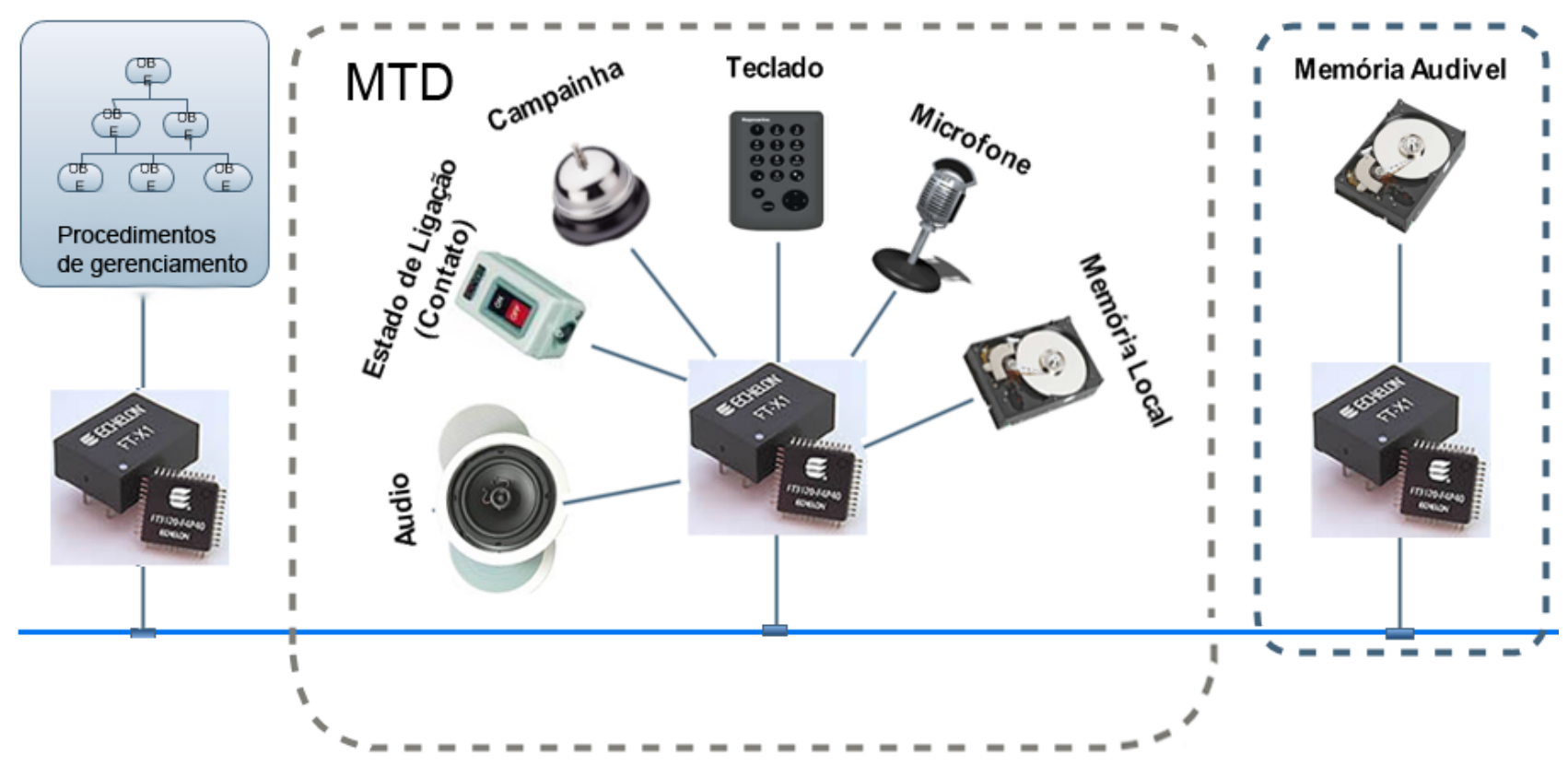

Figura 51: O MTD com todos os objetos desenvolvidos em separado

Como ilustra a Erro: Origem da referência não encontrada um MTD é formado pelos componentes básicos de engenharia controlando: microfone, auto-falante, teclado, campainha, contato seco para identificação do fone fora do gancho.

A aplicação do modelo middleware ODSIP neste trabalho de pesquisa facultou a operação a ser feita. Assim, com ferramentas de gerenciamento distribuídas nos componentes atuadores e sensores, é possível fazer e desfazer os enlaces telefônicos.

Na Figura 50 está exemplificada a visão da computação no atendimento de uma conexão entre dois ramais MTD em uma operação padrão de enlace. Os OBEs estão apresentados como setas e existem clusters formados por conjuntos de OBEs, lembrando que estes clusters trabalham em conjunto e devem ser transportados juntos se forem deslocados para outro nó da rede.

Uma observação importante é que ficarão abertas as possibilidades dos tipos de informação e acontecem dificuldades na padronização das mesmas. De outro lado, possibilita a padronização na construção dos objetos de automação, tratando-os como fábrica de componentes, não apenas de produtos e seus perfis funcionais e sim perfil funcionais de OBE.

Outro ponto que pode ser destacado é a possibilidade de utilizar os componentes, dispositivos de uma automação, como hospedeiros de parte do todo da solução e não só o perfil do produto a que se destina.

Todo este projeto foi desenvolvido para não utilizar o banco de dados 
LNS, ou seja, os próprios dispositivos instalados formam o banco de dados distribuído. Quando é necessário entrar ou sair algum módulo do sistema, isto será feito atualizando os endereços na própria planta.

Outra implementação da mesma solução esta apresentado na Figura 51 com todo o hardware do MTD em um processador instanciado com todos os OBEs desenvolvidos em separado, como apresentado na Erro: Origem da referência não encontrada.

O sistema de supervisão foi desenvolvido para criar seu banco de dados local a partir dos dispositivos que estão instalados e com isso ele acompanha as mutações de conexões dinâmicas. Esse método de acompanhamento foi necessário ao se utilizar os mecanismos de middleware ODSIP de forma dinâmica.

O sistema supervisório também é capaz de localizar pessoas dentro de um empreendimento, pois os transponders, informam ao sistema.

\subsection{Conclusões deste Capítulo}

A aplicação dos princípios do presente trabalho viabilizou o projeto de pesquisa no desenvolvimento de uma central de atendimento telefônico pervasiva, que considera o deslocamento do usuário nos ambientes. Tal projeto originou ainda a dissertação de mestrado de Cunha (2008), e contribuiu para consolidar a proposta, possibilitando uma nova aplicação em ferrovias.

Com esse estudo de caso acredita-se ter demonstrado a viabilidade desta tese, com resultados aplicados na automação com sistema de comunicação telefônica pervasiva. 


\section{Considerações Finais}

\subsection{Atendimento aos Objetivos}

O modelo de objetos básicos de engenharia distribuídos e o relacionamento dinamicamente reconfigurável possibilita a aplicação de redes como a LonWorks $®$ em problemas que não seriam facilmente atendidos (ou até mesmo haveria a impossibilidade de atendê-los) quando do uso da tecnologia na sua forma convencional.

Um problema que exemplificou bem o mérito da solução proposta foi o desenvolvimento de uma central de atendimento telefônico baseada na rede de controle LonWorks ${ }^{\circledR}$. Não foram encontrados relatos na literatura que discutem tal solução, que envolve uma implementação completamente distribuída, sendo que ela prevê também que os sinais de voz sejam digitalizados e transmitidos por meio da rede de controle. As proposições desta tese inspiraram a dissertação de mestrado de um pesquisador do mesmo grupo de pesquisa, que contribuiu para consolidar e validar as proposições, incorporando ainda conceitos de sistemas multi-agentes (CUNHA, 2008). Nesse trabalho detalhou-se as formas de utilização prática do modelo de relacionamento dinamicamente reconfigurável, que para o problema em questão, viabilizou a sua implementação, que certamente não teria como ser atendida com a aplicação convencional da tecnologia LonWorks $\circledR^{2}$

Outro problema que foi utilizado para mostrar a viabilidade da proposta e que vem se beneficiando dela é o do piloto automático para uso ferroviário.

\subsection{Principais Contribuições}

Assim, modelo de relacionamento dinamicamente reconfigurável se constitui em uma extensão do uso da tecnologia LonWorks $\AA$, permitindo a ampliação do seu escopo de utilização de uma forma inédita e de aplicabilidade prática imediata. Tratase, assim, de uma extensão do seu modelo de objetos, viabilizando que os conceitos de middleware pudessem ser aplicados na automação de sistemas baseados nessa 
tecnologia, possibilitando a modificação de comportamentos do sistema de automação à medida que novas situações no ambiente sejam detectadas, que é uma característica considerada na computação pervasiva.

Assim, abre-se uma oportunidade para que sistemas de automação possam atender com maior facilidade e naturalidade novas demandas que se acredita que passem cada vez mais a ganhar espaço: as aplicações pervasivas. $O$ acompanhamento de pessoas, animais e objetos e a mudança do comportamento do sistema de automação face a mudanças no contexto devem ser passíveis de serem naturalmente considerados nos sistemas de automação do futuro. Os dispositivos inteligentes embarcados nos ambientes, de forma transparente para o usuário, terão capacidade de obter informações do local no qual eles se inserem, alterando dinamicamente os modelos computacionais do ambiente, controlando, configurando e ajustando as aplicações para melhor atender às necessidades do usuário. Este ambiente também pode e deve ser capaz de detectar e incorporar dinamicamente outros dispositivos, permanentes ou temporários.

Dessa forma, o desenvolvimento de uma nova classe de aplicações que explora as mudanças de contexto dentro de um domínio dinâmico, tratando a informação de qualquer sistema em qualquer interface que esteja próxima do usuário, mantendo a abstração de tecnologias e protocolos entre sistemas, passará a ser uma atividade corriqueira, encontrando recursos de suporte para apoiar tais desenvolvimentos.

\subsection{Outras Contribuições}

Conforme apresentado neste trabalho, é possível simplificar muitos processos de comunicação a partir de utilização do mecanismo ODSIP em vez do uso da comunicação por meio de mensagens explicitas, e utilizando tabelas e processos de criação de canais de comunicação dinamicamente.

Foram consideradas diversas recomendações, além da redefinição e aplicação de modelagens já conceituadas, como os modelos de referência OSI e RMODP, e por meio da interação entre eles, otimizar processos complexos e camadas superiores que até então poderiam ser consideradas como de maior complexidade. 
Neste trabalho alguns conceitos sobre middleware foram estabelecidos em função de se ligar objetos e criar canais de comunicação. No entanto, a tarefa de criar objetos de engenharia, conforme vem sendo abordado comumente, ainda engloba pequenos processos, que devem ser reconsiderados e possivelmente separados dessa atividade principal, com a finalidade de otimizar os processos de engenharia. Além disso, algumas das categoria de middleware devem ser revisadas e com a aplicação de alguns novos conceitos propostos neste trabalho, aumentar o desempenho do sistema ao se utilizar canais de redes de comunicação.

Vale ressaltar que foram consideradas apenas as ferramentas que executam as ligações dinâmicas entre os objetos computacionais de uma aplicação distribuída, e não o que se convencionou como middleware, ou seja, todas as ferramentas que criam e instanciam os objetos, depois executam as conexões entre eles.

Em relação à implementação de redes de controle, o presente trabalho pode contribuir no sentido de simplificar tal implementação. Novas topologias de rede poderão ser propostas com o uso apenas de roteadores para compatibilizar diferentes tipos de meios físicos, mas que seguem o mesmo protocolo de comunicação. Quando se considera apenas o conceito de seletor, sem número de fonte ou destino, isso poderá abreviar os tempos de propagação das mensagens, além de diminuir os tamanhos de seus cabeçalhos.

\subsection{Perspectivas de Continuidade}

Como continuidade a esse trabalho sugere-se que a presente proposta possa ser considerada em outros protocolos de automação de ampla difusão, como por exemplo, o CAN, o ModBUS e o FieldBus, para que possam ser tratados como ODSIP e se utilizar das ferramentas do LonWorks $₫$ para integração entre sistemas utilizando um LonMaker ou NL220, ou outros.

Uma atividade interessante sugerida é o desenvolvimento de um sistema CORBA-ODSIP para automação predial e residencial. Esse tipo de solução poderá vir a reduzir o custo de algumas dessas tecnologias para uso em automação residencial.

Neste trabalho não foram abordados os aspectos de atrasos (delay) e de jitter em uma rede de controle, como considerados por Canovas (2006), que utilizou a 
tecnologia LonWorks $®$ juntamente com redes TCP/IP, discutindo as principais implicações desse uso conjunto.

Os trabalhos de pesquisa a respeito das simulações de rede LonWorks ${ }^{\circledR}$ (RÜPING; HUNSTOCK; GUNREBEN, 1997) poderão ser otimizados com os conceitos do ODSIP e middleware ODSIP aqui discutidos, e poderão criar modelos de simulação provavelmente mais simples.

Não se estudou neste trabalho as limitações da tecnologia na construção das tabelas e gerenciamentos de buffers para a comunicação das variáveis e nem os tamanhos mais recomendados. No trabalho SDCTP tratou-se com mensagens pequenas e foi analisado o aspecto de tratamento do ODSIP e middleware ODSIP. Porém, não foram abordados todos os demais mecanismos para tratamento de buffers e as limitações das tabelas do LonWorks ${ }^{\circledR}$ e L-Core. Esta limitação deverá ser analisada no momento de sua aplicação. Existem limites relacionados à tecnologia precisam ser transpostos. Alguns processadores modernos, como o ARM7, já implementam a norma EIA 709.1 sem as limitações das tabelas de endereçamento e das variáveis de rede, como no NeuronChipß.

$\mathrm{Na}$ tabela que define domínio estão disponíveis apenas dois domínios em um nó LonWorks $\AA$; porém na tecnologia desenvolvida pela LoyTec, uma vez que sua plataforma esta mais voltada para soluções de roteadores e switches, a necessidade da existência dessa tabela de domínio é questionável, podendo não existir. Uma análise mais profunda possibilitará desenvolver modelagens otimizadas para a atividade do nó que se deseja criar em uma rede de automação.

Esta proposta de modelamento em automação, sugere o desdobramento dos estudos dos mecanismos apresentados neste trabalho: a criação e desenvolvimento de softwares de sistemas computacionais em ambiente da TI, que poderão ser utilizados e compartilhados na criação dos "dispositivos orientados a objetos" para Tecnologia de Automação (TA); e implementar soluções de automação, modelado como um sistema computacional distribuído em uma plataforma unificada. 


\section{REFERÊNCIAS}

AAGEDAL, J. O.; BERE, A.-J. ODP-based QoS-support in UML. In: Enterprise Distributed Object Computing Workshop. Proceedings ... Austria, p. 310-321, outubro de 1997.

ALVES FILHO, M. S. Aplicação de Redes de Controle Distribuído em Processo de Pesagem Automatizado e Informatizado. 2001. 254 p. Dissertação (Mestrado) - Escola Politécnica, Universidade de São Paulo, São Paulo, 2001.

APPLEBAUM, M. A.; BUSHBY, S. T. The 450 Golden Gate Project: The World's First Large-Scale Use of BACnetß. ASHRAE Journal, EUA, vol. 40, n. 4, 1998.

ARAUJO, R. B. Computação Ubíqua: Pricípios, Tecnologias e Desafios. In: XXI SIMPÓSIO BRASILEIRO DE REDES DE COMPUTADORES, 21., Proceedings ..., 2003, Natal. p. 45-115.

AURA. Site da universidade contendo informações sobre o projeto de computação pervasiva. Disponível em: <http://www.pervasive.jku.at/Research/>. Acesso em: 2 de janeiro de 2009.

BAKKEN, D. E. Middleware. In: Encyclopedia of Distributed Computing, 2003.

BERESFORD, A. KALLÓ, C. K.; KRETSCHMER, U.; MATTERN, F.; MUEHLENBROCK, $M$. The First Summer School on Ubiquitous and Pervasive Computing. IEEE Pervasive Computing, vol. 2, no. 1, p. 84-88, janeiro - março de 2003.

BERNSTEIN, P.. Middleware: A Model for Distributed System Services. Communications of the ACM, 39:2, February 1996, 86-98.

BUSHBY, S. T. Communication Gateways: Friend or Foe? ASHRAE Journal, EUA, v. 40, p. 50-53, 1998.

BUSHBY, S. T. Expanding BACnet $\AA^{\prime}$ 's Horizons. HPAC Engineering, EUA, p. 28-30, 2001.

BUTLER, J. BACnet ${ }^{\circledR}$ an Obkect-Oriented Network Protocol for Monitoring and Distributed Control. Circuit Cellar INK, EUA, p. 26-31, 1997.

CAMPBELL, A.; G. COULSON, G.; KOUNAVIS, M. Managing Complexity: Middleware Explained. IT Professional, IEEE Computer Society, 1:5, September/October 1999, 22-28.

CANOVAS, S. R. M. Integração entre redes LonWorks ${ }^{\circledR}$ e redes IP: aplicações, requisitos e soluções. 2006. 196 p. Dissertação (Mestrado) - Escola Politécnica, Universidade de São Paulo, São Paulo, 2006.

COVIELLO NETO, P. BACnet ${ }^{\circledR}$ Ficção ou Realidade? Revista Climatização, Brasil, n. 12, p. 30-34, 2001.

COVIELLO NETO, P. Detecção de Incêndio e Gerenciamento Predial. Revista Climatização, Brasil, n. 22, p. 66-67, 2002. 
CUNHA, R. A. Aplicação de Técnicas de Inteligência Artificial para o Gerenciamento Dinâmico de Dispositivos de um PABX Distribuído. 2008. 122 p. Dissertação (Mestrado) - Escola Politécnica, Universidade de São Paulo, São Paulo, 2008.

ECHELON CORPORATION. Site da Empresa contendo informações sobre o protocolo de comunicação LonTalk®. Disponível em: < http://www.echelon.com/developers/lonworks/protocol/default.htm>. Acesso em: 16 de janeiro de 2009.

ECHELON CORPORATION. Site da Empresa contendo informações sobre a empresa e a tecnologia LonWorks ${ }^{\circledR}$. Disponível em: <http://www.echelon.com>. Acesso em: 17 de junho de 2007.

ECHELON CORPORATION. Neuron C reference guide. Palo Alto, 1995. 1 v. (b).

ECHELON CORPORATION. Introduction to the LonWorks ${ }^{\circledR}$ System, Palo Alto, 1999. 1 V. $(078-0183-01 A)$.

ECHELON CORPORATION. LonWorks ${ }^{\circledR}$ FTT-10A Free Topology Transceiver User's Guide, Palo Alto, 2001. 1 v. (078-0156-01G).

ECHELON CORPORATION. LonMaker ${ }^{\mathrm{TM}}$ User's Guide, Palo Alto, 2003. 3.1 v. (0780168-02E). (a)

ECHELON CORPORATION. NodeBuilder User's Guide. Palo Alto, Echelon, 2003. 1 v. (b)

FAROOQUI, K.; LOGRIPPO, L.; MEER, J. The ISO Reference Model for Open Distributed Processing: An Introduction. Computer Networks and ISDN Systems, 1996.

FIELDBUS FOUNDATION. Site da fundação contendo informações sobre o protocolo fieldbus. Disponível em : <http://www.fieldbus.org/> . Acesso em: 19 de junho de 2007.

GAIA. Site da universidade contendo informações sobre o projeto de computação pervasiva. Disponível em : <http://gaia.cs.uiuc.edu/> . Acesso em: 1 de janeiro de 2009.

HAAKENSTAD, L. K.; How to Specify BACnet $\AA$-Based Systems. Engineered Systems, EUA, v. 14, p. 46-55, 1997.

HÜBNER, J. F.; SICHMAN, J. S.; BECERRA, J. R. Aplicação da arquitetura de objetos distribuídos em sistemas multi-agentes. In: IX SEMINÁRIO DE COMPUTAÇÃO, 9., 2000, Blumenau. Anais... Brasil: FURB, 2000, p. 37-47.

HULL, G. Mysths of Lonworks and BACnet $($. Building Operating Management, EUA, v. 14, p. 33-36, 1997.

HUR, S., KIM, D., PARK, G. Building automation system via LonWorks ${ }^{\circledR}$ and Linux based personal computer. Department of Electrical Engineering, Korea University, v. 1, n. 5, p. $136-701,2005$.

IDA, C. O.; WEBER, T. S. Uma arquitetura Altamente Disponível Aplicada a Sistemas de 
Controle Embutidos de Tempo Real. In: Workshop de Testes e Tolerância a Falhas, 2003, Natal. IV workshop de Testes e Tolerências a Falhas (WTF), Anais ..., 2003. p. 79-86.

INTILLE, S. S. Designing a home of the future. IEEE Pervasive Computing, vol. AbrilJunho, p. 80-86, 2002.

KIM, B. H.; CHO, K. H.; PARK, K. S. Toward LonWorks tecnology and its applications to automation. The $4^{\text {th }}$ Korea-Russia International Symposium on Science and Technology, Proceedings ..., v. 2, p. 197-202, 2000.

KUMAR, M., SHIRAZI, B. A., DAS, S. K., SUNG, B. Y., LEVINE, D., SINGHAL, M. PICO: A Middleware Framework for Pervasive Computing. Pervasive Computing - IEEE, EUA, $p$. 72-79, julho-dezembro 2003.

KUNES, M.; SAUTER, T. Fieldbus-Internet Connectivity: The SNMP Approach. IEEE Transactions on Industrial Electronics, v. 48, n. 6, p. 1248-1256, Dezembro de 2001.

LHEUREUX, B.; SCHULTE, R.; NATIS, Y.; MCCOY, D.; GASSMAN, B.; SINUR, J.; THOMPSON, J.; PEZZINI, M.; KENNEY, F.; FRIEDMAN, T.; GILBERT, M.; PHIFER, G. Who's Who in Middleware. Gartner RAS Core Strategic Analysis Report, 2004.

LONMARK® INTERNATIONAL. Site do órgão padronizador das estruturas na tecnologia LonWorks e certificador de produtos. Disponível em: <http://www.lonmark.org/>. Acesso em: 19 jan. 2008.

LOYTEC. Site da empresa Loytec contendo informações a respeito de seu chip L-Core. Disponível em: <http://www.loytec.com/english/products/lcore.htm>. Acesso em: 19 jan. 2009.

McENTEE, M. ARCNET. In: HVAC Systems. Engineered Systems, EUA, p. 102, 1997.

MODBUS-IDA. Site com informações sobre o protocolo modbus. Disponível em: <http://www.modbus.org/>. Acesso em: 19 de junho de 2007.

MOTOROLA. LonWorks ${ }^{\circledR}$ Technology Device Data, rev. 4, 1997.

NEWMAN, H. M. The Many Advantages of BACnet ${ }$. Refrigertion Service Egineers Society Journal, EUA, 1999.

$\mathrm{OH}$, J. Y.; PARK, J. H.; JUNG, G. H.; KANG, S. J. CORBA based core middleware architecture supporting seamless interoperability between tandard home network middlewares. IEEE Transactions on Consumer Electronics, vol. 49, p. 581-586, 2003.

RAJI, R. S. Control Networks and the Internet. In: MAHALIK, N. P. (Ed.) Fieldbus Technology: The Digital Control Networking System for Automation and Control Applications. German: Springer-Verlag GmbH \& Co., 2002, p. 171-182. ISBN 3-54040183-0

RAYMOND, K. Reference Model of Open Distributed Processing (RM-ODP): Introduction. In: IFIP TC/WG 6.1 international conference on open distributed processing, 3, 1994. 
Proceedings ..., Brisbane, Australia: Springer, 1995. p.p.3-15.. ISBN 0412711508, 9780412711503.

ROMÁN, M., hess, C., CERQUeIRA, R., RANGANATHAN, A., CAMPBELL, R. H., NAHRSTEDT, K. A Middleware Infrastructure for Active Spaces. IEEE Pervasive Computing, vol. outubro-dezembro, no. 4, p. 74-83, 2002.

RÜPING, S.; HUNSTOCK, R.; GUNREBEN, U. Simulation of LonWorks Systems. In: LonUsers International Fall 97 Conference, Proceedings ..., Amsterdam, 1997.

SALBER, D., DEY, A.K., ABOWD, G.D. The Context Toolkit: Aiding the Development of Context-Enabled Applications. CHI'99. Proceedings ..., ACM Press, p.434-441, Pittsburgh, PA, 1999, Maio.

SHOHAM, Y. Agent-Oriented Programming. Journal of Artificial Intelligence, n. 60, p. 5192, 1991.

SWAN, B. The Language of BACnet巴. Engineered Systems, EUA, p. 90-100, 1997.

TANDLER, P., STREITZ, N., PRANTE, T. Roomware - Moving Toward Ubiquitous Computers. IEEE Micro, vol. novembro-dezembro, p. 36-47, 2002.

TANENBAUM, A. S. Computer Networks. 3.ed. Upper Saddler River: Prentice Hall, p. 813, 1996.

WEISER, M. D. The Computer for the Twenty-First Century. In: Scientific American, setembro de 1991.

ZAMBONELLI, F., OMICINI, A. Challenges and Research Directions in Agent-Oriented Software Engineering. Autonomous Agents and Multi-Agent Systems. Kluwer Academic Publishers, v. 3, n. 9, p. $253-283,2004$.

ZINKY, J.; BAKKEN, D.; , R. Architectural Support for Quality of Service for CORBA Objects, Theory and Practice of Object Systems, 3:1, April 1997. 